\title{
El desempeño económico de los gobiernos municipales mexicanos en los procesos de desarrollo a escala local
}

\section{The economic performance of the Mexican municipal governments in the processes of development at local scale}

\author{
Antonio Sánchez-Bernal \\ María Luisa García-BÁtiz*
}

\begin{abstract}
Several analytical perspectives on decentralization state that local governments are leading actors and, in the new context of globalization, democratization and dismantling of the Nation-State, are suitable to coordinate processes of local economic development; in Mexico a number of valuable researches on decentralization have been carried out, based on study cases, in order to show how some municipal governments instrumented innovations so as to improve their management abilities. Nevertheless, these studies dot not allow learning the national tendency, and neither do they make comparisons along time; privileging thus the analysis of the economic dimension. The present work offers elements to conclude that the Mexican municipal governments do not have the necessary conditions to promote processes of local economic development.
\end{abstract}

Keywords: local governments; local development; decentralization; governmental performance.

\section{Resumen}

Diversas perspectivas analíticas sobre descentralización plantean que los gobiernos locales son actores protagónicos, y en los nuevos contextos de globalización, democratización y desmantelamiento del Estado-nación, son los indicados para coordinar procesos de desarrollo económico local. En México se han desarrollado valiosas investigaciones sobre descentralización, basadas en estudios de caso, para mostrar cómo algunos gobiernos municipales instrumentaron innovaciones con el fin de mejorar sus capacidades de gestión. Sin embargo, estos estudios no permiten conocer la tendencia nacional de los cambios en el desempeńo de los gobiernos municipales, y tampoco hacen comparaciones en el tiempo; privilegiando así el análisis de la dimensión económica. El presente trabajo ofrece elementos para concluir que los gobiernos municipales mexicanos no presentan las condiciones necesarias para promover procesos de desarrollo económico local.

Palabras clave: gobiernos locales, desarrollo local, descentralización, desempeño gubernamental.

*Universidad de Guadalajara, México. Correos-e: maluisagarciabatiz@gmail.com, antonios@ cucea.udg.mx. 


\section{Introducción}

En los últimos 20 años, la literatura académica sostiene que los gobiernos locales se han convertido en actores protagónicos de la promoción del desarrollo económico local. El presente trabajo muestra una evaluación de los gobiernos municipales (GM) durante los años 1990, 2000 y 2005, para señalar la magnitud y tendencias en el desempeño de éstos, con el fin de establecer argumentos sobre la capacidad que pueden tener para generar procesos de desarrollo económico local; para lograrlo, esta investigación se centra en el estudio del desempeño en su dimensión económica.

Asimismo, se pretende saber si el desempeño de los GM se relaciona con dos premisas que en diferentes estudios se presentan como conclusiones. La primera afirma que los GM urbanos (los más grandes), especializados en actividades productivas urbanas (sobre todo manufacturas y servicios) y con mayor dinamismo económico (menores niveles de marginación), cuentan con más capacidades organizacionales y, por tanto, son quienes deben presentar mejor desempeño; por otra parte, la segunda plantea que la alternancia política promueve la tendencia a consolidar GM más eficientes, es decir, con mejor desempeño.

$\mathrm{Si}$ lo antes expuesto es verdad, entonces las posibilidades para generar procesos de desarrollo local en municipios que no tienen estas características, son muy bajas; esto implicaría que la gran mayoría de los municipios mexicanos tiene limitaciones para promover procesos de desarrollo económico a escala local. Sin embargo, el presente estudio muestra que los cambios en el desempeño de los GM durante los años 1990, 2000 y 2005 , no presentan una tendencia clara y contundente para afirmar que la descentralización ha generado un entorno adecuado que mejore su desempeño; asimismo, se encontró un comportamiento errático en la relación entre GM urbanos y alternancia política con mejor desempeño gubernamental.

Este trabajo se desarrolla en cinco apartados: en el primero se establecen postulados donde se argumenta que los gobiernos locales juegan un nuevo e importante papel para lograr el desarrollo económico local (DEL); en el segundo se hace una presentación concisa del proceso de descentralización y fortalecimiento de los GM en México; el tercero explica la metodología para establecer el nivel de desempeño de los GM; en el cuarto se presentan los resultados del análisis; y finalmente, el quinto reporta las conclusiones. 


\section{El papel de los gobiernos locales en el desarrollo económico local}

Aunque desde diferentes enfoques, ${ }^{1}$ los estudios sobre descentralización han impulsado fuertemente el interés por descifrar, explicar y estudiar el nuevo rol y la cada vez mayor importancia que toman los gobiernos locales en la promoción del desarrollo; los trabajos realizados a partir de los enfoques sociológico y politológico reconocen que en tiempos de mayor democracia, los gobiernos locales se vuelven importantes porque son el ámbito público más cercano a la población. Por tanto, éstos se convierten en un actor clave para recuperar y promover la participación ciudadana, proveer servicios públicos y sociales, y fortalecer la gobernabilidad (Ziccardi, 1995; Guillén, 1996; Brugué y Gomà, 1998; Finot, 2002; Montecinos, 2005). Por otra parte, también se argumenta que en tiempos de globalización, la política se delimita y los gobiernos locales juegan roles estratégicos en las políticas públicas, influyendo en los estilos de gobierno para alentar esquemas de intervención más cooperativos y relacionales, con el propósito de llevarlos a una mejor actuación (Brugué y Gomà, 1998).

Partiendo de los estudios de enfoque económico de la descentralización, dos perspectivas han analizado el papel de los gobiernos locales: en primer lugar, el federalismo fiscal estudia cuáles son las capacidades de los gobiernos locales para manejar la hacienda y las finanzas públicas de manera eficiente, así como sus posibilidades para convertirse en un instrumento de promoción del desarrollo local (Montecinos, 2005; Arroyo y Sánchez, 1996); en segundo lugar, el regionalismo o la vertiente de los estudios de desarrollo regional, considera que la descentralización es un medio estratégico para generar territorios competitivos mediante el aprovechamiento de los recursos endógenos, la creación de entornos locales innovadores, la cooperación de los actores públicos y privados, y el fortalecimiento de la capacidad de decisión de los gobiernos locales, a quienes se les otorga un nuevo e importante rol (Sánchez, 2008; Montecinos, 2005; Silva, 2003; Sánchez y García, 2001; García et al., 1998).

El nuevo papel que debe jugar un actor tan importante como el gobierno local, deviene de la transformación del Estado-nación, la cual se da básicamente con los procesos de descentralización como contratendencia respecto a la propensión que existía a centralizar las decisiones políticas y económicas en los gobiernos nacionales (Finot, 2002). Ahora se tiende a ceder espacios o áreas de acción, responsabilidades, funciones,

\footnotetext{
${ }^{1}$ De acuerdo con Montecinos (2005), en los estudios sobre descentralización se pueden identificar cuatro enfoques teóricos: económico, sociológico, el de la nueva gestión pública y el politológico; además, de acuerdo con Fernández (2002, citado en Montecinos, 2005), se puede agregar el enfoque del optimismo multilateral, que más que un enfoque teórico, se refiere a los trabajos y esfuerzos que los organismos internacionales han realizado para promover la descentralización.
} 
recursos y poder a los gobiernos locales o subnacionales (Sánchez, 2008; Montecinos, 2005; Finot, 2002; Sánchez y García, 2001; Rodríguez, 1999; Cabrero, 1993) convirtiéndolos en los promotores y facilitadores del desarrollo económico local (Arocena, 1995; Boisier, 1996; Vázquez, 1998; Sánchez, 1998; García et al., 1998; Rondinelli, 2001).

Asimismo, complementando las posiciones que revaloran el papel de los gobiernos locales, la visión de la gestión pública considera la descentralización como un desafío para la administración pública, pues ahora se plantea que sea estratégica, eficiente, eficaz, de calidad y democrática (Osborne y Gaebler, 1994 citado en Montecinos, 2005; Ward, 1998; Brugué y Gallego, 2001; Cabrero, 2000, 2003). Con esta nueva concepción de los gobiernos locales, han surgido investigaciones y proyectos para sistematizar las acciones orientadas a identificar y conocer su cambio y desempeño. A partir de los años noventa, se reconocen y premian las experiencias innovadoras de gestión de los GM, conocidas como mejores prácticas (Montecinos, 2005; Surawski, 2003).

En México, los estudios que abordan la descentralización y los cambios en los GM (Merino, 1994; Cabrero, 1995; Guillén, 1996; Rodríguez, 1999; Arroyo y Sánchez, 2003) se han concentrado en la presentación de estudios de caso que muestran resultados en dos vertientes aparentemente contradictorias: la primera se relaciona con estudios de resultados pesimistas, pues plantean que hay serias dificultades para implementar exitosamente los procesos de descentralización, y hacen énfasis en que los objetivos de eficiencia, eficacia e inclusión de los ciudadanos (democratización de la gestión) no se han logrado. La segunda vertiente es de corte optimista, y plantea que la descentralización implica cambios estructurales para abrir oportunidades a los GM. La mayoría de estos estudios reportan cambios, transformación e innovaciones gubernamentales, que desde una visión optimista se reflejan en mejores formas de gestión.

Los estudios de caso han aportado una riqueza relevante al análisis de la gestión municipal; sin embargo, no permiten tener un panorama general de los alcances logrados por estos gobiernos en todo el país, hacer comparaciones temporales sobre el comportamiento de su desempeño, ni tener una visión amplia de cuál es la situación al respecto en un país determinado. No obstante, sugieren algunas conclusiones generales que se han convertido en tesis básicas sobre sus capacidades para impulsar procesos de desarrollo económico local. Esto es, ofrecen las condiciones de los GM para lograr un mejor desempeño. En términos generales, se argumenta que en la medida en que los gobiernos locales construyan capacidades organizacionales, humanas e institucionales, intervendrán mejor en los mercados locales, impulsarán el crecimiento económico y mejorarán las condiciones de vida. 
Así, el fortalecimiento de las capacidades de gestión de los gobiernos locales permite realizar mejores políticas públicas y lograr objetivos de desarrollo económico local. Desde estas perspectivas se acepta explícita e implícitamente que:

a) Los GM más grandes (urbanos y metropolitanos), con especialización económica relativamente diversificada, donde predominan las actividades manufactureras, de servicios y mejores niveles socioeconómicos (menor marginación), tienen mayores capacidades y posibilidades para realizar innovaciones en la gestión, lograr mejores desempeños (Cabrero, 2000; Guillén, 1996; Sánchez y García, 2001) e impulsar el DEL.

b) Los estudios de corte politológico agregan a lo anterior que la alternancia política promueve la tendencia a consolidar mejores gobiernos, con el objetivo de mantenerse en el poder e imprimir un sello específico a la gestión pública municipal (Pardo, 1994; Merino, 1994; Morales, 2005).

Sin embargo, la relación causal entre mayores capacidades para la gestión y el DEL aún no está soportada por un marco teórico sólido, por lo que autores como Bardhan (2002) expresan la necesidad de realizar más investigación sobre el peso de los gobiernos locales en el impulso de negocios y el desarrollo, pues la literatura se ha concentrado en presentar estudios de casos empíricos (se refiere especialmente a los trabajos que informan dicho proceso en China). Así, vale la pena preguntarse: ¿̨uáles son las posibilidades de que los GM mexicanos puedan impulsar procesos de DEL?, ¿̇son los GM más grandes, con especialidad en actividades urbanas, mayor diversificación productiva, mejores niveles socioeconómicos y alternancia política, quienes presentan los mejores desempeños?

Como un primer acercamiento para responder estas preguntas, a continuación se presenta la evaluación del desempeńo de los GM y su aportación al desarrollo económico local, en el contexto de la descentralización; pues recordemos que a más de 20 años de iniciar el proceso formal de descentralización en México (a partir de la reforma constitucional del artículo 115), es de esperarse que los GM tengan consolidada una estructura organizacional capaz de responder a las nuevas tareas y formas de gestión que el entorno nacional e internacional requiere.

\section{Descentralización y fortalecimiento de los GM en México}

En las últimas dos décadas, el marco institucional de los gobiernos municipales se ha modificado dos veces de manera sustancial: el primer 
cambio se realizó en el año 1983, cuando se renovó el artículo 115 constitucional que establece para los municipios una hacienda propia, atribuciones sobre la planeación del territorio, y la oferta de los servicios públicos que tienen efecto en la calidad de vida de los habitantes; el segundo se llevó a cabo en 1999 para modificar nuevamente el artículo 115, en este caso se define al ayuntamiento como entidad de gobierno, y fortalece la capacidad reglamentaria de los gobiernos municipales (Acedo, 2007).

Aunado a estos cambios fundamentales, en el marco institucional se han creado nuevas reglas en la política del Poder Ejecutivo durante los últimos sexenios. En el periodo 1982-1988 se instrumentó una política de descentralización del gobierno federal de corte gubernamental y orientada a la transferencia de poder a los gobiernos estatales. En los esfuerzos por impulsar el desarrollo en todo el país, esta descentralización se sumó a la reforma del artículo 115 constitucional y la emitió el Sistema Nacional de Planeación Democrática, que involucra a los tres niveles de gobierno.

De la misma manera, en el sexenio 1988-1994 se consolidó la descentralización en dos sectores clave: educación y salud. Sin embargo, principalmente se instrumentó el Programa Nacional de Solidaridad, que impulsó cualquier iniciativa municipal o estatal que tuviera sustento en la comunidad. Este programa fue muy popular y originó comités de solidaridad en todos los municipios del país. En el periodo 1994-2000 se generó una división real entre los poderes Ejecutivo, Legislativo y Judicial; se avanzó en el sistema de coordinación fiscal y se fortalecieron los gobiernos municipales, pues se les dio el carácter constitucional de gobierno (Rodríguez, 1999). Asimismo, el sexenio 2000-2006 se caracterizó por el incremento de recursos a los municipios mediante aportaciones federales.

En resumen, a partir del año 1983 los gobiernos municipales han sido objeto de una notable transformación. El cambio en el marco institucional, y los efectos en el presupuesto de los ayuntamientos, generó el inicio de un proceso para cambiar la forma en que se desempeñan los gobiernos municipales en México, y de igual forma, las expectativas de los ciudadanos sobre este orden de gobierno. Por tanto, evaluar los cambios en el desempeño de los gobiernos municipales es relevante porque nos permite observar los resultados de las políticas de descentralización.

\section{Metodología para estimar el nivel de desempeño de los gobiernos municipales}

La metodología utilizada en el presente trabajo corresponde a la propuesta por Sánchez et al. (2003), la cual sostiene que los criterios básicos para construir el índice de desempeño de los gobiernos municipales (Idegob) son: primero, que la información utilizada para la estimación esté dispo- 
nible para cualquier persona; y segundo, que el índice permita comparar el desempeño de los GM. Asimismo, la metodología plantea que la capacidad de organización de los GM se debe utilizar para conducir tres aspectos que influyen directamente en su desempeño económico: 1) captación y uso de recursos económicos, 2) manejo de recursos humanos, y 3) construcción de infraestructura. En la medida que los GM realicen de manera eficiente estas tres actividades obtendrán un mejor desempeño en la gestión.

Sustentado en todo lo antes expuesto, se construyó el Idegob, el cual es un índice ponderado, donde el peso de cada variable estimada se obtuvo mediante la aplicación del método Delphi. ${ }^{2}$ Los indicadores y variables, así como los puntajes asignados por los expertos, se muestran en el cuadro 1. A continuación se exponen las ventajas (como ya se hizo en Sánchez et al., 2003) del análisis del Idegob.

- El Idegob es un indicador que se concentra en el cálculo del desempeño de los gobiernos municipales. ${ }^{3}$

- En comparación con otros métodos para medir el desempeño de los gobiernos municipales (que combinan información pública accesible con información generada o recopilada ex profeso para

\footnotetext{
${ }^{2}$ Este método es una técnica para estructurar, a partir de la consulta con expertos, un proceso de comunicación que permite a un grupo de individuos tratar un asunto complejo. El Delphi se basa en la sistematización de los juicios intuitivos de un grupo de expertos; éstos se seleccionan y se les pide su opinión sobre una cuestión específica. Las opiniones de los expertos se realizan de forma anónima y autónoma en rondas sucesivas, con la intención de construir consensos (Astogarraga, s/f). En este caso las rondas de opinión se hicieron con la aplicación de un cuestionario vía correo electrónico. La intención fue, precisamente, que un grupo de expertos opinaran sobre la influencia que diferentes variables en la oferta de servicios públicos, la autonomía financiera y la eficacia en el gasto público tienen en el desempeńo de los gobiernos municipales. Los participantes en la ponderación de las variables que forman el Idegob son parte del equipo de investigación que en la Universidad de Guadalajara ha venido estudiando, desde hace más de 10 ańos, el tema de políticas públicas para el desarrollo regional y local: los doctores Basilio Verduzco Chávez, Alejandro Macías, Antonio Sánchez Bernal, María Luisa García Bátiz, Édgar Demetrio Tovar García y la maestra Claudia Sánchez Bernal. Asimismo, se incluyó la opinión de dos expertos que inicialmente participaron en el equipo de investigación seńalado antes, y que después se integraron a trabajar en el sector público: los maestros Macedonio León Rodríguez y María Eugenia Casas.

${ }^{3}$ Existen otras iniciativas importantes de medición con intenciones diferentes a las del Idegob, una de ellas es la de Ibarra et al. (2002), que propone medir el desempeño de los gobiernos en los municipios, y no el desempeño de los gobiernos municipales; ésta es una diferencia importante que permite incluir en la construcción del indicador propuesto por Ibarra $e t$ al. variables que no dependen del gobierno municipal, como las de política monetaria, política fiscal, política de fomento económico federal y estatal, servicios de salud y servicios de seguridad. Otros ejemplos importantes son el del Centro de Investigación y Docencia Económicas (CIDE)-Comisión Federal de Mejora Regulatoria (Cofemer), que tiene como objetivo medir la competitividad de las ciudades; y el del Instituto Nacional para el Federalismo y el Desarrollo Municipal (Inafed), cuya finalidad es calcular el índice de desarrollo municipal basado en la propuesta de desarrollo humano (Cabrero et al., 2007; Flamand et al., 2007).
} 
estimar sus indicadores), ${ }^{4}$ el cálculo del Idegob utiliza información de fácil acceso y actualización. Toda la información necesaria se obtiene de diversos resultados periódicos del Instituto Nacional de Estadística, Geografía e Informática (INEGI) disponibles para todo público. $^{5}$

- Permite comparaciones en el tiempo. En este caso la estimación del Idegob implicó la construcción de una base de datos con cada una de las variables seleccionadas para los años 1990, 2000 y 2005. Se calcularon y ordenaron las variables, y se procedió a asignarles los puntos conforme a la opinión de los expertos (cuadro 1). De esta manera se obtuvieron los Idegob de los GM para los años 1990, 2000 y 2005.

- En comparación con otros índices e indicadores construidos por diferentes organizaciones (como la AMMAC o el Inafed), el Idegob es un índice completo y global que no se concentra en evaluar sólo un aspecto o área de la gestión (Sánchez et al., 2003).

- Además, en comparación con otras intenciones de medición, el Idegob es un índice diseñado para calcular el desempeño del 100\% de los GM mexicanos. ${ }^{6}$ Así, para el presente trabajo, se calculó el Idegob para 2,412 municipios, de los cuales 37 no aplicaron para el cálculo del año 1990 por falta de información o porque son municipios de reciente creación.

Sin embargo, el Idegob presenta una limitante importante relacionada con la posible correlación que existe entre algunas de las variables que conforman los indicadores para medir el desempeño; es el caso de la oferta de servicios públicos, con la variable de marginación o desarrollo económico, que según nuestro modelo se ve impactada por el desempeño. Sin embargo, como se muestra en el cuadro 1, la ponderación o puntaje que los expertos le han dado al indicador de oferta de servicios públicos, no es mayor que la de los indicadores de autonomía financiera, eficiencia y creación de infraestructura. Además, en el cálculo del índice también tiene un peso importante el indicador de mecanismos de financiamiento, con esto, los efectos de la posible correlación se debilitan.

${ }^{4}$ Como las iniciativas del Centro de Servicios Municipales Heriberto Jara (Cesem), el Banco Nacional de Obras (Banobras) y la Asociación de Municipios de México, A.c. (ammac) (Saltalamacchia y Ziccardi, 2005; CESOP, 2004).

${ }^{5}$ Básicamente se utilizó como fuente de información el Sistema Municipal de Bases de Datos (Simbad) del INEGI.

${ }^{6}$ Hay otros proyectos de medición, como los de Cabrero et al. (2007), quienes calcularon el índice de competitividad para las 60 zonas metropolitanas más importantes de México, esto es, un total de 225 municipios; y el de Ibarra et al. (2002), que mide el dsempeńo del gobierno en 100 municipios mexicanos. 


\section{Cuadro 1}

\section{Composición del Idegob y asignación de puntajes}

\begin{tabular}{|c|c|c|c|c|}
\hline Indicador & Puntaje & Variables & Escala & Puntaje \\
\hline \multirow{6}{*}{$\begin{array}{l}\text { 1. Oferta de servicios } \\
\text { públicos }\end{array}$} & 20 & 1.1. Cobertura de agua & $100 \%=10$ & 10 \\
\hline & & & $0.0 \%=0$ & \\
\hline & & 1.2. Cobertura de drenaje & $100 \%=5$ & 5 \\
\hline & & 1.3. Cobertura de & $100 \%=5$ & 5 \\
\hline & & electricidad & & \\
\hline & & & $0.0 \%=0$ & \\
\hline \multirow[t]{4}{*}{ 2. Autonomía financiera } & 20 & $\begin{array}{l}\text { 2.1. Porcentaje de ingresos } \\
\text { propios (IP/IT) }\end{array}$ & $0-25=5$ & 20 \\
\hline & & & $26-50=10$ & \\
\hline & & & $51-75=15$ & \\
\hline & & & $76-100=20$ & \\
\hline \multirow[t]{12}{*}{ 3. Eficiencia en gasto } & 20 & $\begin{array}{l}\text { 3.1. Porcentaje de gasto } \\
\text { administrativo (GA/IT) }\end{array}$ & $0-25=8$ & 8 \\
\hline & & & $26-50=6$ & \\
\hline & & & $51-75=4$ & \\
\hline & & & $76-100=2$ & \\
\hline & & $\begin{array}{l}\text { 3.2. Porcentaje de ingresos } \\
\text { propios con respecto al } \\
\text { gasto administrativo } \\
(\mathrm{IP} / \mathrm{GA})\end{array}$ & $0-25=2$ & 8 \\
\hline & & & $26-50=4$ & \\
\hline & & & $51-75=6$ & \\
\hline & & & 76 y más $=8$ & \\
\hline & & $\begin{array}{l}\text { 3.3. Trabajadores en el } \\
\text { gobierno ( } \mathrm{PT} / \mathrm{TG})\end{array}$ & 201 y más $=4$ & 4 \\
\hline & & & $151-200=3$ & \\
\hline & & & $101-150=2$ & \\
\hline & & & Menos de $100=1$ & \\
\hline \multirow[t]{10}{*}{$\begin{array}{l}\text { 4. Mecanismos de } \\
\text { financiamiento }\end{array}$} & 15 & $\begin{array}{l}\text { 4.1. Endeudamiento } \\
\text { (DI/GT) }\end{array}$ & $0-10=2$ & 6.5 \\
\hline & & & $11-20=4$ & \\
\hline & & & 21 y más $=6.5$ & \\
\hline & & 4.2. Presión fiscal (IP/PT) & $0-100=1$ & 8.5 \\
\hline & & & $101-200=2$ & \\
\hline & & & $201-300=3$ & \\
\hline & & & $301-400=4$ & \\
\hline & & & $401-500=5$ & \\
\hline & & & $501-600=6$ & \\
\hline & & & 601 y más $=8.5$ & \\
\hline \multirow[t]{4}{*}{$\begin{array}{l}\text { 5. Creación de } \\
\text { infraestructura }\end{array}$} & 25 & $\begin{array}{l}\text { 5.1. Porcentaje de gasto en } \\
\text { obra pública }(\mathrm{GOP} / \mathrm{GT})\end{array}$ & $0-25=7$ & 25 \\
\hline & & & $26-50=13$ & \\
\hline & & & $51-75=19$ & \\
\hline & & & $76-100=25$ & \\
\hline Total & 100 & Total & & 100 \\
\hline
\end{tabular}

Fuente: Sánchez et al. (2003).

IP = ingresos propios; $\mathrm{PT}$ = población total; $\mathrm{IT}$ = ingresos totales; $\mathrm{TG}$ = personal ocupado en actividades del gobierno; $\mathrm{GT}$ = egresos totales; $\mathrm{DI}$ = deuda en la cuenta de ingresos; $\mathrm{GA}$ = gastos administrativos; GOP = gasto en obra pública y fomento. 
Una primera lectura de los resultados (arrojados por el índice propuesto) se puede hacer analizando los cambios en el nivel del Idegob por municipio. Sin embargo, la limitación más relevante al leer los resultados así, es que cualquier cambio marginal en el índice se reporta como positivo, lo que puede generar una sobreestimación de las mejoras gubernamentales; por tanto, se propone analizar el desempeño de los GM estratificando los resultados. Por esta razón se crearon las siguientes categorías de desempeño de los GM: excelente, bueno, regular y malo. Las calificaciones se derivan de los criterios presentados en el cuadro 2 .

Así, la definición de mejoría en el desempeño del gobierno municipal se obtiene de la siguiente manera: se resta el Idegob del último periodo, menos el índice del periodo anterior para cada municipio; si la diferencia es positiva significa que hubo mejora en el nivel de desempeño, en cambio, si es negativa significa que disminuyó. Una segunda forma es observando los cambios en categoría de desempeño para cada periodo en los municipios. La comparación del Idegob de los años 1990, 2000 y 2005 se realiza entre el total de observaciones, y en algunos análisis, únicamente entre grupos de observaciones requeridos para el caso.

\section{El desempeño de los gobiernos municipales 1990, 2000 y 2005}

Al analizar el cambio positivo en el nivel del Idegob por municipio, se observa que aunque no hayan logrado cambiar de categoría (malo, regular, bueno y excelente), sólo 432 gobiernos municipales (de un total de 2,375) presentaron mejoras en el nivel de desempeño; es decir, $18 \%$ durante el periodo 1990-2000. Esta situación es más favorable en el periodo 2000-2005, pues se presenta un cambio sustancial positivo en el desempeño porque $75.5 \%$ mejoró el nivel del Idegob. No obstante, como se menciona en el apartado anterior, la medición puede dar una sobreestimación de las mejoras gubernamentales, por tanto, observar el comportamiento del trabajo de los GM por categoría de desempeño nos puede mostrar un resultado más certero.

La estimación del Idegob ${ }^{7}$ para los años 1990, 2000 y 2005 reporta que aproximadamente $50 \%$ de los GM del país presenta un nivel de desempeño en las categorías excelente y bueno, mientras el otro $50 \%$ está en las de regular o malo. Sin embargo, es importante señalar que la proporción de municipios en las categorías de desempeño malo presenta tendencia a crecer en el periodo de 1990 a 2005 (gráfica I).

\footnotetext{
${ }^{7}$ En el Anexo 1 se presenta la estimación del Idegob para cada uno de los gobiernos municipales en los ańos 1990, 2000 y 2005.
} 


\section{Cuadro 2}

\section{Categorías de desempeño para los gobiernos municipales considerando el Idegob}

\begin{tabular}{cll}
\hline Grupo & Desempeño & \multicolumn{1}{c}{ Criterio } \\
\hline A & Excelente & $\begin{array}{l}\text { Por encima de la media más una desviación } \\
\text { estándar }\end{array}$ \\
B & Bueno & $\begin{array}{l}\text { Entre la media y la media más una } \\
\text { desviación estándar }\end{array}$ \\
C & Regular & $\begin{array}{l}\text { Entre la media y la media menos una desviación } \\
\text { estándar } \\
\text { Por debajo de la media menos una } \\
\text { desviación estándar }\end{array}$ \\
\hline
\end{tabular}

Fuente: Elaboración propia.

Nota: Los límites de los grupos se calcularon con base en la estadística descriptiva, utilizando la media y la desviación estándar.

\section{Gráfica I}

Gobiernos municipales por categoría de desempeńo, 1990-2005

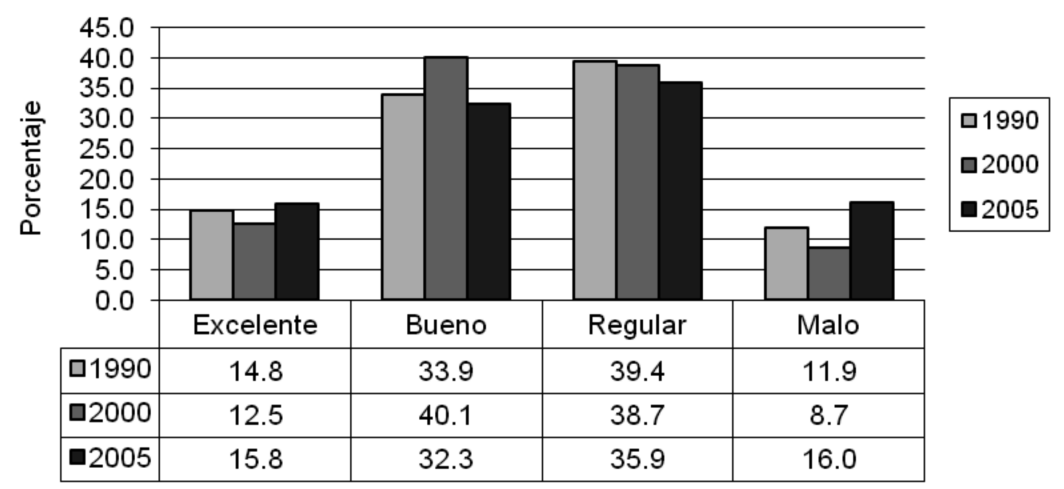

Desempeño

Fuente: Elaboración propia.

En primera instancia podríamos deducir que los municipios clasificados con un nivel de regular y malo presentan menos capacidad para coordinar procesos de desarrollo local, esto implica que en la mitad de los municipios del país, el gobierno como un actor clave para impulsar el desarrollo económico local, tiene serias deficiencias en su desempeño.

En la gráfica II se presenta una comparación por categorías de desempeño de los municipios entre los periodos 1990-2000, 2000-2005 y 1990-2005. Los resultados exponen que no hay una tendencia a la mejora del desempeño; por el contrario, en el periodo 2000-2005 éstos revelan un aumento de más de 7 puntos en los GM con categoría malo, y 


\section{Gráfica II \\ Cambio en la proporción de gobiernos municipales por categoría de desempeño}

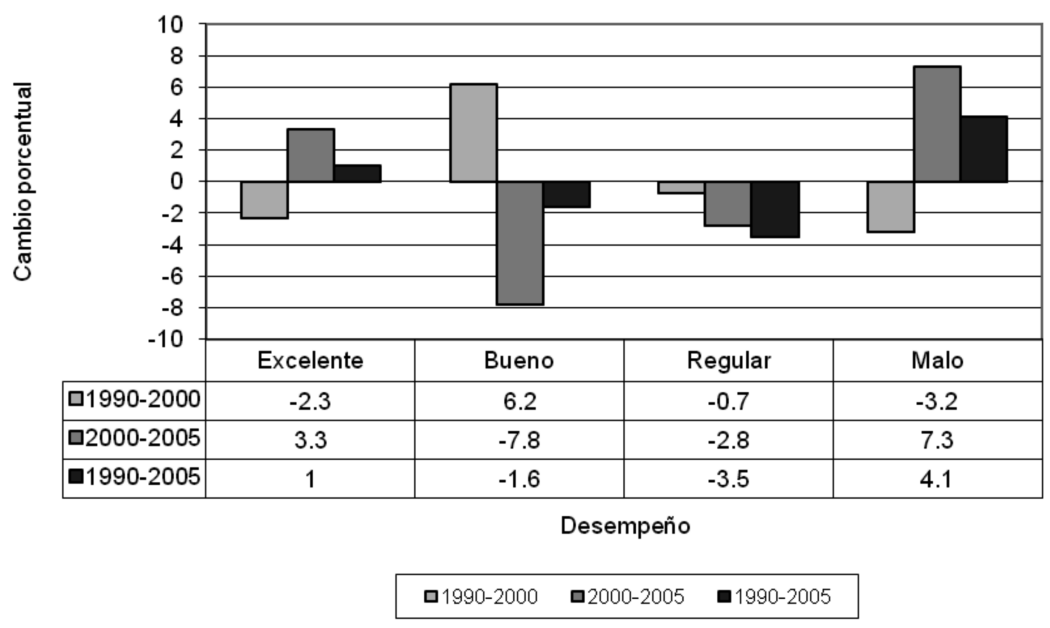

Fuente: Elaboración propia.

más de 4, si se toma en cuenta el periodo completo 1990-2005. En contraste, la categoría de desempeño excelente gana terreno, pero sólo de 3.3 puntos porcentuales entre los ańos 1990 y 2000, y 1 punto, de 1990 a 2005. Lo anterior indica una polarización en el comportamiento del desempeño de los GM (gráfica II), donde al final del periodo 1990-2005 observamos un crecimiento mayor en las categoría de desempeño malo, y menor en los de excelente, en detrimento de las categorías intermedias regular y bueno.

En resumen, se puede decir que el cambio en el desempeño de los GM no es un proceso a corto plazo ni sigue una línea recta; esto nos lleva a sugerir que la política de descentralización no asegura el entorno y los incentivos suficientes para que los GM mejoren su desempeño, sino que es necesario profundizar en el estudio del tipo de descentralización que se está generando, y cómo ésta puede garantizar la construcción de capacidades en los gobiernos locales encaminada a mejorar su desempeño. Lo anterior supone el diseño de sistemas de evaluación generales y continuos del comportamiento de los GM.

\subsection{Tamaño del municipio y desempeño del GM}

Como se mencionó en el primer apartado, existe la creencia de que los municipios más grandes son los que tienen mayor capacidad de gobierno, 


\section{Cuadro 3}

Municipios que mejoraron su nivel de Idegob por tamaño con respecto al total de su categoría, 1990-2000, 2000-2005 (porcentaje)

\begin{tabular}{lcc}
\hline Tamaño de municipios & $1990-2000$ & $2000-2005$ \\
\hline Grandes & 14.5 & 77.1 \\
Medianos & 16.7 & 20.5 \\
Pequeños & 18.8 & 76.8 \\
\hline
\end{tabular}

Fuente: Elaboración propia.

y por tanto, se espera que presenten los mejores desempeños. Sin embargo, al analizar el cambio positivo en el nivel de Idegob, se puede decir que la idea anterior no se confirma porque se observa que en la década de los noventa, los municipios pequeños fueron los que en términos relativos presentaron una marcado avance, pues casi $19 \%$ mejoraron su nivel en el Idegob. Este progreso se consolida en el periodo 2000-2005, con $77 \%$ de GM pequeños y grandes, aun cuando no cambiaran de categoría (cuadro 3).

En contraste, un primer acercamiento a los datos por categoría nos indica que la idea de mayor tamaño-mejor desempeño se confirma, pues los datos del cuadro 4 muestran que cerca de $74 \%$ de los municipios grandes, en el año 2005 cuentan con un desempeño excelente o bueno, mientras el porcentaje para los municipios pequeños y medianos es de casi 44 puntos.

Sin embargo, un análisis más detallado de los datos muestra que el tamaño no necesariamente es una garantía para mantener y contar con el mejor desempeño de los GM. En la gráfica III se muestra un comportamiento errático en el cambio de la proporción de municipios por categoría de desempeño gubernamental y tamaño del municipio. De los años 1990 a 2000, en términos generales, los municipios pequeños empeoraron su desempeńo. Es decir, la proporción de municipios pequeños con desempeño excelente, disminuyó en poco más de 7 puntos porcentuales, y aumentaron los de categoría regular y buena. Mientras los municipios medianos y grandes con desempeńo excelente, aumentaron proporcionalmente 5 y $27 \%$, respectivamente; además, disminuyeron los municipios de desempeño malo y regular en estos últimos tipos de municipio.

Contrario a lo sucedido en el periodo 1990-2000, en los años 20002005 los municipios pequeños con GM de categoría excelente, aumentaron en 4 puntos porcentuales, bajó la proporción en los de desempeño regular y bueno, y creció en más de $8 \%$ los de malo. Por otro lado, los municipios grandes empeoraron en la proporción de quienes contaban 


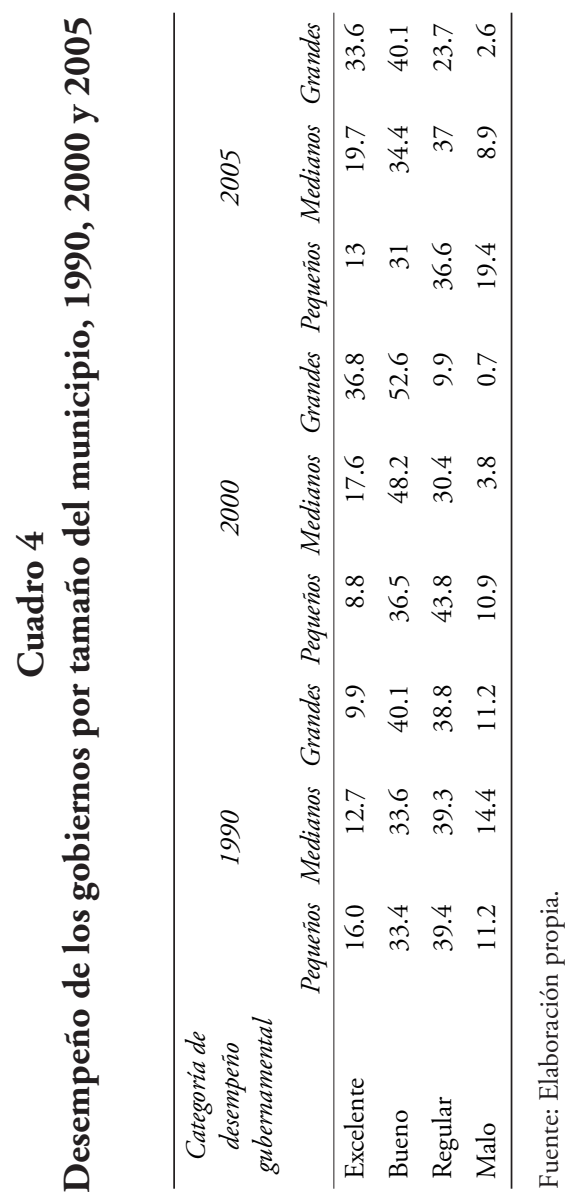




\section{Gráfica III}

Cambio en la proporción de los municipios por categoría de desempeño y tamaño

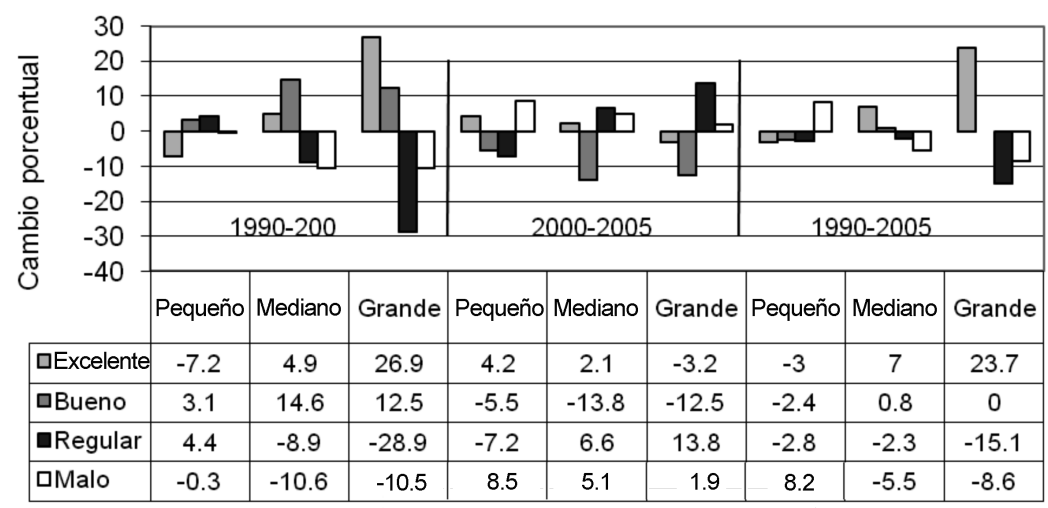

ExcelenteaBueno RegularaMalo

Fuente: Elaboración propia.

con desempeño excelente, además de disminuir la proporción de municipios medianos y grandes con buen desempeño, y aumentaron los de regular y malo. A pesar de lo anterior, al analizar el periodo completo 1990-2005 se sostiene que los gobiernos de municipios grandes son los que presentan los mejores desempeños.

Una conclusión relevante en los dos tipos de análisis (cambio en el nivel del Idegob y categoría de desempeño) para medir la mejoría en el desempeño por tamaño de los municipios, es que efectivamente los gobiernos municipales han mejorado, pero no como se esperaba; y por otra parte, se afirma la creencia de que el tamaño de los municipios es determinante. Si bien al medir la diferencia en el cambio de nivel del índice (Idegob) parece que la mejora es contundente, al cruzar el resultado con los cambios positivos de categoría (ascendente), se observa un comportamiento con quiebres en los periodos analizados; éstos impiden observar una tendencia que permita asegurar que el tamaño de los municipios es determinante en el desempeño de los GM. Es decir, el tamaño del municipio no garantiza mejor capacidad gubernamental que se refleje en un mayor desempeño. 


\subsection{Especialización productiva municipal y desempeño de los $G M$}

Para calcular la especialización productiva se aplicó el cociente de especialización o localización. ${ }^{8}$ En términos generales, éste mide la participación de la población económicamente activa (PEA) municipal, por gran sector de actividad productiva a escala nacional (cálculo posible únicamente para los años 1990 y 2000). Por otra parte, es importante señalar que los censos de población sólo permiten calcular el índice por gran sector de actividad productiva primario, secundario y terciario, por lo que el cálculo resulta muy grueso, motivo por el cual se piensa que habrá una subestimación de la posible diversificación económica municipal. Para superar de alguna manera este obstáculo, se analiza la relación de especialización productiva municipal y desempeño, utilizando solamente el cambio en el nivel de Idegob. Los resultados del cuadro 5 muestran que los municipios que tuvieron un cambio positivo mayor en cuanto a su nivel de Idegob, son aquéllos que se especializan en el sector primario y secundario $(22 \%)$, primario $(18 \%)$, terciario $(16.4 \%)$, y secundario y terciario $(13 \%)$.

\section{Cuadro 5 \\ Gobiernos municipales que mejoran su nivel de desempeño con respecto al total por sector de especialización, 1990-2000 (porcentajes)}

\begin{tabular}{lcccc}
\hline $\begin{array}{c}\text { Especialización } \\
\text { productiva }\end{array}$ & Mejoró & No mejoró & No aplica & Total \\
\hline Primario & 18.0 & 80.8 & 1.2 & 100 \\
Secundario & 12.4 & 83.3 & 4.3 & 100 \\
$\begin{array}{l}\text { Terciario } \\
\text { Primario y }\end{array}$ & 16.4 & 82.8 & 0.9 & 100 \\
$\begin{array}{l}\text { secundario } \\
\text { Primario y }\end{array}$ & 21.9 & 76.5 & 1.6 & 100 \\
terciario & 9.5 & 90.5 & 0.0 & 100 \\
$\begin{array}{l}\text { Secundario } \\
\text { y terciario }\end{array}$ & 13.0 & 85.0 & 2 & 100 \\
$\quad$ Total & 17.8 & 80.7 & 1.5 & 100 \\
\hline
\end{tabular}

Fuente: Elaboración propia.

${ }^{8}$ Uno de los métodos más utilizados en estudios empíricos para definir si un sector es de base económica, es el cociente de localización (CL), que utiliza como información el empleo en los distintos sectores de la economía siguiendo la siguiente fórmula:

$$
\left.\mathrm{CL}=\left(\mathrm{e}_{\mathrm{i}} / \mathrm{e}_{\mathrm{t}}\right) / \mathrm{E}_{\mathrm{i}} / \mathrm{E}_{\mathrm{t}}\right)
$$

Donde $e_{i}=$ empleo local en la industria (i); $e_{t}=$ total de empleo local; $E_{i}=$ empleo nacional en la industria (i); $\mathrm{y}_{\mathrm{t}}=$ total de empleo nacional. 
Estos resultados nos permiten sugerir que, en términos generales, sí hay una tendencia para confirmar que la diversificación económica es un factor preponderante en los municipios que presentaron mayor proporción de mejoría en su nivel de Idegob. Ahora bien, no existe evidencia contundente para asegurar que la especialización productiva en actividades primordialmente urbanas, garantiza un mejor desempeño de los GM.

\subsection{Marginación y desempeño de los GM}

Para analizar la relación entre mejores niveles de desarrollo socioeconómico, y el desempeño de los GM, se decidió aplicar los índices de marginación por municipio. Se entiende que entre más bajo es este índice, los municipios gozan de mejores niveles de desarrollo socioeconómico. Este apartado pretende identificar si existe una relación entre la mejora en el desempeño de los GM, y la disminución de la marginación. Los resultados reportados en el cuadro 6 establecen que en los periodos 1990-2000 y 2000-2005, 49\% de los municipios del país disminuyeron su nivel de marginación; no obstante, sólo 10\% mejoró su desempeño, mientras que en el segundo, lo hizo el 36.3 por ciento.

\section{Cuadro 6}

Gobiernos municipales por cambio en su desempeño y comportamiento en el índice de marginación municipal, 1990-2000 y 2000-2005

\begin{tabular}{lcccc}
\hline \multicolumn{1}{c}{ Desempeño } & \multicolumn{2}{c}{$1990-2000$} & \multicolumn{2}{c}{ 2000-2005 } \\
& $\begin{array}{c}\text { Disminuyó } \\
\text { marginación }\end{array}$ & $\begin{array}{c}\text { Aumentó } \\
\text { marginación }\end{array}$ & $\begin{array}{c}\text { Disminuyó } \\
\text { marginación }\end{array}$ & $\begin{array}{c}\text { Aumentó } \\
\text { marginación }\end{array}$ \\
\hline Mejoró desempeño & 10.1 & 8.0 & 39.4 & 36.3 \\
No mejoró desempeńo & 39.0 & 42.9 & 10.9 & 13.4 \\
\hline
\end{tabular}

Fuente: Elaboración propia.

De acuerdo con los resultados anteriores, se concluye que el nivel de desempeño de los GM no necesariamente se relaciona con los de marginación o desarrollo socioeconómico de los municipios. Este resultado no debe sorprender si recordamos que los gobiernos municipales sólo ejercían (durante el periodo estudiado) alrededor de $4 \%$ del gasto total presupuestado. Así, dado el aumento de la relación de municipios que disminuyeron su nivel de marginación, mejoraron su desempeño y capacidad financiera, se puede sugerir que el esfuerzo de los gobiernos municipales influye en las condiciones de vida de los ciudadanos. 


\subsection{Alternancia política y desempeño de los $G M$}

Al principio del presente trabajo se mencionó la idea de que la alternancia política alienta a los GM a instrumentar acciones efectivas para mejorar su desempeńo; esto con el fin de que los partidos políticos con gobiernos municipales en funciones puedan mantener el poder. Es decir, la alternancia generaría un mejor desempeño de los gobiernos municipales. No obstante, los datos que se presentan en el cuadro 7 establecen que de los 2,412 gobiernos municipales analizados, $37.4 \%$ muestra alternancia; sin embargo, de éstos, sólo $4.8 \%$ presentó mejora en el desempeño de sus GM, mientras que del $44 \%$ que no tuvo alternancia política, $7 \%$ mejoró su desempeño.

\section{Cuadro 7 \\ Comparación porcentual de gobiernos municipales que mejoraron su desempeńo y que presentaron alternancia política}

\begin{tabular}{lcc}
\hline \multicolumn{2}{c}{ Desempeño } & Alternacia \\
\hline & Sí & No \\
Mejoró desempeño & 4.8 & 7.1 \\
No mejoró desempeño & 32.6 & 37.0 \\
\hline
\end{tabular}

Fuente: Elaboración propia.

Para concluir podemos decir que los resultados son contundentes y exponen que en el periodo 1990-2005 (motivo de la presente investigación) la alternancia política no tuvo influencia en el grado de desempeño de los GM.

\section{Conclusiones}

Los cambios en el desempeño de los GM durante los años 1990, 2000 y 2005 no presentan una tendencia clara y contundente que permita afirmar que la descentralización ha generado un entorno adecuado para mejorar el desempeño de los gobiernos municipales; por el contrario, encontramos comportamientos erráticos y poco alentadores. La mayoría de los GM no evidenciaron mejoras en el nivel de desempeño. Asimismo, más de 50\% de los GM se ubican (en el 2005) en las categorías de desempeño regular y malo. Además, al final del periodo 1990-2005 se observa un crecimiento importante de la proporción de GM con una categoría de desempeño malo. Por tanto, se puede sugerir que pocos gobiernos municipales están en posibilidades de coordinar procesos de desarrollo local. 
Los resultados nos permiten apuntar que el cambio en el desempeño de los GM, en el contexto de la descentralización, no confirma que los municipios más grandes, con mejores niveles de desarrollo y con alternancia política, logran tener los mejores desempeńos; mientras se sugiere que la diversificación económica impulsa a los GM a mejorar su desempeño. No obstante, no hay evidencia para decir que los municipios especializados en actividades económicas urbanas (sin diversificación) muestren mejores desempeños en sus GM.

La presente investigación nos aproxima a conocer (a nivel macro) las tendencias que presentan los GM en cuanto a los cambios en su desempeño; en esta línea de estudio, con el Idegob podemos explorar, en trabajos futuros, los patrones territoriales del comportamiento en el desempeño de los GM. Asimismo, obtener mayor conocimiento sobre los gobiernos municipales y sus capacidades, después de estudiar estos desempeños, nos acerca a conocer qué características tienen los GM que mejoraron en este aspecto, y además disminuyeron significativamente la marginación de su población. Sin embargo, queda pendiente mejorar el Idegob y la metodología empleada para su medición, para identificar las correlaciones o relaciones causales que hay entre mejor desempeño, diversificación económica, tamaño del municipio y nivel de desarrollo.

En resumen, el análisis del desempeño de los GM sustentado en el Idegob permite establecer que la organización GM, fundamental para el desarrollo de sus territorios (en el caso de México), no presenta las mejores condiciones para promover procesos de desarrollo económico local; esta situación nos lleva a proponer que el estudio del desempeño de los GM a nivel macro, se complemente en una misma intención analítica con el sondeo de aspectos, como la construcción de capacidades institucionales, organizacionales y humanas a escala micro, que pueden explicar por qué hay gobiernos municipales que en un contexto (más o menos general) de descentralización logran mejorar su desempeño. 


\section{Anexo 1 \\ Índice de desempeño de los gobiernos municipales (Idegob) de México por entidad federativa, 1990-2000}

\begin{tabular}{|c|c|c|c|c|c|c|c|}
\hline AGUASCALIENTES & 1990 & 2000 & 2005 & Allende & 53.0871 & 42.7547 & 42.0754 \\
\hline Aguascalientes & 59.9142 & 61.4563 & 61.5890 & Arteaga & 50.5074 & 42.224 & 52.1455 \\
\hline Asientos & 47.7251 & 44.5715 & 41.6890 & Candela & 51.5789 & 38.91 & 49.2256 \\
\hline Calvillo & 48.9198 & 42.7997 & 44.5277 & Castaños & 52.0127 & 42.7413 & 51.3588 \\
\hline Cosío & 53.3489 & 44.4963 & 43.4507 & Cuatrociénegas & 47.2978 & 45.9701 & 42.5519 \\
\hline Jesús María & 56.6699 & 49.8539 & 53.3710 & Escobedo & 45.6406 & 37.2542 & 38.3691 \\
\hline Pabellón de Arteaga & 48.6486 & 48.1079 & 53.4213 & Francisco I. Madero & 52.7109 & 48.0085 & 42.1582 \\
\hline Rincón de Romos & 51.5244 & 42.4942 & 46.2656 & Frontera & 53.5044 & 50.1702 & 45.9721 \\
\hline San José de Gracia & 46.1341 & 40.5821 & 42.3486 & General Cepeda & 50.8395 & 41.5897 & 52.5921 \\
\hline Tepezalá & 52.8176 & 48.3081 & 43.1136 & Guerrero & 55.6174 & 38.6404 & 44.7773 \\
\hline BAJA CALIFORNIA & 1990 & 2000 & 2005 & Hidalgo & 44.4965 & 37.8438 & 47.5558 \\
\hline Ensenada & 60.7226 & 50.7961 & 51.7209 & Jiménez & 45.3857 & 41.4071 & 44.3316 \\
\hline Mexicali & 50.8665 & 49.3486 & 57.4238 & Juárez & 46.1053 & 38.6491 & 52.8562 \\
\hline Tecate & 50.0629 & 53.2942 & 55.4309 & Lamadrid & 48.946 & 39.5217 & 40.8411 \\
\hline Tijuana & 57.1532 & 52.2268 & 58.3284 & Matamoros & 50.6224 & 48.6654 & 41.6993 \\
\hline Playas de Rosarito & 0 & 61.6601 & 71.0201 & Monclova & 54.8102 & 43.7055 & 43.4112 \\
\hline BAJA CALIFORNIA S. & 1990 & 2000 & 2005 & Morelos & 62.7614 & 40.1425 & 41.2115 \\
\hline Comondú & 67.4664 & 44.8547 & 48.5701 & Múzquiz & 50.9723 & 44.6628 & 44.5127 \\
\hline Mulegé & 57.025 & 46.1365 & 47.3453 & Nadadores & 52.0372 & 43.342 & 37.9709 \\
\hline $\mathrm{Paz}, \mathrm{La}$ & 69.5828 & 53.9282 & 53.1681 & Nava & 59.5028 & 54.1172 & 51.3226 \\
\hline Cabos, Los & 67.9711 & 62.5205 & 63.4817 & Ocampo & 48.0995 & 40.028 & 40.8383 \\
\hline Loreto & 0 & 50.6493 & 49.2285 & Parras & 51.744 & 42.7342 & 44.6965 \\
\hline CAMPECHE & 1990 & 2000 & 2005 & Piedras Negras & 58.0647 & 44.4673 & 46.3735 \\
\hline Calkiní & 45.0837 & 46.2949 & 42.2382 & Progreso & 49.0246 & 67.9051 & 49.3907 \\
\hline Campeche & 61.8176 & 49.0998 & 54.0492 & Ramos Arizpe & 57.7704 & 65.5648 & 66.0880 \\
\hline Carmen & 45.7719 & 38.7303 & 43.1522 & Sabinas & 59.3096 & 50.4689 & 55.3012 \\
\hline Champotón & 45.9969 & 38.7855 & 46.3873 & Sacramento & 62.3132 & 39.4145 & 41.3544 \\
\hline Hecelchakán & 45.9575 & 35.9258 & 37.7291 & Saltillo & 63.5173 & 49.7392 & 51.3457 \\
\hline Hopelchén & 42.1011 & 43.7725 & 39.4161 & San Buenaventura & 51.8634 & 43.7671 & 40.4887 \\
\hline Palizada & 38.9308 & 35.7477 & 39.3960 & San Juan de Sabinas & 54.5639 & 44.6109 & 44.8831 \\
\hline Tenabo & 45.9527 & 36.2722 & 37.2429 & San Pedro & 51.357 & 46.9674 & 41.0164 \\
\hline Escárcega & 14.1727 & 41.3741 & 48.6852 & Sierra Mojada & 52.7315 & 39.1727 & 40.1605 \\
\hline Calakmul & 0 & 36.7824 & 33.4530 & Torreón & 61.6796 & 53.3037 & 63.6524 \\
\hline COAHUILA & 1990 & 2000 & 2005 & Viesca & 49.6861 & 40.9289 & 48.3689 \\
\hline Abasolo & 50.4825 & 39.7023 & 42.3528 & Villa Unión & 50.9543 & 40.1381 & 41.6739 \\
\hline Acuña & 61.6238 & 49.3589 & 47.0307 & Zaragoza & 50.5025 & 47.6288 & 44.7283 \\
\hline
\end{tabular}




\begin{tabular}{|c|c|c|c|c|c|c|c|}
\hline \multicolumn{4}{|l|}{ ontinúa... } & \\
\hline COLIMA & 1990 & 2000 & & Chiapa de Corzo & 48.9228 & 37.0316 & 46.6660 \\
\hline Armería & 52.8734 & 42.6305 & 46.1291 & Chiapilla & 52.964 & 42.2408 & 50.3656 \\
\hline Colima & 57.8672 & 50.5142 & 53.6449 & Chicoasén & 48.854 & 43.2259 & 48.6073 \\
\hline Comala & 56.8078 & 54.4138 & 43.7769 & Chicomuselo & 43.2266 & 37.7084 & 42.6248 \\
\hline Coquimatlán & 53.5828 & 39.5006 & 44.4444 & Chilón & 44.4443 & 41.7044 & 53.9717 \\
\hline Cuauhtémoc & 52.4883 & 42.6819 & 46.4799 & Escuintla & 45.5165 & 38.4238 & 52.0600 \\
\hline Ixtlahuacán & 48.5591 & 49.9559 & 48.2744 & Francisco León & 8.9269 & 33.9224 & 53.3400 \\
\hline Manzanillo & 62.0677 & 55.7295 & 50.8619 & Frontera Comalapa & 48.162 & 53.5398 & 49.5839 \\
\hline Minatitlán & 56.5542 & 40.3027 & 49.4147 & Frontera Hidalgo & 42.4421 & 33.7338 & 41.0533 \\
\hline Tecomán & 60.3989 & 43.7684 & 50.4803 & Grandeza, La & 48.7349 & 33.0776 & 48.4492 \\
\hline Villa de Alvarez & 58.72 & 54.5895 & 51.7970 & Huehuetán & 45.1611 & 41.9988 & 42.7176 \\
\hline CHIAPAS & 1990 & 2000 & & Huixtán & 42.2783 & 33.5603 & 50.7296 \\
\hline Acacoyagua & 46.3197 & 38.0959 & 54.2055 & Huitiupán & 49.1006 & 34.3498 & 58.1406 \\
\hline Acala & 54.6526 & 41.102 & 49.9626 & Huixtla & 48.7172 & 44.0601 & 46.8061 \\
\hline Acapetahua & 43.3642 & 35.3552 & 43.9111 & Independencia, La & 44.4414 & 37.8898 & 56.3005 \\
\hline Altamirano & 44.6067 & 33.6153 & 55.4343 & Ixhuatán & 49.3872 & 40.7181 & 50.9284 \\
\hline Amatán & 37.7024 & 35.4747 & 51.7809 & Ixtacomitán & 45.4884 & 44.969 & 40.0151 \\
\hline Amatenango & 49.3312 & 39.8882 & 56.0426 & Ixtapa & 47.2351 & 41.2205 & 46.7454 \\
\hline Amatenango del Valle & 47.3287 & 35.7567 & 46.6900 & Ixtapangajoya & 44.8897 & 39.8667 & 39.4416 \\
\hline Angel Albino Corzo & 50.4613 & 39.632 & 48.8420 & Jiquipilas & 50.5831 & 38.0565 & 55.5121 \\
\hline Arriaga & 53.2418 & 43.8287 & 46.6629 & Jitotol & 49.2177 & 40.7387 & 50.9656 \\
\hline Bejucal de Ocampo & 41.749 & 31.9128 & 38.3792 & & 395568 & 394004 & \\
\hline Bella Vista & 39.5624 & 36.899 & 54.4775 & Libertad, La & 43.952 & 34.8964 & 40.9022 \\
\hline Berriozábal & 49.8389 & 40.919 & 46.0647 & Mapastepec & 46.4412 & 36.9917 & 47.8973 \\
\hline Bochil & 52.3756 & 37.6997 & 56.5756 & Margaritas, Las & 41.7512 & 35.2422 & 40.2898 \\
\hline Bosque, El & 53.5417 & 40.7483 & 47.7941 & Mazapa de Madero & 50.3819 & 43.232 & 53.6933 \\
\hline Cacahoatán & 49.6405 & 42.9494 & 47.3138 & & & & \\
\hline Catazajá & 43.8676 & 38.102 & 46.5467 & & & & \\
\hline Cintalapa & 49.2077 & 37.2535 & 53.4693 & & & 36.9099 & 41.5131 \\
\hline Coapilla & 50.0818 & 40.3295 & 46.8037 & & 36.2238 & 39.2157 & 37.7762 \\
\hline $\begin{array}{l}\text { Comitán } \\
\text { de Domínguez }\end{array}$ & 54.0579 & 47.6929 & 48.2379 & Nicolás Ruíz & 48.3245 & 48.1001 & 48.4273 \\
\hline Concordia, $\mathrm{La}$ & 49.1548 & 38.0362 & 55.0122 & Ocosingo & 44.3626 & 34.009 & 53.0730 \\
\hline Copainalá & 49.68 & 46.15 & 47.8171 & Ocotepec & 45.0192 & 37.5691 & 55.6866 \\
\hline Chalchihuitán & 35.6544 & 30.6409 & 34.8488 & $\begin{array}{l}\text { Ocozocoautla } \\
\text { de Espin }\end{array}$ & 50.3196 & 40.629 & 56.4045 \\
\hline Chamula & 42.9918 & 33.3231 & 38.9864 & Ostuacán & 41.9336 & 35.0058 & 52.9511 \\
\hline Chanal & 43.866 & 33.166 & 38.1755 & Osumacinta & 50.5456 & 39.6934 & 45.4647 \\
\hline Chapultenango & 38.3266 & 42.022 & 45.1254 & Oxchuc & 42.3796 & 30.4596 & 48.2664 \\
\hline Chenalhó & 42.7638 & 38.5905 & 58.9828 & Palenque & 46.0004 & 37.2755 & 55.1621 \\
\hline
\end{tabular}




\begin{tabular}{|c|c|c|c|c|c|c|c|}
\hline Pantelhó & 40.8051 & 40.64 & 53.3194 & Venustiano Carranza & 51.2065 & 40.141 & 55.4381 \\
\hline Pantepec & 46.36 & 45.9158 & 49.0655 & Villa Corzo & 45.1761 & 37.7783 & 54.3746 \\
\hline Pichucalco & 41.0592 & 35.397 & 45.8536 & Villaflores & 51.3317 & 39.4765 & 54.0654 \\
\hline Pijijiapan & 41.4967 & 36.0499 & 50.7659 & Yajalón & 46.6573 & 50.892 & 47.7319 \\
\hline Porvenir, El & 46.3971 & 34.0685 & 51.1152 & San Lucas & 44.5805 & 49.6652 & 57.5354 \\
\hline Villa Comaltitlán & 44.9542 & 49.9552 & 44.8913 & Zinacantán & 46.3585 & 36.2042 & 53.1772 \\
\hline \multirow{2}{*}{$\begin{array}{l}\text { Pueblo Nuevo } \\
\text { Solistah }\end{array}$} & 47.5166 & 40.2068 & 59.3043 & San Juan Cancuc & 38.4836 & 32.0579 & 54.9292 \\
\hline & \multirow[b]{2}{*}{51.0399} & \multirow[b]{2}{*}{45.2803} & \multirow[b]{2}{*}{49.2346} & CHIHUAHUA & 1990 & 2000 & 2005 \\
\hline Rayón & & & & Ahumada & 59.5041 & 45.8107 & 46.3355 \\
\hline Reforma & 48.6839 & 45.7226 & 50.5972 & Aldama & 59.8746 & 47.4542 & 52.8341 \\
\hline Rosas, Las & 46.4607 & 38.3924 & 47.8780 & Allende & 52.3663 & 41.4315 & 45.8857 \\
\hline Sabanilla & 43.8786 & 40.2084 & 55.9922 & Aquiles Serdán & 50.467 & 41.3162 & 45.0725 \\
\hline Salto de Agua & 43.0417 & 52.6789 & 56.0209 & Ascensión & 63.0664 & 45.3059 & 53.8077 \\
\hline San Cristóbal de las & 49.4515 & 41.815 & 50.5574 & Bachíniva & 55.2562 & 45.3178 & 46.9292 \\
\hline San Fernando & 45.3674 & 37.1574 & 53.1112 & Balleza & 39.5051 & 32.0857 & 39.3396 \\
\hline Siltepec & 45.7993 & 36.3648 & 52.9440 & Batopilas & 35.6778 & 36.1629 & 36.1899 \\
\hline Simojovel & 47.6308 & 36.821 & 55.9765 & Bocoyna & 36.9362 & 40.622 & 35.3010 \\
\hline Sitalá & 41.1517 & 30.0065 & 46.6899 & Buenaventura & 50.9899 & 46.419 & 45.7769 \\
\hline Socoltenango & 48.3813 & 38.4875 & 55.0493 & Camargo & 63.2261 & 46.7415 & 46.2234 \\
\hline Solosuchiapa & 52.3315 & 42.0101 & 47.1333 & Carichí & 39.5864 & 41.9571 & 42.4121 \\
\hline Soyaló & 49.9772 & 50.2064 & 57.0201 & Casas Grandes & 57.6842 & 40.982 & 45.3448 \\
\hline Suchiapa & 50.6302 & 38.4694 & 55.1213 & Coronado & 49.5738 & 40.4915 & 43.0760 \\
\hline Suchiate & 44.1905 & 36.7268 & 45.7402 & Coyame del Sotol & 57.5717 & 44.4652 & 47.9922 \\
\hline Sunuapa & 38.1186 & 39.1346 & 50.9531 & Cruz, La & 50.6566 & 47.2318 & 43.1611 \\
\hline Tapachula & 45.1827 & 44.9238 & 47.1395 & Cuauhtémoc & 60.6708 & 47.4989 & 65.4570 \\
\hline Tapalapa & 46.3359 & 36.9809 & 47.9909 & Cusihuiriachi & 51.0466 & 44.2194 & 44.8712 \\
\hline Tapilula & 54.4959 & 40.1341 & 47.0663 & Chihuahua & 50.2295 & 64.3211 & 62.0130 \\
\hline Tecpatán & 53.198 & 44.401 & 45.5380 & Chínipas & 39.0802 & 32.825 & 37.8358 \\
\hline Tenejapa & 47.9027 & 41.2763 & 49.8347 & Delicias & 63.7619 & 55.3731 & 60.1275 \\
\hline Teopisca & 49.826 & 39.507 & 58.3676 & Dr. Belisario & 48.6911 & 39.6451 & 44.1399 \\
\hline Tila & 44.0835 & 37.2584 & 55.1688 & Domíngu & & & \\
\hline Tonalá & 47.942 & 36.0149 & 45.2608 & Galeana & 54.268 & 45.1562 & 47.2492 \\
\hline Totolapa & 42.7825 & 44.9118 & 50.7184 & Santa Isabel & 47.0041 & 41.9968 & 48.0557 \\
\hline Trinitaria, La & 39.6113 & 44.2715 & 55.2008 & Gómez Farías & 43.8805 & 52.4575 & 41.8108 \\
\hline Tumbalá & 40.6664 & 34.8719 & 53.2329 & Gran Morelos & 43.4388 & 39.6492 & 41.8746 \\
\hline Tuxtla Gutiérrez & 55.4423 & 44.3079 & 52.0620 & Guachochi & 41.8595 & 41.7727 & 46.2615 \\
\hline Tuxtla Chico & 41.7186 & 37.5804 & 49.5772 & Guadalupe & 52.1975 & 42.7524 & 46.7166 \\
\hline Tuzantán & 46.1715 & 36.6324 & 53.4017 & Guadalupe y Calvo & 38.4344 & 34.763 & 46.2582 \\
\hline Tzimol & 42.6004 & 38.4974 & 48.9338 & Guazapares & 43.8513 & 33.7312 & 39.0954 \\
\hline Unión Juárez & 51.9769 & 38.6589 & 47.1571 & Guerrero & 44.1031 & 45.3954 & 44.3797 \\
\hline
\end{tabular}


continúa...

\begin{tabular}{|c|c|c|c|}
\hline Hidalgo del Parral & 51.7684 & 47.2929 & 46.552 \\
\hline Huejotitán & 40.2198 & 41.3963 & 39.601 \\
\hline Ignacio Zaragoza & 48.8965 & 18.7282 & 48.05 \\
\hline Janos & 60.6898 & 45.6537 & 46.38 \\
\hline Jiménez & 59.021 & 43.5729 & 45.01 \\
\hline Juárez & 68.1583 & 56.7915 & 60.99 \\
\hline Julimes & 54.349 & 47.2267 & 43.401 \\
\hline López & 51.9527 & 41.377 & 43.24 \\
\hline Madera & 52.1666 & 40.668 & 39.57 \\
\hline Maguarichi & 36.5964 & 38.6174 & 40.250 \\
\hline Manuel Benavides & 50.3926 & 39.4283 & 41.268 \\
\hline Matachí & 51.3841 & 41.9116 & 41.91 \\
\hline Matamoros & 51.392 & 42.0466 & 42.45 \\
\hline Meoqui & 62.0657 & 47.8525 & 55.47 \\
\hline Morelos & 38.9301 & 36.8524 & 37.29 \\
\hline Moris & 38.5444 & 41.0526 & 49.55 \\
\hline Namiquipa & 45.1273 & 40.4739 & 47.726 \\
\hline Nonoava & 36.5662 & 42.8239 & 38.00 \\
\hline Nuevo Casas Grandes & 56.7349 & 46.679 & 55.471 \\
\hline Ocampo & 41.0065 & 33.5833 & 41.67 \\
\hline Ojinaga & 59.4412 & 46.3873 & 46.50 \\
\hline Praxedis G. Guerrero & 52.399 & 42.5801 & 45.76 \\
\hline Riva Palacio & 53.0097 & 42.3554 & 42.10 \\
\hline Rosales & 58.2015 & 46.194 & 41.963 \\
\hline Rosario & 46.5333 & 41.5138 & 47.11 \\
\hline $\begin{array}{l}\text { San Francisco de } \\
\text { Borj }\end{array}$ & 46.6263 & 40.3538 & 41.97 \\
\hline $\begin{array}{l}\text { San Francisco } \\
\text { de Conc }\end{array}$ & 50.2415 & 43.115 & \\
\hline
\end{tabular}

San Francisco del Oro $58.6484 \quad 46.180450 .2682$

Santa Bárbara $\quad 52.3306 \quad 43.1412 \quad 50.6241$

Satevó $\quad 46.4582 \quad 46.4555 \quad 48.9977$

Saucillo $\quad 53.0217 \quad 41.8767 \quad 45.4784$

$\begin{array}{llll}\text { Temósachi } & 52.2065 & 37.37 & 40.6410\end{array}$

Tule, El $\quad 44.976 \quad 38.7832 \quad 39.3930$

Urique $\quad 42.7414 \quad 41.247 \quad 42.4198$

$\begin{array}{llll}\text { Uruachi } & 36.0988 & 37.7195 & 38.3034\end{array}$

Valle de Zaragoza $\quad 49.0192 \quad 41.0296 \quad 43.3930$

\begin{tabular}{lrrc}
\hline \multicolumn{1}{c}{ DURANGO } & 1990 & 2000 & 2005 \\
\hline Canatlán & 46.5722 & 45.33 & 46.6992 \\
Canelas & 40.055 & 42.2925 & 46.3190 \\
\hline
\end{tabular}

Coneto de Comonfort $\quad 58.439 \quad 38.2169 \quad 39.2552$

Cuencamé $\quad 47.002948 .9585 \quad 41.0307$

Durango $\quad 65.1436 \quad 51.7123 \quad 48.2384$

General Simón Bolívar 45.5709 $47.4258 \quad 47.3820$

Gómez Palacio $\quad 63.7062 \quad 49.677254 .3579$

Guadalupe Victoria $\quad 48.3144 \quad 48.5454 \quad 43.7119$

Guanaceví $\quad 56.9747 \quad 41.5082 \quad 43.2861$

Hidalgo $\quad 52.5974 \quad 45.0136 \quad 40.4460$

Indé $\quad 54.8886 \quad 40.1688 \quad 47.7509$

Lerdo $\quad 50.5066 \quad 46.837248 .0939$

Mapimí $\quad 66.7934 \quad 40.3761 \quad 45.9946$

Mezquital $\quad 37.6979 \quad 43.9379 \quad 45.0279$

Nazas $\quad 50.8791 \quad 39.6458 \quad 41.5439$

Nombre de Dios $\quad 44.7516 \quad 39.832 \quad 42.2849$

Ocampo $\quad 49.0335 \quad 45.501 \quad 40.6450$

Oro, El $\quad 51.4558 \quad 40.9421 \quad 50.3426$

Otáez $\quad 37.9057 \quad 41.0622 \quad 42.8942$

Pánuco de Coronado $52.1932 \quad 39.7866 \quad 41.1277$

Peñón Blanco $\quad 52.1379 \quad 37.0925 \quad 37.3329$

Poanas $\quad 52.8796 \quad 47.8265 \quad 45.8237$

Pueblo Nuevo $\quad 54.1599 \quad 43.9045 \quad 45.2421$

Rodeo $\quad 48.9161 \quad 46.9192 \quad 52.7020$

San Bernardo $\quad 42.5068 \quad 45.642244 .1203$

San Dimas $\quad 46.7844 \quad 42.385139 .7658$

San Juan de Guadalupe $49.8151 \quad 36.5079 \quad 43.0314$

San Juan del Río $\quad 49.1182 \quad 40.1925 \quad 48.6677$

San Luis de Cordero $\quad 48.0975 \quad 42.8501 \quad 48.1968$

San Pedro del Gallo $\quad 47.6436 \quad 44.4302 \quad 41.7488$

$\begin{array}{llll}\text { Santa Clara } & 51.3538 \quad 39.9025 & 41.6593\end{array}$

Santiago Papasquiaro $47.1061 \quad 49.0676 \quad 40.0825$

Súchil $\quad 59.4375 \quad 38.4939 \quad 45.8110$

Tamazula $\quad 33.8592 \quad 55.722638 .5958$

Tepehuanes $\quad 54.3653 \quad 48.8425 \quad 44.8033$

Tlahualilo $\quad 55.6877 \quad 38.3983 \quad 40.9128$

Topia $\quad 41.1058 \quad 45.0159 \quad 40.7409$

Vicente Guerrero $\quad 51.677 \quad 41.0748 \quad 43.9855$

Nuevo Ideal $\quad 16.3988 \quad 46.4044 \quad 46.1411$

\begin{tabular}{lrcc}
\hline \multicolumn{1}{c}{ GUANAJUATO } & 1990 & 2000 & 2005 \\
\hline Abasolo & 53.376 & 56.5428 & 50.9537 \\
Acámbaro & 57.9101 & 58.8716 & 46.8349
\end{tabular}


continúa.

\begin{tabular}{|c|c|c|c|c|c|c|c|}
\hline Allende & 64.6727 & 52.2541 & 48.8853 & Valle de Santiago & 66.6555 & 51.0359 & 51.6026 \\
\hline Apaseo el Alto & 48.6018 & 48.6639 & 50.8332 & Victoria & 42.9899 & 50.9282 & 46.6934 \\
\hline Apaseo el Grande & 59.0134 & 44.8551 & 45.2958 & Villagrán & 60.2886 & 41.5553 & 48.0540 \\
\hline Atarjea & 40.8651 & 47.7788 & 34.1763 & Xichú & 36.4267 & 56.3694 & 42.9449 \\
\hline Celaya & 61.7426 & 44.6468 & 53.3171 & Yuriria & 58.3265 & 52.1332 & 50.1754 \\
\hline Manuel Doblado & 54.2041 & 51.8053 & 51.6167 & GUERRERO & 1990 & 2000 & 2005 \\
\hline Comonfort & 60.6516 & 42.5178 & 49.2981 & Acapulco de Juárez & 61.7012 & 53.3724 & 60.8121 \\
\hline Coroneo & 55.2223 & 58.0563 & 51.8719 & Ahuacuotzingo & 41.8742 & 56.9831 & 50.5279 \\
\hline Cortazar & 59.5984 & 51.96 & 42.9884 & $\begin{array}{l}\text { Ajuchitlán } \\
\text { del Progre }\end{array}$ & 55.2123 & 48.6825 & 47.9228 \\
\hline Cuerámaro & 53.7781 & 54.2803 & 53.6977 & Alcozauca & 45.522 & 39.4815 & 41.2142 \\
\hline Doctor Mora & 56.9233 & 53.5101 & 44.5373 & de Guerrero & & & \\
\hline Dolores Hidalgo & 58.8501 & 50.4612 & 46.1566 & Alpoyeca & 48.0291 & 39.9748 & 57.1775 \\
\hline Guanajuato & 48.6681 & 68.8124 & 61.0075 & Apaxtla & 54.396 & 46.1073 & 52.5549 \\
\hline Huanímaro & 47.2512 & 51.0088 & 46.0545 & Arcelia & 57.8257 & 13.8598 & 45.4920 \\
\hline Irapuato & 66.8086 & 47.1519 & 59.9079 & Atenango del Río & 51.789 & 34.2861 & 42.9125 \\
\hline Jaral del Progreso & 64.6724 & 49.7141 & 43.0996 & $\begin{array}{l}\text { Atlamajalcingo } \\
\text { del Mo }\end{array}$ & 60.3005 & 36 & 46.7549 \\
\hline Jerécuaro & 46.1497 & 51.5598 & 57.7335 & Atlixtac & 41.9105 & 42.2644 & 48.8774 \\
\hline León & 69.8995 & 60.3597 & 54.9655 & Atoyac de Alvarez & 68.0875 & 46.5759 & 45.4322 \\
\hline Moroleón & 74.1486 & 50.9333 & 50.5125 & Ayutla de los Libres & 41.2613 & 51.49 & 52.1110 \\
\hline Ocampo & 53.74 & 53.0987 & 51.6963 & Azoyú & 49.0767 & 49.5297 & 42.4125 \\
\hline Pénjamo & 57.8592 & 46.8375 & 49.7948 & Benito Juárez & 52.4565 & 44.8004 & 44.5081 \\
\hline Pueblo Nuevo & 53.1891 & 55.7514 & 50.1524 & Buenavista & 58.8386 & 45.7844 & 57.9451 \\
\hline Purísima del Rincón & 60.2877 & 52.444 & 53.0632 & de Cuéllar & & & \\
\hline Romita & 56.6519 & 64.2514 & 53.2204 & $\begin{array}{l}\text { Coahuayutla } \\
\text { de José M }\end{array}$ & 44.3354 & 35.2364 & 47.1399 \\
\hline Salamanca & 61.6619 & 52.0462 & 45.8814 & Cocula & 52.6125 & 40.304 & 45.0925 \\
\hline Salvatierra & 59.4386 & 50.7149 & 58.7409 & Copala & 63.5594 & 39.0243 & 53.7441 \\
\hline San Diego de la Unión & 44.3037 & 49.4315 & 48.2498 & Copalillo & 35.5637 & 46.5217 & 46.1961 \\
\hline San Felipe & 53.7763 & 54.8691 & 50.1598 & Copanatoyac & 48.1813 & 37.8707 & 48.9642 \\
\hline $\begin{array}{l}\text { San Francisco } \\
\text { del Rin }\end{array}$ & 65.3173 & 55.7161 & 58.9172 & Coyuca de Benítez & 57.599 & 37.6642 & 43.5053 \\
\hline San José Iturbide & 57.6859 & 56.7709 & 48.3078 & Coyuca de Catalán & 56.5606 & 10.7024 & 47.3147 \\
\hline San Luis de la Paz & 56.6651 & 48.2932 & 59.8775 & Cuajinicuilapa & 62.4899 & 48.457 & 52.1142 \\
\hline Santa Catarina & 44.2181 & 53.784 & 48.1440 & Cualác & 49.1283 & 37.7863 & 44.4845 \\
\hline Santa Cruz & 56.5355 & 52.7204 & 48.3218 & Cuautepec & 53.4672 & 11.0198 & 42.6443 \\
\hline & & & & Cuetzala del Progreso & 46.5095 & 39.6029 & 41.6188 \\
\hline Santiago Maravatío & 49.7514 & 58.1391 & 51.9443 & Cutzamala de Pinzón & 60.055 & 39.9874 & 51.2128 \\
\hline Silao & 67.7205 & 50.9385 & 52.3879 & Chilapa de Alvarez & 43.0753 & 49.6052 & 50.9755 \\
\hline Tarandacuao & 52.2187 & 65.9912 & 41.8589 & Chilpancingo & 55.2747 & 41.6117 & 50.2619 \\
\hline Tarimoro & 59.9705 & 49.2147 & 49.5600 & & & & \\
\hline Tierra Blanca & 43.5549 & 52.3703 & 47.0991 & Florencio Villarreal & 63.2781 & 49.4472 & 50.4251 \\
\hline Uriangato & 67.2466 & 53.77 & 56.3962 & $\begin{array}{l}\text { General Canuto } \\
\text { A. Ner }\end{array}$ & & 39.6288 & \\
\hline
\end{tabular}


continúa...

\begin{tabular}{|c|c|c|c|c|c|c|c|}
\hline $\begin{array}{l}\text { General Heliodoro } \\
\text { Cas }\end{array}$ & 40.5999 & 12.8852 & 43.3995 & Xalpatláhuac & 38.0178 & 45.148 & 49.2011 \\
\hline Huamuxtitlán & 57.1498 & 40.3354 & 52.7748 & Xochihuehuetlán & 45.173 & 38.4707 & 47.8487 \\
\hline Huitzuco de & 47.6558 & 44.6293 & 44.5449 & Xochistlahuaca & 58.7053 & 13.798 & 54.6489 \\
\hline & & & & Zapotitlán Tablas & 57.459 & 36.3714 & 49.1897 \\
\hline $\begin{array}{l}\text { Iguala de la } \\
\text { Independ }\end{array}$ & 65.4589 & 45.4139 & 60.2754 & Zirándaro & 50.145 & 33.6699 & 48.8689 \\
\hline Igualapa & 69.9599 & 43.3397 & 45.1661 & Zitlala & 40.4 & 36.4992 & 47.1357 \\
\hline Ixcateopan de & 57.8702 & 36.3933 & 51.9437 & Eduardo Neri & 45.2921 & 49.5734 & 51.2197 \\
\hline Cuauhté & & & & Acatepec & 0 & 32.859 & 45.8948 \\
\hline José Azueta & 60.4734 & 55.1051 & 63.7305 & HIDALGO & 1990 & 2000 & 2005 \\
\hline Juan R. Escudero & 57.6559 & 52.4683 & 46.0657 & Acatlán & 46.8214 & 46.5025 & 39.6739 \\
\hline Leonardo Bravo & 58.4517 & 45.0289 & 57.2871 & Acaxochitlán & 43.9523 & 45.8439 & 38.8280 \\
\hline Malinaltepec & 35.1357 & 34.1157 & 49.2012 & Actopan & 62.2961 & 51.3272 & 42.5100 \\
\hline Mártir de Cuilapan & 45.5389 & 38.3957 & 51.0003 & Agua Blanca & 45.9295 & 44.1981 & 37.4469 \\
\hline Metlatónoc & 42.1452 & 35.9173 & 50.8714 & de Iturbi & & & \\
\hline Mochitlán & 62.09 & 41.0511 & 48.5519 & Ajacuba & 60.5686 & 57.3388 & 42.3458 \\
\hline Olinalá & 49.8936 & 35.2985 & 37.1938 & Alfajayucan & 46.4377 & 48.7443 & 46.5234 \\
\hline Ometepec & 58.3088 & 46.4253 & 44.2238 & Almoloya & 47.8802 & 48.2523 & 49.2911 \\
\hline Pedro Ascencio & 39.5018 & 34.1194 & 46.5132 & Apan & 53.9835 & 50.5422 & 40.0354 \\
\hline Alquis & & & & Arenal, El & 47.3853 & 46.1268 & 40.6569 \\
\hline Petatlán & 51.5295 & 40.4479 & 46.1401 & Atitalaquia & 63.2152 & 20.9495 & 61.3328 \\
\hline Pilcaya & 47.0101 & 42.8102 & 54.6342 & Atlapexco & 33.9798 & 46.0723 & 44.5688 \\
\hline Pungarabato & 67.9915 & 39.4575 & 48.6302 & Atotonilco el Grande & 58.7269 & 46.7462 & 46.0291 \\
\hline Quechultenango & 38.4651 & 51.8433 & 51.7050 & Atotonilco de Tula & 59.0769 & 61.095 & 59.4974 \\
\hline San Luis Acatlán & 41.0918 & 40.6688 & 58.0608 & Calnali & 47.2723 & 44.3141 & 39.2739 \\
\hline San Marcos & 61.6129 & 49.4791 & 41.5552 & Cardonal & 46.2968 & 53.938 & 42.1512 \\
\hline San Miguel Totolapan & 60.1463 & 10.8093 & 39.8882 & Cuautepec & 56.2784 & 48.2542 & 42.7531 \\
\hline Taxco de Alarcón & 58.2846 & 49.1045 & 49.6385 & & & & \\
\hline Tecoanapa & 44.2105 & 14.9007 & 53.2140 & Chapantongo & 45.065 & 47.5538 & 47.7135 \\
\hline Técpan de Galeana & 61.1646 & 45.4513 & 52.4803 & Chapulhuacán & 45.974 & 44.6555 & 37.4343 \\
\hline Teloloapan & 63.0582 & 51.2953 & 42.2340 & Chilcuautla & 44.0592 & 55.9491 & 43.7810 \\
\hline $\begin{array}{l}\text { Tepecoacuilco } \\
\text { de Truj }\end{array}$ & 57.8013 & 40.6339 & 50.7058 & Eloxochitlán & 43.124 & 49.0139 & 40.9525 \\
\hline Tetipac & 54.6185 & 46.0775 & 51.2119 & Emiliano Zapata & 53.2792 & 41.0827 & 42.5638 \\
\hline Tixtla de Guerrero & 69.3701 & 48.9782 & 50.0032 & Epazoyucan & 46.4214 & 46.5902 & 40.7842 \\
\hline Tlacoachistlahuaca & 47.1043 & 51.4914 & 54.4425 & Francisco I. Madero & 57.3984 & 51.1026 & 42.0357 \\
\hline Tlacoapa & 50.2096 & 36.2014 & 46.1880 & Huasca de Ocampo & 44.9709 & 48.8144 & 46.8067 \\
\hline Tlalchapa & 54.0675 & 34.9604 & 48.0127 & Huautla & 43.3054 & 45.6016 & 33.3662 \\
\hline Tlalixtaquilla de Mal & 53.9289 & 37.1172 & 48.1864 & Huazalingo & 49.2879 & 42.8341 & 44.1865 \\
\hline Tlapa de Comonfort & 44.6446 & 40.0007 & 43.7259 & Huehuetla & 37.6864 & 43.2174 & 35.0733 \\
\hline Tlapehuala & 72.7711 & 50.0424 & 43.9002 & Huejutla de Reyes & 44.5088 & 40.7909 & 36.5204 \\
\hline Unión de Isidoro & 50.5138 & 36.3006 & 53.2844 & Huichapan & 67.3745 & 47.1946 & 53.5644 \\
\hline Mont & & & & Ixmiquilpan & 56.4108 & 51.1746 & 41.8851 \\
\hline
\end{tabular}


continúa.

\begin{tabular}{|c|c|c|c|c|c|c|c|}
\hline Jacala de Ledezma & 47.3744 & 51.1479 & 42.2664 & Tianguistengo & 40.754 & 44.0073 & 44.4014 \\
\hline Jaltocán & 43 & 39.1837 & 39.7721 & Tizayuca & 69.9641 & 59.9163 & 53.5124 \\
\hline Juárez Hidalgo & 40.58 & 42.2215 & 40.0645 & Tlahuelilpan & 60.9099 & 52.8659 & 45.3463 \\
\hline Lolotla & 42.3142 & 45.4194 & 36.6364 & Tlahuiltepa & 37.4939 & 51.9283 & 39.2528 \\
\hline Metepec & 48.7797 & 40.4535 & 46.7606 & Tlanalapa & 56.7015 & 50.6244 & 40.2500 \\
\hline San Agustín Metzquiti & 53.7575 & 53.1329 & 40.7792 & Tlanchinol & 39.5594 & 50.8448 & 45.3127 \\
\hline Metztitlán & 51.281 & 44.0783 & 38.9475 & Tlaxcoapan & 63.608 & 51.9643 & 42.4621 \\
\hline Mineral del Chico & 44.7854 & 37.1285 & 37.3818 & Tolcayuca & 48.8223 & 45.5248 & 42.4460 \\
\hline Mineral del Monte & 48.785 & 39.9649 & 39.3667 & Tula de Allende & 64.8299 & 49.6197 & 50.3601 \\
\hline Misión, La & 38.0296 & 41.7899 & 41.9456 & Tulancingo de Bravo & 65.1554 & 50.4046 & 43.9428 \\
\hline \multirow{2}{*}{$\begin{array}{l}\text { Mixquiahuala } \\
\text { de Juáre }\end{array}$} & 49.8545 & 51.324 & 42.0064 & Xochiatipan & 38.1719 & 41.9747 & 42.3213 \\
\hline & & & & Xochicoatlán & 43.4397 & 46.0966 & 40.0611 \\
\hline Molango de Escamilla & 49.2102 & 42.9754 & 37.1720 & Yahualica & 43.049 & 43.2179 & 37.0426 \\
\hline Nicolás Flores & 40.0348 & 44.5877 & 38.2182 & \multirow{2}{*}{$\begin{array}{l}\text { Zacualtipán de } \\
\text { Angele }\end{array}$} & \multirow[t]{2}{*}{51.9938} & \multirow[t]{2}{*}{50.5112} & \multirow[t]{2}{*}{41.7266} \\
\hline Nopala de Villagrán & 49.3868 & 45.2568 & 40.5269 & & & & \\
\hline Omitlán de Juárez & 47.9287 & 46.2168 & 38.9290 & Zapotlán de Juárez & 49.6503 & 50.7862 & 44.6545 \\
\hline San Felipe Orizatlán & 47.3444 & 57.1397 & 39.3776 & Zempoala & 50.7552 & 52.3571 & 44.6796 \\
\hline Pacula & 41.8358 & 40.0038 & 36.5763 & Zimapán & 53.8573 & 51.0887 & 40.5957 \\
\hline Pachuca de Soto & 68.5983 & 54.3392 & 57.3997 & JALISCO & 1990 & 2000 & 2005 \\
\hline Picaflores & 42.0036 & 48.1795 & 43.4247 & Acatic & 47.2839 & 51.7719 & 62.1252 \\
\hline Progreso de Obregón & 58.0977 & 51.8834 & 43.2073 & Acatlán de Juárez & 62.3015 & 20.2162 & 59.5700 \\
\hline Mineral de la Reforma & 57.3578 & 56.7081 & 61.5322 & Ahualulco de Mercado & 58.4607 & 45.0097 & 60.5667 \\
\hline San Agustín Tlaxiaca & 52.312 & 45.8115 & 39.6924 & Amacueca & 57.7273 & 49.7266 & 55.3874 \\
\hline San Bartolo Tutotepec & 37.7473 & 42.9817 & 39.8542 & Amatitán & 62.7333 & 50.9601 & 66.4397 \\
\hline San Salvador & 52.681 & 47.8945 & 47.6314 & Ameca & 63.4925 & 54.1853 & 55.2645 \\
\hline Santiago de Anaya & 49.0335 & 54.9722 & 40.9141 & \multirow{2}{*}{$\begin{array}{l}\text { San Juanito } \\
\text { de Escobe }\end{array}$} & \multirow[t]{2}{*}{53.9255} & \multirow{2}{*}{42.4433} & \multirow[t]{2}{*}{56.3965} \\
\hline \multirow{2}{*}{$\begin{array}{l}\text { Santiago Tulantepec } \\
\text { d }\end{array}$} & 50.889 & 44.6323 & 49.4090 & & & & \\
\hline & & & & Arandas & 60.6154 & 51.9384 & 65.8582 \\
\hline Singuilucan & 46.6596 & 51.2734 & 41.0044 & Arenal, El & 56.8196 & 49.0742 & 54.1211 \\
\hline Tasquillo & 51.8916 & 47.8391 & 49.3799 & Atemajac de Brizuela & 49.2269 & 18.5861 & 43.2763 \\
\hline Tecozautla & 49.1026 & 57.7939 & 48.7182 & Atengo & 49.2346 & 48.8098 & 45.7021 \\
\hline Tenango de Doria & 45.2109 & 50.9265 & 42.9246 & Atenguillo & 55.3091 & 41.5793 & 60.0695 \\
\hline Tepeapulco & 64.0369 & 44.0402 & 45.3524 & Atotonilco el Alto & 74.3234 & 54.6129 & 63.4232 \\
\hline $\begin{array}{l}\text { Tepehuacán de } \\
\text { Guerrer }\end{array}$ & 37.8805 & 49.8298 & 35.7111 & Atoyac & 55.7966 & 53.5517 & 50.6727 \\
\hline \multirow{2}{*}{$\begin{array}{l}\text { Tepeji del Río de } \\
\text { Oca }\end{array}$} & 66.0255 & 49.3232 & 49.6977 & Autlán de Navarro & 60.2731 & 56.6162 & 63.7115 \\
\hline & & & & Ayotlán & 62.9583 & 52.8939 & 57.3537 \\
\hline Tepetitlán & 51.018 & 17.5942 & 41.1042 & Ayutla & 55.5917 & 19.5847 & 56.2150 \\
\hline Tetepango & 52.1812 & 51.0221 & 44.0265 & Barca, La & 61.0225 & 45.811 & 57.4693 \\
\hline Villa de Tezontepec & 54.5307 & 46.4916 & 46.1204 & & 40.5009 & 431931 & 4263 \\
\hline $\begin{array}{l}\text { Tezontepec de } \\
\text { Aldama }\end{array}$ & 50.3386 & 47.3509 & 48.4410 & Doranos & & & \\
\hline & & & & Cabo Corrientes & 50.6896 & 42.3394 & 45.1306 \\
\hline
\end{tabular}


continúa.

\begin{tabular}{|c|c|c|c|c|c|c|c|}
\hline Casimiro Castillo & 63.0967 & 45.9564 & 52.3412 & Mexticacán & 48.2756 & 51.7472 & 53.0995 \\
\hline Cihuatlán & 65.9171 & 17.3347 & 54.4927 & Mezquitic & 39.8822 & 40.1933 & 39.9004 \\
\hline Zapotlán El Grande & 69.2662 & 54.3299 & 60.2352 & Mixtlán & 49.3664 & 17.8819 & 48.8810 \\
\hline Cocula & 64.5978 & 20.1713 & 47.3525 & Ocotlán & 64.0301 & 50.1801 & 60.8549 \\
\hline Colotlán & 54.6223 & 17.9955 & 58.9422 & Ojuelos de Jalisco & 56.108 & 50.1632 & 51.5759 \\
\hline $\begin{array}{l}\text { Concepción } \\
\text { de Buenos }\end{array}$ & 64.8952 & 51.6477 & 58.4992 & Pihuamo & 59.0753 & 47.5711 & 48.4643 \\
\hline Cuautitlán de García & 47.6709 & 15.2673 & 48.8056 & Poncitlán & 49.4283 & 19.6722 & 45.8055 \\
\hline Cuautla & 57.0816 & 61.6952 & 44.0837 & Puerto Vallarta & 66.5639 & 62.9505 & 57.8246 \\
\hline Cuquío & 48.0125 & 46.7962 & 44.7974 & Villa Purificación & 51.2968 & 18.1838 & 51.4405 \\
\hline Chapala & 64.558 & 19.7698 & 61.9748 & Quitupan & 45.7299 & 17.0642 & 45.9406 \\
\hline Chimaltitán & 45.1871 & 40.3764 & 40.6579 & $\begin{array}{l}\text { Salto, El } \\
\text { San Cristóbal }\end{array}$ & $\begin{array}{l}60.0264 \\
44.5971\end{array}$ & $\begin{array}{l}47.6271 \\
16.6637\end{array}$ & $\begin{array}{l}62.5282 \\
41.7733\end{array}$ \\
\hline Chiquilistlán & 55.2526 & 51.3514 & 45.9655 & de la B & & & \\
\hline Degollado & 59.5268 & 52.4512 & 52.5619 & $\begin{array}{l}\text { San Diego de } \\
\text { Alejandr }\end{array}$ & 49.7664 & 52.5524 & 46.3123 \\
\hline Ejutla & 59.957 & 60.6041 & 59.3108 & San Juan de los Lagos & 68.5549 & 50.0211 & 54.6117 \\
\hline Encarnación de Díaz & 64.1143 & 45.1742 & 63.3559 & San Julián & 66.2251 & 50.9412 & 64.6946 \\
\hline Etzatlán & 60.6951 & 20.2181 & 52.4579 & San Marcos & 53.3293 & 19.3659 & 48.7264 \\
\hline Grullo, El & 60.0069 & 54.4665 & 53.6261 & San Martín de Bolaños & 49.2424 & 14.976 & 40.0651 \\
\hline Guachinango & 52.7127 & 47.2848 & 57.5280 & San Martín de Hidalgo & 61.8742 & 46.0551 & 52.0601 \\
\hline Guadalajara & 64.4796 & 51.6109 & 58.2811 & San Miguel el Alto & 64.073 & 19.8638 & 53.5913 \\
\hline Hostotipaquillo & 48.5911 & 17.664 & 52.1429 & Gómez Farías & 53.4989 & 19.3233 & 46.3347 \\
\hline Huejúcar & 47.4295 & 18.1688 & 53.9001 & San Sebastián & 45.182 & 49.26 & 46.0807 \\
\hline Huejuquilla el Alto & 47.6014 & 15.1033 & 45.0382 & & & & \\
\hline Huerta, La & 61.45 & 17.8364 & 46.5289 & $\begin{array}{l}\text { Santa María de } \\
\text { los Án }\end{array}$ & 52.3052 & 45.1126 & 43.5765 \\
\hline $\begin{array}{l}\text { Ixtlahuacán de } \\
\text { los Me }\end{array}$ & 55.1231 & 19.7768 & 48.0989 & Sayula & 61.5085 & 47.001 & 45.7422 \\
\hline Ixtlahuacán del Río & 50.8998 & 43.5502 & 45.1946 & Tala & 68.2012 & 20.6739 & 60.3793 \\
\hline Jalostotitlán & 64.5374 & 19.9132 & 61.3420 & Talpa de Allende & 54.3444 & 53.1338 & 63.7107 \\
\hline Jamay & 56.2952 & 45.0222 & 54.6735 & Tamazula de Gordiano & 57.8605 & 43.9567 & 45.6520 \\
\hline Jesús María & 49.755 & 50.7907 & 55.1305 & Tapalpa & 60.8613 & 17.9775 & 44.3775 \\
\hline Jilotlán de los Dolor & 51.1883 & 42.5992 & 46.0643 & Tecalitlán & 57.5303 & 43.5673 & 44.8539 \\
\hline Jocotepec & 63.2596 & 50.8277 & 55.1922 & Tecolotlán & 58.1999 & 44.0782 & 47.9282 \\
\hline Juanacatlán & 65.4457 & 45.2506 & 55.2470 & $\begin{array}{l}\text { Techaluta } \\
\text { de Monteneg }\end{array}$ & 55.6538 & 45.106 & 48.3878 \\
\hline Juchitlán & 64.9114 & 46.4252 & 44.7436 & Tenamaxtlán & 50.6043 & 42.9526 & 48.9225 \\
\hline Lagos de Moreno & 57.7491 & 45.6863 & 62.1373 & Teocaltiche & 58.0886 & 51.1504 & 55.1565 \\
\hline Limón, El & 60.2586 & 42.5173 & 55.4978 & Teocuitatlán & 52.2671 & 19.7559 & 52.8762 \\
\hline Magdalena & 55.3265 & 42.69 & 52.3659 & de Coron & & & \\
\hline Santa María del Oro & 38.7976 & 42.8433 & 44.4739 & Tepatitlán de Morelos & 68.9612 & 65.0068 & 60.3701 \\
\hline Manzanilla de la Paz, & 60.1491 & 42.3584 & 48.2476 & Tequila & 62.4371 & 54.3492 & 53.1779 \\
\hline Mascota & 69.2701 & 44.8681 & 46.3711 & Teuchitlán & 57.1603 & 47.0634 & 69.1071 \\
\hline Mazamitla & 53.0364 & 17.1442 & 54.2137 & Tizapán el Alto & 57.3791 & 47.6059 & 68.1404 \\
\hline
\end{tabular}


continúa..

\begin{tabular}{|c|c|c|c|c|c|c|c|}
\hline $\begin{array}{l}\text { Tlajomulco de } \\
\text { Zúńiga }\end{array}$ & 63.2976 & 66.7891 & 69.5943 & Apaxco & 50.3054 & 51.6229 & 45.0305 \\
\hline Tlaquepaque & 70.8903 & 44.0192 & 54.8947 & Atenco & 45.7045 & 44.7396 & 39.6593 \\
\hline Tolimán & 53.8883 & 47.4611 & 44.0769 & Atizapán & 52.0622 & 20.6533 & 45.6510 \\
\hline Tomatlán & 58.135 & 44.8276 & 48.1081 & Atizapán de Zaragoza & 67.3759 & 52.763 & 55.7145 \\
\hline Tonalá & 64.5429 & 42.163 & 52.2023 & Atlacomulco & 62.4833 & 49.3093 & 43.7850 \\
\hline Tonaya & 56.5425 & 57.7196 & 56.9972 & Atlautla & 52.08 & 38.4373 & 40.9292 \\
\hline Tonila & 53.7461 & 45.0796 & 46.6372 & Axapusco & 49.7866 & 38.7734 & 43.6207 \\
\hline Totatiche & 47.3494 & 15.6606 & 49.6923 & Ayapango & 49.6113 & 39.9689 & 41.8911 \\
\hline Tototlán & 57.2931 & 53.5814 & 61.4795 & Calimaya & 50.5218 & 40.7471 & 46.2087 \\
\hline Tuxcacuesco & 53.526 & 43.594 & 42.1143 & Capulhuac & 57.8037 & 40.9716 & 45.3252 \\
\hline Tuxcueca & 55.0656 & 19.7536 & 54.7155 & $\begin{array}{l}\text { Coacalco de } \\
\text { Berriozáb }\end{array}$ & 74.459 & 47.1529 & 52.8217 \\
\hline Tuxpan & 58.9619 & 45.8263 & 54.3417 & Coatepec Harinas & 49.0183 & 45.2596 & 48.1155 \\
\hline Unión de San Antonio & 54.0361 & 53.506 & 54.3513 & Cocotitlán & 48.5067 & 40.7767 & 42.9789 \\
\hline Unión de Tula & 53.5336 & 47.6088 & 52.4686 & Coyotepec & 49.0973 & 39.5991 & 43.7718 \\
\hline Valle de Guadalupe & 63.8519 & 51.3114 & 49.6535 & Cuautitlán & 66.138 & 56.2807 & 58.2282 \\
\hline Valle de Juárez & 65.3194 & 53.3461 & 45.9428 & Chalco & 59.7531 & 43.4584 & 46.8528 \\
\hline San Gabriel & 52.4988 & 45.0511 & 57.6233 & Chapa de Mota & 43.3068 & 37.0297 & 39.9507 \\
\hline Villa Corona & 55.3148 & 20.7767 & 46.7003 & Chapultepec & 60.2892 & 43.7937 & 44.3466 \\
\hline Villa Guerrero & 47.7726 & 13.9308 & 40.9025 & Chiautla & 47.6079 & 38.8408 & 46.1609 \\
\hline Villa Hidalgo & 64.6555 & 61.0575 & 62.1712 & Chicoloapan & 63.3705 & 46.4876 & 44.2083 \\
\hline Cañadas de Obregón & 63.6392 & 41.2872 & 56.9791 & Chiconcuac & 65.375 & 19.4946 & 44.5809 \\
\hline Yahualica de González & 54.0013 & 41.8407 & 60.2591 & Chimalhuacán & 55.4702 & 40.6589 & 50.7360 \\
\hline Zacoalco de Torres & 64.6849 & 44.1249 & 62.8624 & Donato Guerra & 38.3521 & 40.9409 & 46.0986 \\
\hline Zapopan & 63.1875 & 58.8183 & 61.5898 & Ecatepec de Morelos & 67.9587 & 45.1233 & 47.3495 \\
\hline Zapotiltic & 66.3237 & 52.8509 & 54.6470 & Ecatzingo & 45.4866 & 35.8409 & 44.8257 \\
\hline Zapotitlán de Vadillo & 50.0369 & 46.5672 & 53.4350 & Huehuetoca & 54.5624 & 53.4912 & 55.3875 \\
\hline Zapotlán del Rey & 51.8286 & 19.1266 & 54.2644 & Hueypoxtla & 55.6911 & 40.2392 & 45.5126 \\
\hline Zapotlanejo & 63.7053 & 60.1739 & 63.7811 & Huixquilucan & 72.5601 & 63.1937 & 63.5449 \\
\hline $\begin{array}{c}\text { ESTADO DE } \\
\text { MEXICO }\end{array}$ & 1990 & 2000 & 2005 & Isidro Fabela & 45.1983 & 36.3029 & 40.8201 \\
\hline Acambay & 46.529 & 38.3098 & 45.8215 & Ixtapaluca & 64.5563 & 49.5566 & 50.1464 \\
\hline Acolman & 52.2017 & 47.609 & 55.0486 & Ixtapan de la Sal & 55.9821 & 42.0883 & 61.7934 \\
\hline Aculco & 46.3898 & 45.3624 & 39.4020 & Ixtapan del Oro & 39.2644 & 40.6667 & 40.1907 \\
\hline Almoloya de & 44.7587 & 44.7308 & 40.8168 & Ixtlahuaca & 48.9343 & 45.171 & 47.2957 \\
\hline Alquisira & & & & Xalatlaco & 56.6599 & 40.2351 & 42.4871 \\
\hline Almoloya de Juárez & 44.2418 & 41.7492 & 38.9773 & Jaltenco & 62.7031 & 38.816 & 45.8594 \\
\hline Almoloya del Río & 57.3543 & 18.842 & 45.6544 & Jilotepec & 50.633 & 44.2539 & 39.8109 \\
\hline Amanalco & 41.5101 & 44.38 & 45.6892 & Jilotzingo & 56.5729 & 38.8271 & 40.9680 \\
\hline Amatepec & 46.7298 & 45.7216 & 34.9089 & Jiquipilco & 49.3896 & 45.0852 & 46.8793 \\
\hline Amecameca & 54.124 & 42.584 & 42.2823 & Jocotitlán & 48.4987 & 44.1801 & 41.5610 \\
\hline
\end{tabular}


continúa...

\begin{tabular}{|c|c|c|c|c|c|c|c|}
\hline Joquicingo & 49.965 & 38.8752 & 42.3178 & Temoaya & 48.1713 & 43.4969 & 48.7551 \\
\hline Juchitepec & 49.5693 & 39.1979 & 43.8373 & Tenancingo & 42.3613 & 40.5757 & 41.8309 \\
\hline Lerma & 56.9899 & 48.1906 & 46.9516 & Tenango del Aire & 48.843 & 43.7839 & 42.1726 \\
\hline Malinalco & 46.8072 & 38.5725 & 42.2549 & Tenango del Valle & 53.8342 & 40.3967 & 41.6895 \\
\hline Melchor Ocampo & 65.761 & 39.7677 & 44.7503 & Teoloyucán & 61.5528 & 43.3293 & 43.2152 \\
\hline Metepec & 68.7827 & 62.3281 & 55.3857 & Teotihuacán & 55.8724 & 49.8864 & 41.6776 \\
\hline Mexicaltzingo & 52.0564 & 45.4435 & 42.9400 & Tepetlaoxtoc & 49.0286 & 44.6058 & 41.8299 \\
\hline Morelos & 43.6485 & 42.5533 & 45.3510 & Tepetlixpa & 49.337 & 38.4757 & 42.5525 \\
\hline Naucalpan de Juárez & 62.4827 & 52.852 & 53.4526 & Tepotzotlán & 67.969 & 52.0471 & 58.7320 \\
\hline Nezahualcóyotl & 74.4618 & 45.2299 & 45.7994 & Tequixquiac & 51.5629 & 47.8001 & 41.7687 \\
\hline Nextlalpan & 61.3529 & 41.1996 & 44.3638 & Texcaltitlán & 47.9091 & 43.228 & 45.9109 \\
\hline Nicolás Romero & 67.6334 & 43.4533 & 48.2996 & Texcalyacac & 54.0755 & 39.3353 & 42.5468 \\
\hline Nopaltepec & 55.552 & 39.8161 & 42.7710 & Texcoco & 67.7904 & 44.3904 & 48.7403 \\
\hline Ocoyoacac & 59.8241 & 43.6542 & 44.1589 & Tezoyuca & 51.6323 & 41.5227 & 40.4978 \\
\hline Ocuilan & 52.7097 & 42.8278 & 41.1620 & Tianguistenco & 55.2352 & 42.7235 & 43.7988 \\
\hline Oro, El & 49.0146 & 44.0379 & 38.9983 & Timilpan & 47.3571 & 42.011 & 40.2138 \\
\hline Otumba & 55.8966 & 39.3155 & 48.4406 & Tlalmanalco & 49.9141 & 39.819 & 42.0547 \\
\hline Otzoloapan & 39.1892 & 42.312 & 43.6786 & Tlalnepantla de Baz & 67.4766 & 50.9981 & 58.0935 \\
\hline Otzolotepec & 57.4232 & 46.9535 & 41.0463 & Tlatlaya & 39.1 & 35.4377 & 44.0283 \\
\hline Ozumba & 50.0634 & 39.148 & 42.5683 & Toluca & 60.3773 & 48.0496 & 54.7676 \\
\hline Papalotla & 58.413 & 42.1392 & 46.2083 & Tonatico & 55.0456 & 43.254 & 48.1520 \\
\hline Paz, La & 58.4764 & 44.2441 & 43.5277 & Tultepec & 60.1345 & 39.8483 & 68.1753 \\
\hline Polotitlán & 57.2415 & 41.7237 & 53.4528 & Tultitlán & 67.7768 & 42.9398 & 47.6933 \\
\hline Rayón & 57.6169 & 19.2709 & 43.4565 & Valle de Bravo & 67.4636 & 37.7508 & 49.7951 \\
\hline San Antonio la Isla & 49.6933 & 41.0482 & 49.9344 & Villa de Allende & 44.2046 & 49.132 & 50.0243 \\
\hline San Felipe del Progre & 37.3571 & 41.9652 & 46.4610 & Villa del Carbón & 56.7382 & 41.8651 & 40.1584 \\
\hline \multirow{2}{*}{$\begin{array}{l}\text { San Martín de } \\
\text { las Pir }\end{array}$} & 58.3179 & 39.3751 & 41.7834 & Villa Guerrero & 56.9667 & 46.6585 & 42.8780 \\
\hline & & & & Villa Victoria & 43.1755 & 46.959 & 42.7933 \\
\hline San Mateo Atenco & 49.6563 & 38.9341 & 40.7222 & Xonacatlán & 53.6992 & 39.5242 & 42.4260 \\
\hline $\begin{array}{l}\text { San Simón de } \\
\text { Guerrero }\end{array}$ & 53.31 & 34.4957 & 37.4178 & Zacazonapan & 41.0947 & 37.6493 & 50.2062 \\
\hline Santo Tomás & 46.5513 & 35.726 & 39.6379 & Zacualpan & 41.4433 & 33.4436 & 35.1516 \\
\hline \multirow{2}{*}{$\begin{array}{l}\text { Soyaniquilpan } \\
\text { de Juár }\end{array}$} & 42.6314 & 42.4087 & 39.8428 & Zinacantepec & 48.0633 & 37.3384 & 40.1754 \\
\hline & & & & Zumpahuacán & 57.8267 & 44.1419 & 46.6610 \\
\hline Sultepec & 44.9781 & 40.0972 & 43.2697 & Zumpango & 58.8689 & 43.8332 & 45.1089 \\
\hline Tecámac & 60.5369 & 43.1142 & 48.6420 & Cuautitlán Izcalli & 74.0153 & 52.482 & 51.4111 \\
\hline Tejupilco & 45.0015 & 43.1178 & 47.3330 & Valle de Chalco & 0 & 48.6518 & 49.7354 \\
\hline Temamatla & 48.0451 & 40.2217 & 41.4387 & Solid & & & \\
\hline Temascalapa & 64.2394 & 43.6122 & 41.2290 & MICHOACAN & 1990 & 2000 & 2005 \\
\hline Temascalcingo & 47.3988 & 45.0166 & 46.5028 & Acuitzio & 50.5286 & 47.024 & 47.9186 \\
\hline Temascaltepec & 43.2946 & 35.1846 & 38.4472 & Aguililla & 48.2507 & 45.2201 & 45.7547 \\
\hline
\end{tabular}




\begin{tabular}{|c|c|c|c|c|c|c|c|}
\hline \multicolumn{4}{|l|}{ ntinúa... } & \multicolumn{4}{|l|}{ 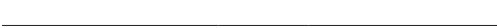 } \\
\hline Alvaro Obregón & 49.365 & 49.1476 & 51.2529 & Ixtlán & 55.6279 & 47.7222 & 42.5009 \\
\hline Angamacutiro & 54.7921 & 54.6539 & 49.7174 & Jacona & 64.0056 & 42.2908 & 53.0543 \\
\hline Angangueo & 45.7384 & 39.6102 & 44.7567 & Jiménez & 54.3245 & 50.0896 & 55.9662 \\
\hline Apatzingán & 66.6414 & 44.4527 & 54.6207 & Jiquilpan & 61.0635 & 50.9899 & 46.1537 \\
\hline Aporo & 48.9934 & 48.4007 & 54.4928 & Juárez & 54.1452 & 50.4901 & 53.5015 \\
\hline Aquila & 42.3808 & 31.6383 & 40.8934 & Jungapeo & 50.24 & 47.9747 & 54.9582 \\
\hline Ario & 57.4742 & 46.2729 & 47.2090 & Lagunillas & 52.1768 & 43.0688 & 52.4148 \\
\hline Arteaga & 46.2282 & 37.2039 & 46.8503 & Madero & 55.342 & 45.0722 & 45.3190 \\
\hline Briseñas & 49.6457 & 44.7091 & 47.5839 & Maravatío & 43.8546 & 55.5363 & 52.2981 \\
\hline Buenavista & 53.5282 & 50.2985 & 51.8024 & Marcos Castellanos & 67.614 & 49.1442 & 52.7867 \\
\hline Carácuaro & 38.0959 & 40.2738 & 46.2037 & Lázaro Cárdenas & 66.9661 & 43.4934 & 47.9432 \\
\hline Coahuayana & 56.9723 & 38.514 & 47.3293 & Morelia & 65.6394 & 58.7279 & 64.2200 \\
\hline Coalcomán de & 55.8469 & 41.5518 & 47.5840 & Morelos & 46.4541 & 55.7533 & 50.2208 \\
\hline Vázquez & & & & Múgica & 51.7621 & 45.2776 & 48.3313 \\
\hline Coeneo & 48.6579 & 48.3271 & 51.6597 & Nahuatzen & 47.8336 & 41.5065 & 50.0489 \\
\hline Contepec & 52.793 & 48.0869 & 54.4050 & Nocupétaro & 42.2363 & 39.8145 & 45.7004 \\
\hline Copándaro & 46.8476 & 43.9952 & 49.4989 & Nuevo Parangaricutiro & 61.58 & 43.9289 & 51.5842 \\
\hline Cotija & 62.7935 & 51.0522 & 45.4965 & Nuevo Urecho & 52.0166 & 48.2032 & 51.0463 \\
\hline Cuitzeo & 54.9211 & 46.7512 & 55.1675 & Numarán & 61.098 & 47.4988 & 51.3638 \\
\hline Charapan & 48.2957 & 46.4329 & 47.9157 & Ocampo & 44.5059 & 42.4356 & 42.4207 \\
\hline Charo & 48.5347 & 48.1763 & 49.0286 & Pajacuarán & 54.0271 & 49.0462 & 51.1799 \\
\hline Chavinda & 59.3561 & 56.635 & 54.5150 & Panindícuaro & 50.6693 & 49.4791 & 51.2398 \\
\hline Cherán & 49.4792 & 46.0334 & 55.3724 & Parácuaro & 47.8308 & 48.6675 & 49.4815 \\
\hline Chilchota & 44.8121 & 47.8018 & 49.7825 & Paracho & 49.997 & 50.1511 & 46.9551 \\
\hline Chinicuila & 45.3756 & 44.4277 & 48.7801 & Pátzcuaro & 62.6899 & 52.7676 & 51.8457 \\
\hline Chucándiro & 51.4195 & 48.3428 & 55.2343 & Penjamillo & 53.9269 & 48.8485 & 50.3182 \\
\hline Churintzio & 52.5621 & 48.9215 & 53.1361 & Peribán & 60.868 & 44.2861 & 50.7405 \\
\hline Churumuco & 45.6165 & 42.7466 & 44.6262 & Piedad, La & 63.4306 & 52.9224 & 49.1630 \\
\hline Ecuandureo & 57.3505 & 50.6281 & 52.2138 & Purépero & 64.1237 & 48.924 & 43.5991 \\
\hline Epitacio Huerta & 43.7133 & 52.2496 & 49.7905 & Puruándiro & 59.5839 & 53.4695 & 56.4199 \\
\hline Erongarícuaro & 55.3856 & 47.2353 & 48.5064 & Queréndaro & 54.0487 & 18.2752 & 49.3358 \\
\hline Gabriel Zamora & 49.2599 & 39.0703 & 46.6969 & Quiroga & 53.3733 & 52.8673 & 53.3142 \\
\hline Hidalgo & 56.0281 & 51.1856 & 51.3135 & Cojumatlán de & 59.953 & 48.0575 & 56.3019 \\
\hline Huacana, La & 46.8655 & 39.1387 & 49.6223 & Régules & & & \\
\hline Huandacareo & 63.0122 & 52.1087 & 52.6602 & Reyes, Los & 60.6343 & 41.4398 & 48.0024 \\
\hline Huaniqueo & 48.9956 & 48.7405 & 51.7572 & Sahuayo & 70.4827 & 59.1253 & 54.4009 \\
\hline Huetamo & 48.7774 & 43.7729 & 44.2377 & San Lucas & 48.147 & 47.8574 & 41.0337 \\
\hline Huiramba & 46.4182 & 39.6909 & 47.0793 & Santa Ana Maya & 55.2605 & 50.973 & 52.9131 \\
\hline Indaparapeo & 53.1675 & 49.3829 & 50.4343 & Salvador Escalante & 46.3287 & 48.1102 & 48.5353 \\
\hline Irimbo & 49.1851 & 41.8606 & 52.8446 & Senguio & 45.0848 & 46.9205 & 48.8454 \\
\hline
\end{tabular}


continúa...

\begin{tabular}{|c|c|c|c|c|c|c|c|}
\hline Susupuato & 44.0924 & 45.9042 & 49.8392 & Cuernavaca & 59.6872 & 57.3219 & 69.8778 \\
\hline Tacámbaro & 57.3708 & 46.7298 & 49.5843 & Emiliano Zapata & 58.2455 & 43.3602 & 67.4879 \\
\hline Tancítaro & 49.87 & 46.7612 & 59.7576 & Huitzilac & 49.2408 & 37.4867 & 46.7009 \\
\hline Tangamandapio & 50.4664 & 49.1573 & 51.1343 & Jantetelco & 57.4433 & 16.3522 & 48.4826 \\
\hline Tangancícuaro & 60.3501 & 49.8566 & 47.9725 & Jiutepec & 59.9741 & 59.1367 & 59.3332 \\
\hline Tanhuato & 62.6675 & 50.1691 & 51.1769 & Jojutla & 54.7441 & 56.9231 & 53.0752 \\
\hline Taretan & 50.6438 & 41.387 & 49.4840 & Jonacatepec & 45.6577 & 44.6143 & 45.5441 \\
\hline Tarímbaro & 53.0288 & 50.6225 & 52.9314 & Mazatepec & 60.4949 & 45.5527 & 47.6535 \\
\hline Tepalcatepec & 52.4245 & 38.7883 & 47.5270 & Miacatlán & 50.4664 & 47.4036 & 47.1952 \\
\hline Tingambato & 50.1708 & 40.7588 & 50.1829 & Ocuituco & 46.6806 & 45.7149 & 48.1850 \\
\hline Tingüindín & 57.2986 & 41.0803 & 47.4061 & Puente de Ixtla & 50.8927 & 46.9172 & 40.1836 \\
\hline Tiquicheo de Nicolás & 38.9371 & 42.1948 & 44.6477 & Temixco & 64.476 & 50.5299 & 44.9488 \\
\hline Tlalpujahua & 46.8614 & 46.8883 & 48.1434 & Tepalcingo & 48.903 & 42.8627 & 47.0565 \\
\hline Tlazazalca & 52.9236 & 54.4967 & 56.9893 & Tepoztlán & 59.7763 & 47.3567 & 53.2516 \\
\hline Tocumbo & 61.0392 & 43.1237 & 51.6452 & Tetecala & 51.8526 & 46.9662 & 49.6987 \\
\hline Tumbiscatío & 42.1474 & 36.2185 & 45.9456 & Tetela del Volcán & 57.9569 & 53.0334 & 47.7799 \\
\hline Turicato & 47.9056 & 45.4781 & 46.1319 & Tlalnepantla & 41.4059 & 48.7321 & 38.5506 \\
\hline Tuxpan & 53.4146 & 47.5324 & 48.9409 & Tlaltizapán & 58.6864 & 41.0971 & 57.5981 \\
\hline Tuzantla & 38.4749 & 43.8425 & 50.7771 & Tlaquiltenango & 59.4774 & 37.9115 & 46.9173 \\
\hline Tzintzuntzan & 44.6097 & 46.0606 & 48.5673 & Tlayacapan & 52.0636 & 14.6404 & 43.4991 \\
\hline Tzitzio & 41.2242 & 42.3101 & 39.9995 & Totolapan & 52.8029 & 44.9192 & 45.5498 \\
\hline Uruapan & 65.2362 & 41.8747 & 52.7741 & Xochitepec & 51.1453 & 61.6851 & 67.0333 \\
\hline Venustiano Carranza & 53.9898 & 49.5831 & 49.4821 & Yautepec & 58.8984 & 51.9393 & 45.5179 \\
\hline Villamar & 50.8904 & 48.9854 & 49.8783 & Yecapixtla & 49.1681 & 48.4607 & 41.1866 \\
\hline Vista Hermosa & 50.5941 & 48.5991 & 50.2817 & Zacatepec de Hidalgo & 52.497 & 41.6928 & 42.5910 \\
\hline Yurécuaro & 60.9935 & 51.2842 & 51.3300 & Zacualpan de Amilpas & 45.6933 & 41.1845 & 44.9613 \\
\hline Zacapu & 56.2425 & 50.1417 & 52.0598 & Temoac & 44.4367 & 13.9928 & 36.9002 \\
\hline Zamora & 68.2025 & 53.3418 & 53.1403 & NAYARIT & 1990 & 2000 & 2005 \\
\hline Zináparo & 46.4698 & 55.2084 & 55.9076 & Acaponeta & 54.2001 & 47.1068 & 46.2895 \\
\hline Zinapécuaro & 51.3177 & 40.977 & 43.6163 & Ahuacatlán & 48.811 & 40.7149 & 41.5084 \\
\hline Ziracuaretiro & 49.1483 & 39.8015 & 50.1070 & Amatlán de Cañas & 55.6238 & 43.4756 & 41.4324 \\
\hline Zitácuaro & 59.9067 & 43.1173 & 50.7314 & Compostela & 54.4654 & 45.2807 & 54.5404 \\
\hline José Sixto Verduzco & 51.9212 & 50.8134 & 52.0206 & Huajicori & 44.1429 & 41.0739 & 39.4520 \\
\hline MORELOS & 1990 & 2000 & 2005 & Ixtlán del Río & 57.9558 & 46.7111 & 48.0899 \\
\hline Amacuzac & 46.0201 & 17.8041 & 50.3041 & Jala & 51.4716 & 38.8952 & 41.7526 \\
\hline Atlatlahucan & 69.0938 & 68.7532 & 67.1803 & Xalisco & 49.0801 & 42.7004 & 52.2563 \\
\hline Axochiapan & 52.7213 & 44.8889 & 41.9223 & Del Nayar & 51.3565 & 41.0928 & 45.0712 \\
\hline Ayala & 51.8651 & 46.2492 & 48.9177 & Rosamorada & 55.121 & 46.1072 & 42.9217 \\
\hline Coatlán del Río & 52.5918 & 39.0662 & 49.4249 & Ruíz & 49.98 & 45.2413 & 47.5815 \\
\hline Cuautla & 62.5923 & 40.9755 & 43.0227 & San Blas & 50.7892 & 39.4396 & 51.7268 \\
\hline
\end{tabular}


continúa..

San Pedro Lagunillas $52.3673 \quad 40.5063 \quad 41.3415$

Santa María del Oro $\quad 50.8977 \quad 42.5618 \quad 47.7311$

Santiago Ixcuintla $\quad 54.8266 \quad 39.7782 \quad 45.6384$

Tecuala $\begin{array}{lll}57.4621 & 41.2148 \quad 46.7667\end{array}$

Tepic $58.6948 \quad 40.9531 \quad 43.5326$

Tuxpan $55.2838 \quad 38.9954 \quad 48.4308$

Yesca, La $46.3223 \quad 43.9437 \quad 41.9262$

Bahía de Banderas 53.443354 .335373 .8263

\begin{tabular}{lccc} 
NUEVO LEON & 1990 & 2000 & 2005 \\
\hline Abasolo & 54.4735 & 44.9262 & 40.9586
\end{tabular}

Agualeguas

Aldamas, Los $\begin{array}{lll}47.2234 & 46.4565 \quad 44.3028\end{array}$ $53.5768 \quad 38.7424 \quad 38.7742$

Allende

Anáhuac

Apodaca

Aramberri

Bustamante

Cadereyta Jiménez

Carmen

Cerralvo

Ciénega de Flores

China

Doctor Arroyo

Doctor Coss

Doctor González

Galeana

García

San Pedro Garza

Garcí

General Bravo

General Escobedo

General Terán

General Trevińo

General Zaragoza

General Zuazua

Guadalupe

Herreras, Los

Higueras

Hualahuises

$\begin{array}{lll}57.055 & 46.3065 & 47.5499\end{array}$

$51.2083 \quad 46.9498 \quad 42.6495$

$63.8878 \quad 64.4761 \quad 55.7999$

$\begin{array}{llll}54.5627 & 36.1619 & 43.6801\end{array}$

$\begin{array}{lll}54.3968 & 56.6308 \quad 52.1755\end{array}$

$62.1555 \quad 44.2214 \quad 53.2018$

$56.6923 \quad 46.1558 \quad 45.9892$

$53.5496 \quad 40.5565 \quad 43.2965$

$\begin{array}{lll}56.8792 & 60.7907 \quad 56.8995\end{array}$

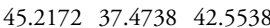

$\begin{array}{llll}44.5436 & 35.8657 \quad 35.5177\end{array}$

$\begin{array}{llll}47.7254 & 44.6553 \quad 40.9470\end{array}$

$\begin{array}{lll}47.685 & 39.8843 \quad 40.2627\end{array}$

$48.0886 \quad 40.6638 \quad 44.6001$

$\begin{array}{llll}52.3425 & 42.4709 & 68.7180\end{array}$

$70.4021 \quad 60.3699 \quad 66.1974$

$50.1323 \quad 44.2587 \quad 43.9910$

$56.8775 \quad 51.3435 \quad 52.2716$

$\begin{array}{lll}54.4524 & 38.6717 & 40.9779\end{array}$

$42.8803 \quad 45.5114 \quad 41.0869$

$41.0486 \quad 35.4699 \quad 33.4356$

$47.1949 \quad 42.5908 \quad 44.7816$

$73.085 \quad 50.4862 \quad 52.6696$

$61.1606 \quad 41.891 \quad 47.5000$

$50.0424 \quad 46.68 \quad 43.4113$

$48.0818 \quad 38.6413 \quad 40.7787$

Iturbide
Juárez

$60.0542 \quad 43.5948 \quad 55.4911$

Lampazos de Naranjo $53.8458 \quad 53.672941 .6803$

Linares

$49.3159 \quad 43.6545 \quad 52.1129$

Marín

Melchor Ocampo

$50.9336 \quad 42.4062 \quad 51.0419$

Mier y Noriega

Mina

Montemorelos

Monterrey

Parás

Pesquería

Ramones, Los

Rayones

Sabinas Hidalgo

Salinas Victoria

San Nicolás de

los $\mathrm{Ga}$

Hidalgo

$\begin{array}{lll}51.7733 & 42.1335 & 51.5217\end{array}$

$40.2124 \quad 36.464 \quad 38.9759$

$\begin{array}{lll}44.9864 & 57.7058 \quad 39.1367\end{array}$

$56.1689 \quad 43.184 \quad 51.8566$

$61.9024 \quad 55.4297 \quad 56.0230$

$49.9661 \quad 42.4637 \quad 47.6636$

$60.0262 \quad 51.4338 \quad 46.2498$ $47.2579 \quad 39.7274 \quad 48.8577$

$48.5177 \quad 37.4059 \quad 40.1374$

$\begin{array}{lll}63.3305 & 42.9893 \quad 43.9247\end{array}$

$49.5522 \quad 51.4576 \quad 41.0636$ $63.5529 \quad 51.711 \quad 54.8705$

Santa Catarina

$52.8537 \quad 41.4989 \quad 47.9442$

Santiago

$60.4311 \quad 45.8613 \quad 52.1739$

$67.0522 \quad 56.3361 \quad 58.1591$

Vallecillo

$52.267 \quad 41.338 \quad 48.2104$

Villaldama

$48.681 \quad 39.6786 \quad 41.9373$

\begin{tabular}{lccc}
\multicolumn{1}{c}{ OAXACA } & 1990 & 2000 & 2005 \\
\hline Abejones & 39.5174 & 44.4074 & 50.0881 \\
Acatlán de Pérez & 57.6217 & 45.0673 & 48.9266
\end{tabular}

Figu

Asunción Cacalotepec $7.4375 \quad 36.9611 \quad 56.8471$

Asunción Cuyotepeji $41.1848 \quad 38.166754 .9143$

Asunción Ixtaltepec $56.4689 \quad 17.2585 \quad 43.8176$

Asunción Nochixtlán $14.8393 \quad 47.3479 \quad 56.7825$

Asunción Ocotlán $\quad 41.754 \quad 12.9165 \quad 33.8707$

Asunción Tlacolulita $\quad 44.1261 \quad 34.822 \quad 54.7634$

Ayotzintepec $47.8173 \quad 37.6366 \quad 48.1201$

Barrio de la Soledad， $57.5413 \quad 45.291950 .4284$

Calihualá

$51.7239 \quad 36.2318 \quad 43.0172$

Candelaria Loxicha $\quad 42.3218 \quad 33.5425 \quad 56.2751$

Ciénega de Zimatlán $60.0289 \quad 59.3374 \quad 50.2446$

Ciudad Ixtepec $\quad 55.5462 \quad 19.6904 \quad 45.4276$

Coatecas Altas $\quad 44.0571 \quad 35.4655 \quad 48.9867$

Coicoyán de $\quad 35.8995 \quad 34.673 \quad 35.0483$

las Flore 
continúa...

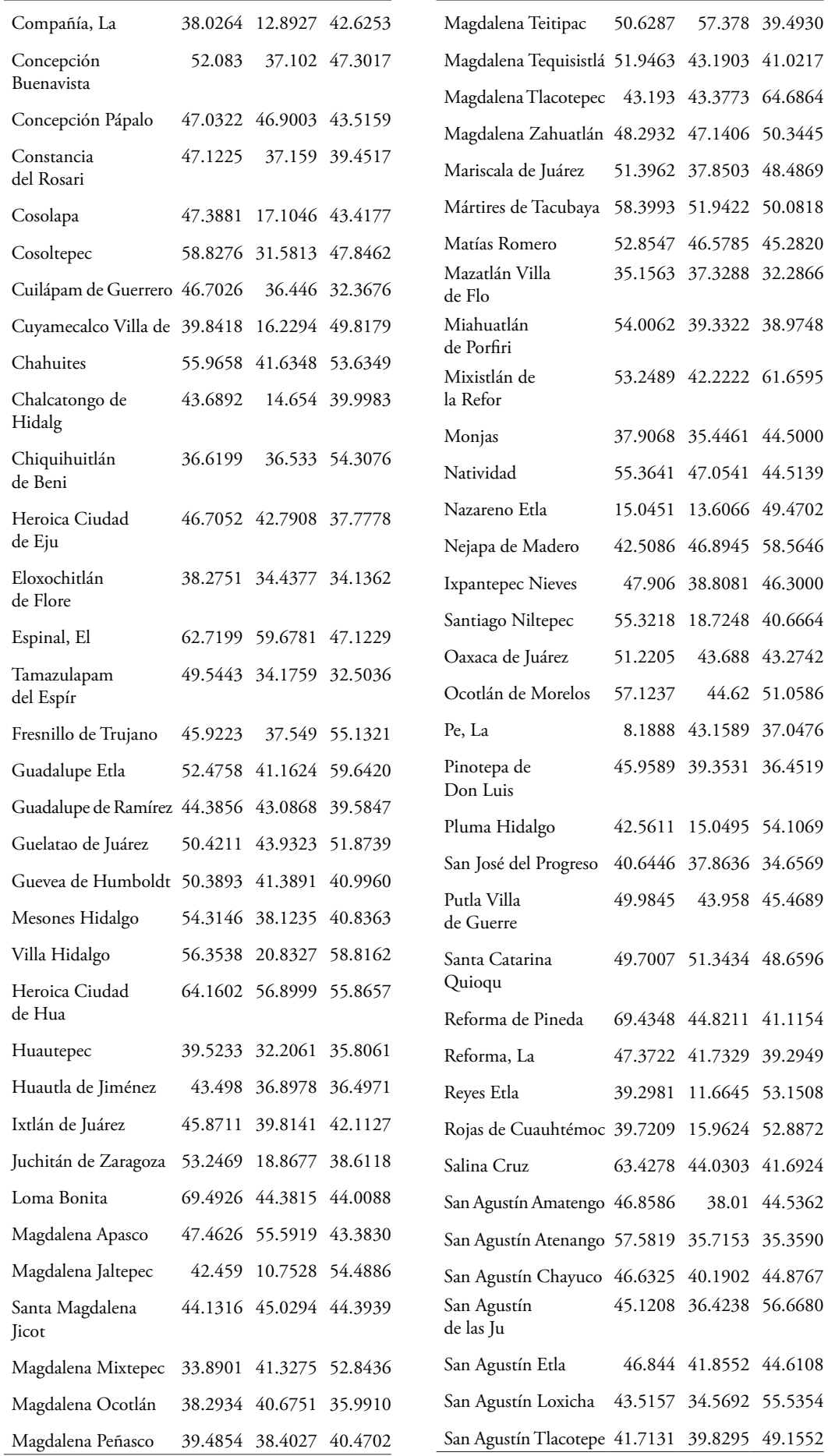


continúa...

\begin{tabular}{lrrr}
\hline San Andrés & 10.5009 & 36.191 & 36.2316 \\
Cabecera N & & & \\
San Andrés Dinicuiti & 47.9594 & 39.7246 & 41.6104 \\
San Andrés & 39.8187 & 34.8044 & 46.6759 \\
Huaxpaltep & & & \\
San Andrés Huayapam & 47.7475 & 60.8801 & 68.5419 \\
San Andrés Ixtlahuaca & 37.6219 & 32.709 & 47.1897 \\
San Andrés Lagunas & 43.7654 & 40.787 & 51.3571 \\
San Andrés Nuxiño & 29.4346 & 33.8601 & 35.9675 \\
San Andrés Paxtlán & 34.7386 & 33.1367 & 47.7984 \\
San Andrés Sinaxtla & 46.7024 & 17.5135 & 47.8343 \\
San Andrés Solaga & 55.0872 & 55.8415 & 60.1918 \\
San Andrés Teotilalpa & 45.8336 & 39.1644 & 35.9219 \\
San Andrés Tepetlapa & 41.8793 & 47.7863 & 54.1504 \\
San Andrés Yaá & 39.5556 & 48.6364 & 51.1473 \\
San Andrés Zabache & 39.0503 & 39.4242 & 53.8012 \\
San Andrés Zautla & 40.053 & 39.6633 & 41.7823 \\
San Antonino Castillo & 57.5097 & 43.0116 & 55.0619 \\
San Antonino el Alto & 34.4447 & 53.7506 & 53.6203 \\
San Antonino & 40.372 & 37.484 & 43.9265 \\
Monte Ve & & & \\
San Antonio Acutla & 46.4783 & 42.5806 & 50.2619 \\
San Antonio & 41.4854 & 36.2712 & 42.8912 \\
de Can & & & \\
\hline
\end{tabular}

de la Cal

San Antonio Huitepec 38.543146 .830653 .6866

San Antonio

$49.8496 \quad 39.2937 \quad 41.6760$

Nanahuatí

San Antonio Sinicahua $\quad 1.3469 \quad 37.5952 \quad 34.3278$

San Antonio Tepetlapa $41.620531 .5554 \quad 48.3338$

San Baltazar Chichicá $16.530838 .1076 \quad 69.7442$

San Baltazar Loxicha $35.533238 .3644 \quad 44.5185$

San Baltazar Yatzachi $41.1183 \quad 45.6797 \quad 49.6303$

San Bartolo Coyotepec $45.2099 \quad 17.2124 \quad 59.4485$

San Bartolomé Ayautla $40.8158 \quad 38.1407 \quad 37.3214$

San Bartolomé Loxicha 46.429952 .242553 .4138

San Bartolomé $\quad 41.586656 .766470 .4395$

Quialan

San Bartolomé $\quad 42.9236 \quad 40.517257 .4685$

Yucuańe

San Bartolomé $\quad 49.935946 .755965 .4800$

Zoogoch

San Bartolo Soyaltepe $37.098 \quad 37.0084 \quad 53.1268$

San Bartolo Yautepec $\quad 43.15 \quad 39.6327 \quad 50.9266$

\begin{tabular}{lrrr} 
San Bernardo & 48.2309 & 38.3619 & 43.7486 \\
Mixtepec & & & \\
San Blas Atempa & 62.9339 & 41.8893 & 52.7247 \\
San Carlos Yautepec & 42.274 & 35.9712 & 39.5174 \\
San Cristóbal Amatlán & 44.7265 & 40.7036 & 51.4665 \\
San Cristóbal Amoltep & 31.563 & 7.1779 & 45.7073 \\
San Cristóbal Lachiri & 57.6013 & 49.932 & 70.5692 \\
San Cristóbal Suchixt & 51 & 44.875 & 67.2342 \\
San Dionisio del Mar & 54.1911 & 34.5543 & 49.2939 \\
San Dionisio & 49.6377 & 40.6561 & 56.2141 \\
Ocotepec & & & \\
San Dionisio Ocotlán & 35 & 52.8448 & 51.4215 \\
San Esteban Atatlahuc & 39.7073 & 9.624 & 35.5781 \\
San Felipe Jalapa de & 40.5837 & 49.2864 & 45.3843 \\
San Felipe Tejalapam & 36.4043 & 10.8814 & 33.5695 \\
San Felipe Usila & 36.6693 & 36.0573 & 53.4919 \\
San Francisco & 33.1534 & 47.2479 & 48.8692 \\
Cahuacu & & & \\
\hline
\end{tabular}

San Francisco Cajonos $45.3298 \quad 49.150 .7177$

San Francisco Chapula $43.5265 \quad 43.094 \quad 46.5348$

San Francisco $\quad 45.6078 \quad 61.06150 .0244$

Chindúa

San Francisco del Mar 51.396552 .146754 .1734

San Francisco $\quad 41.7011 \quad 38.04853 .3586$

Huehuet

San Francisco Ixhuatá $52.218 \quad 49.3421 \quad 40.6034$

San Francisco Jaltepe $48.8856 \quad 36.85 \quad 42.4959$

San Francisco Lachigo 45.465911 .385660 .9757

San Francisco Loguech 30.379940 .660146 .3151

San Francisco Nuxańo $38.5424 \quad 44 \quad 45.2766$

San Francisco Ozolote 62.735138 .950343 .5046

San Francisco Sola $\quad 40.7816 \quad 45.843554 .4949$

San Francisco Telixtl $45.6834 \quad 16.3351 \quad 41.7264$

San Francisco Teopan $39.3738 \quad 55.656 \quad 42.6146$

San Francisco Tlapanc $49.4007 \quad 42.133941 .8193$

San Gabriel Mixtepec 45.818246 .103141 .7583

San Ildefonso Amatlán 39.924941 .737252 .8868

San Ildefonso Sola $\quad 28.8803 \quad 32.9677 \quad 37.7273$

San Ildefonso $\quad 15.5546 \quad 53.511656 .1689$

Villa A

San Jacinto Amilpas $\quad 40.2527 \quad 17.2402 \quad 44.2906$

$\begin{array}{llll}\text { San Jacinto Tlacotepe } \quad 31.2 & 33.25 & 44.4422\end{array}$ 
continúa...

San Jerónimo Coatlán 44.556835 .816137 .4624

San Jerónimo Silacayo $45.955939 .8415 \quad 44.7938$

San Jerónimo Sosola $35.7937 \quad 41.3154 \quad 51.1702$

San Jerónimo Taviche $43.5682 \quad 29.7358 \quad 36.6054$

San Jerónimo Tecoátl $44.9309 \quad 35.7299 \quad 40.2622$

San Jorge Nuchita $\quad 17.7588 \quad 38.7177 \quad 56.2766$

San José Ayuquila

$41.8434 \quad 43.8136 \quad 39.2215$

San José Chiltepec

$55.8507 \quad 39.8905 \quad 42.3678$

San José del Peñasco $42.4494 \quad 38.2148 \quad 40.3426$

San José

Estancia Gra

San José

Independenci

$39.6199 \quad 29.766 \quad 33.8343$

San José Lachiguiri $\quad 36.6768 \quad 9.0826 \quad 43.8348$

San José Tenango $\quad 33.919633 .796651 .4533$

San Juan Achiutla $\quad 47.4167 \quad 40.0562 \quad 51.1880$

San Juan Atepec

Animas Trujano

San Juan Bautista

Ata

San Juan Bautista

Coi

San Juan Bautista

Cui

San Juan Bautista

Gue

San Juan Bautista

Jay

San Juan Bautista

Lo

San Juan Bautista

Suc

San Juan Bautista

Tla

San Juan Bautista

Tla

San Juan Bautista

Tux

San Juan

Cacahuatepec

San Juan Cieneguilla $48.0305 \quad 52.9545 \quad 50.4658$

San Juan Coatzóspam $53.5934 \quad 40.820832 .3761$

San Juan Colorado $\quad 46.9993 \quad 36.6094 \quad 54.8497$

San Juan Comaltepec 34.068344 .032746 .7066

San Juan Cotzocón $41.6236 \quad 14.1397 \quad 42.7376$

San Juan

$\begin{array}{lll}57.2632 & 38.1964 \quad 52.7609\end{array}$

Chicomezúchi

San Juan Chilateca $\quad 51.0556 \quad 59.8232 \quad 53.1101$
San Juan del Estado $\quad 47.6339 \quad 34.3837 \quad 58.0349$

San Juan del Río $\quad 54.7076 \quad 61.2184 \quad 52.0346$

San Juan Diuxi $\quad 42.2314 \quad 10.6618 \quad 48.5745$

San Juan Evangelista $\quad 44.1266 \quad 50.381 \quad 48.7273$

San Juan Guelavía $\quad 8.7425 \quad 38.2517 \quad 50.4265$

San Juan Guichicovi 41.998934 .483939 .6615

San Juan Ihualtepec $39.1204 \quad 46.590943 .7874$

San Juan Juquila Mixe $40.4334 \quad 36.28939 .7938$

San Juan Juquila Vija $53.8431 \quad 39.1074 \quad 56.3441$

San Juan Lachao $\quad 41.5774 \quad 33.8166 \quad 48.2963$

San Juan Lachigalla $\quad 41.1545 \quad 32.4874 \quad 34.1171$

San Juan Lajarcia $\quad 51.1053 \quad 40.892957 .8859$

San Juan Lalana $\quad 34.6575 \quad 10.7693 \quad 35.2058$

San Juan de los Cués $\quad 61.3711 \quad 38.7627 \quad 48.6263$

San Juan Mazatlán $\quad 45.5441 \quad 37.1918 \quad 34.9162$

San Juan Mixtepec - $49.6405 \quad 14.8856 \quad 49.3532$ Distr. 08

San Juan Mixtepec - $49.4967 \quad 47.207744 .3731$ Distr. 26

San Juan Numí $\quad 38.937233 .8744 \quad 57.0566$

San Juan Ozolotepec $45.015538 .887 \quad 44.1989$

San Juan Petlapa $\quad 33.8824 \quad 45.07 \quad 28.0231$

San Juan Quiahije $\quad 49.542837 .438637 .7382$

San Juan Quiotepec $53.068557 .0323 \quad 47.1622$

San Juan Sayultepec $51.2635 \quad 49.7813 \quad 60.3158$

San Juan Tabaá $\quad 58.244 \quad 44.703752 .3191$

San Juan Tamazola 41.095534 .581946 .6036

San Juan Teita $\quad 10.2362 \quad 13.4524 \quad 40.3411$

San Juan Teitipac $\quad 31.687551 .8106 \quad 40.6917$

San Juan Tepeuxila $42.4506 \quad 46.2533 \quad 52.4604$

San Juan Teposcolula $46.438437 .582 \quad 52.5731$

San Juan Yaeé $\quad 48.452948 .862146 .7354$

San Juan Yatzona $\quad 44.092654 .723141 .6899$

San Juan Yucuita $\quad 57.2246 \quad 40.489655 .9022$

San Lorenzo $\quad 46.400737 .0897 \quad 53.2138$

San Lorenzo Albarrada $41.0267 \quad 39.231 \quad 57.3712$

San Lorenzo $\quad 48.484141 .5932 \quad 42.3200$

Cacaotepe

San Lorenzo $\quad 44.16 \quad 44.4394 \quad 37.6736$

Cuaunecui

San Lorenzo $\quad 31.475849 .961158 .7949$

Texmeluca

San Lorenzo Victoria $54.1241 \quad 20.4098 \quad 51.2573$ 
continúa..

San Lucas Camotlán $47.516638 .8534 \quad 40.3880$

San Lucas Ojitlán 47.368632 .423652 .4556

San Lucas Quiaviní $\quad 49.176145 .910365 .6938$

San Lucas Zoquiápam $41.3467 \quad 12.302935 .4371$

San Luis Amatlán $\quad 42.358138 .0602 \quad 49.5526$

San Marcial Ozolotepe $44.857150 .4162 \quad 36.6507$

San Marcos Arteaga 54.315148 .598650 .6541

San Martín de $\quad 46.968938 .5698 \quad 44.9719$

los Can

San Martín

$39.693134 .6667 \quad 37.8165$

Huamelúlpa

San Martín Itunyoso $39.437739 .1248 \quad 36.0091$

San Martín Lachilá $\quad 43.226133 .3512 \quad 36.6615$

San Martín Peras $\quad 43.188943 .848360 .3932$

San Martín Tilcajete 34.326147 .486353 .9759

San Martín Toxpalan 62.799342 .724955 .0197

San Martín Zacatepec $45.508832 .3175 \quad 34.0410$

San Mateo Cajonos $47.953254 .1807 \quad 44.8929$

Capulálpam $\quad 52.109 \quad 48.805 \quad 58.6626$

de Méndez

San Mateo del Mar $\quad 49.3124 \quad 33.6205 \quad 39.5825$

San Mateo Yoloxochitl $53.914240 .5852 \quad 37.6387$

San Mateo Etlatongo $36.958234 .6897 \quad 47.9329$

San Mateo Nejápam $40.8268 \quad 32.5641 \quad 53.0833$

San Mateo Peñasco $\quad 42.691234 .4988 \quad 50.8870$

San Mateo Piñas $\quad 43.282142 .012 \quad 50.7615$

San Mateo Río Hondo $38.202738 .3796 \quad 39.2464$

San Mateo Sindihui 41.599414 .105934 .9786

San Mateo Tlapiltepec $52.9231 \quad 16.2174 \quad 40.0000$

San Melchor Betaza $41.9776 \quad 49.576 \quad 40.6337$

San Miguel Achiutla $48.877648 .4664 \quad 56.6488$

San Miguel $\begin{array}{lll}47.0997 & 35.4735 & 37.9747\end{array}$

Ahuehuetit

San Miguel Aloápam $44.6163 \quad 49.6175 \quad 59.2887$

San Miguel Amatitlán $38.8061 \quad 35.077962 .6023$

San Miguel Amatlán 39.839439 .533141 .2892

San Miguel Coatlán $41.763940 .8638 \quad 40.2152$

San Miguel Chicahua $\quad 3127.8797 \quad 29.3578$

San Miguel Chimalapa $40.8433 \quad 34.401451 .3733$

San Miguel del Puerto $42.718934 .9058 \quad 41.2310$

San Miguel del Río $\quad 41.25 \quad 48.6667 \quad 61.8750$

San Miguel Ejutla $\quad 40.558434 .5138 \quad 49.4593$
San Miguel el Grande $43.668744 .8188 \quad 41.6981$

San Miguel Huautla $35.2074 \quad 37.2222 \quad 53.2712$

San Miguel Mixtepec 38.866344 .090956 .3084

San Miguel $\quad 39.394736 .352 \quad 37.6571$

Panixtlahu

San Miguel Peras $\quad 42.3063 \quad 48.6485 \quad 47.0809$

San Miguel Piedras $34.428613 .642 \quad 42.7538$

San Miguel $\quad 55.477238 .198 \quad 60.0691$

Quetzaltep

San Miguel Santa Flor $40.651232 .1337 \quad 46.4343$

Villa Sola de Vega $\quad 41.226135 .5134 \quad 48.4342$

San Miguel $\quad 54.545352 .2213 \quad 54.3761$

Soyaltepec

San Miguel Suchixtepe $40.680937 .8277 \quad 49.1641$

Villa Talea de Castro $49.708147 .3467 \quad 68.6154$

San Miguel

$47.918920 .4103 \quad 49.6667$

Tecomatlán

San Miguel Tenango $37.3763 \quad 34.399 \quad 46.6279$

San Miguel Tequixtepe $36.733838 .0432 \quad 46.4737$

San Miguel

$41.9158 \quad 47.3992 \quad 45.4444$

Tilquiápam

San Miguel

$52.2342 \quad 44.6716 \quad 49.8997$

Tlacamama

San Miguel Tlacotepec $47.671945 .6624 \quad 42.1554$

San Miguel

$40.228638 .9291 \quad 49.6639$

Tulancingo

San Miguel Yotao $\quad 41.6103 \quad 42.5338 \quad 44.5621$

San Nicolás

$43.855 \quad 38.6552 \quad 46.2416$

San Nicolás Hidalgo $52.1143 \quad 38.0964 \quad 47.2326$

San Pablo Coatlán 37.792336 .351553 .2668

San Pablo Cuatro Vena $33.04979 .2895 \quad 44.4239$

San Pablo Etla

$49.8373 \quad 60.3282 \quad 44.3694$

San Pablo Huitzo

$40.949930 .7466 \quad 42.0601$

San Pablo Huixtepec $44.795340 .026 \quad 57.6820$

San Pablo Macuiltiang 66.960157 .198656 .8464

San Pablo Tijaltepec 46.572934 .646438 .3668 San Pablo Villa $\quad 52.699 \quad 38.349951 .8379$ de Mi

San Pablo Yaganiza $\quad 53.3521 \quad 22.7645 \quad 51.2026$

San Pedro Amuzgos 57.669835 .383136 .4156

San Pedro Apóstol $\quad 40.839536 .928842 .9146$

San Pedro Atoyac $\quad 46.131135 .020648 .6366$

San Pedro Cajonos 52.800655 .134143 .1955 
continúa...

San Pedro Coxcaltepec $35.20949 .449 \quad 51.1818$

San Pedro Comitancill 57.012840 .606747 .5825

San Pedro el Alto $\quad 47.063435 .4808 \quad 33.5034$

San Pedro Huamelula 53.713235 .377836 .7456

San Pedro Huilotepec 59.40145 .588246 .7834

San Pedro Ixcatlán $\quad 40.893548 .463749 .9693$

San Pedro Ixtlahuaca $35.939133 .5347 \quad 49.2803$

San Pedro

Jaltepetong

$38.137932 .6846 \quad 38.3333$

San Pedro Jicayán

$40.2833 \quad 28.1845 \quad 32.8799$

San Pedro Jocotipac 43.498147 .830940 .0977

San Pedro Juchatengo 41.483336 .580640 .6111

San Pedro Mártir $\quad 5.5263 \quad 34.036443 .0943$

San Pedro Mártir $\quad 40.577439 .068344 .5570$

Quie

San Pedro Mártir $\quad 37.368136 .4557 \quad 38.2853$ Yucu

San Pedro Mixtepec - $46.389839 .044 \quad 49.0358$ Distr. 22

San Pedro Mixtepec - 44.758739 .148156 .5294 Distr. 26

San Pedro Molinos $51.737838 .9773 \quad 38.7640$ San Pedro Nopala $\quad 38.493136 .747645 .4009$ San Pedro Ocopetatill 47.613341 .192135 .8750 San Pedro Ocotepec 43.014135 .161741 .0880 San Pedro Pochutla 69.717638 .483540 .5562 San Pedro Quiatoni $\quad 42.673 \quad 44.458258 .9196$ San Pedro Sochiapam 48.650638 .412938 .0990 San Pedro Tapanatepec 52.960346 .199847 .7456 San Pedro Taviche $\quad 43.234936 .2304 \quad 37.6455$ San Pedro Teozacoalco 39.641314 .859352 .4012 San Pedro Teutila $\quad 45.416738 .980954 .6947$ San Pedro Tidaá $\quad 53.7645 \quad 41.7698 \quad 39.3719$ San Pedro Topiltepec 45.802941 .664149 .8440 San Pedro Totolapa $44.437641 .9624 \quad 56.3815$ Villa de Tututepec de $54.329435 .1693 \quad 36.7546$ San Pedro Yaneri $\quad 29.4323 \quad 30.7724 \quad 35.9194$ San Pedro Yólox $\quad 56.2178 \quad 53.125 \quad 61.2807$ San Pedro y San Pablo $52.020632 .56 \quad 39.9132$ Villa de Etla $59.9911 \quad 17.3597 \quad 64.7419$ San Pedro y San Pablo 56.073338 .788742 .5793 San Pedro y San Pablo 49.2175 35.111545 .2424
San Pedro Yucunama 39.898344 .426244 .8806 San Raymundo Jalpan 39.401433 .315159 .4838 San Sebastián Abasolo 53.086360 .139264 .2228 San Sebastián Coatlán 36.494137 .787953 .0444 San Sebastián Ixcapa $46.541634 .5563 \quad 34.6578$ San Sebastián Nicanan $45.847459 .132 \quad 60.1294$ San Sebastián Río Hon 40.236939 .100352 .0835 San Sebastián $\quad 45.848 \quad 40.1516 \quad 55.5984$ Tecomax

San Sebastián Teitipa 40.285442 .564251 .6522 San Sebastián Tutla $48.488157 .7472 \quad 58.0915$ San Simón Almolon- 36.294737 .661254 .7422 gas

San Simón Zahuatlán 35.418545 .790853 .3519 Santa Ana $\quad 39.942452 .3315 \quad 50.6938$ Santa Ana Ateixtlahua 40.105334 .391346 .3008 Santa Ana Cuauhtémoc $39.463437 .4688 \quad 39.7436$

Santa Ana del Valle $\quad 48.6824 \quad 43.5884 \quad 39.0618$ Santa Ana Tavela $\quad 40.006249 .107856 .9603$ Santa Ana Tlapacoyan $42.287916 .6916 \quad 45.9163$ Santa Ana Yareni $\quad 50.704838 .076144 .8491$ Santa Ana Zegache $38.4123 \quad 32.0821 \quad 49.2342$ Santa Catalina Quierí $39.875 \quad 48.025 \quad 53.2045$ Santa Catarina Cuixtl $47.217643 .3359 \quad 43.1667$ Santa Catarina Ixtepe 45.018441 .151855 .5312 Santa Catarina Juquil $53.3335 \quad 37.8205 \quad 41.3757$ Santa Catarina Lachat $44.399 \quad 46.3224 \quad 68.1855$ Santa Catarina Loxich $38.223641 .8896 \quad 60.1640$ Santa Catarina $\quad 55.0965 \quad 43.8523 \quad 49.2751$ Mechoa

Santa Catarina Minas $43.921133 .6063 \quad 45.3130$ Santa Catarina Quiané $38.9344 \quad 41.9403 \quad 54.1678$ Santa Catarina Tayata $41.297637 .6271 \quad 41.2367$ Santa Catarina Ticuá $42.891 \quad 15.1111 \quad 42.2914$ Santa Catarina Yosono $46.432744 .6573 \quad 35.6937$ Santa Catarina $\quad 37.970634 .7083 \quad 40.0435$ Zapoqu

Santa Cruz Acatepec $43.8248 \quad 52.7414 \quad 41.3333$ Santa Cruz Amilpas $20.1236 \quad 47.322 \quad 54.0690$ Santa Cruz de Bravo $53.92 \quad 41.0396 \quad 40.8372$ Santa Cruz Itundujia $\quad 35.829 \quad 34.1661 \quad 33.2536$ 
continúa..

Santa Cruz Mixtepec $41.898643 .4634 \quad 39.6471$

Santa Cruz Nundaco $38.0545 \quad 43.2482 \quad 50.2893$

Santa Cruz Papalutla $45.301654 .0227 \quad 55.1277$

Santa Cruz Tacache de $47.142343 .9873 \quad 49.5703$

Santa Cruz Tacahua $29.0267 \quad 34.2606 \quad 45.3099$

Santa Cruz Tayata $\quad 42.5041 \quad 12.4318 \quad 44.6786$

Santa Cruz Xitla $42.099338 .0056 \quad 40.9851$

Santa Cruz $\quad 54.372147 .1757 \quad 41.8484$

Xoxocotlán

Santa Cruz

Zenzontepe

$\begin{array}{lll}43.4998 & 42.9289 & 27.6279\end{array}$

Santa Gertrudis

$45.5942 \quad 37.9499 \quad 44.2685$

Santa Inés del Monte $38.0758 \quad 5.283 \quad 42.7722$

Santa Inés Yatzeche $35.8131 \quad 40.6047 \quad 53.7143$

Santa Lucía $\quad 62.2757 \quad 47.121 \quad 42.9659$

del Camin

Santa Lucía Miahuatlá 45.950935 .394956 .8803

Santa Lucía $\quad 32.22087 .9639 \quad 46.7209$

Monteverd

Santa Lucía Ocotlán $37.571444 .067 \quad 48.5246$

Santa María Alotepec $41.412636 .7572 \quad 35.8138$

Santa María Apazco $31.31918 .6919 \quad 49.0303$

Santa María

$41.4888 \quad 48.1844 \quad 32.2126$

la Asunci

Heroica Ciudad $\quad 44.016 \quad 37.2065 \quad 39.9393$

de Tla

Ayoquezco de Aldama $51.7589 \quad 16.3746 \quad 47.2293$

Santa María Atzompa $38.3445 \quad 40.37 \quad 38.6644$

Santa María Camotlán 46.573537 .730844 .7513

Santa María Colotepec 41.2187 35.4091 40.0314

Santa María Cortijo 41.735340 .756136 .6154

Santa María $\quad 48.468940 .2287 \quad 50.2626$

Coyotepec

Santa María $\quad 44.019 \quad 41.4366 \quad 45.1576$

Chachoápa

Villa de Chilapa $\quad 64.6199 \quad 19.7468 \quad 52.1095$ de $\mathrm{D}$

Santa María Chilchotl $41.182530 .7877 \quad 51.6226$

Santa María

Chimalapa

Santa María

del Rosar

$40.589411 .6118 \quad 51.5791$

$4042.5657 \quad 35.6019$

Santa María del Tule 51.405854 .407357 .9056

Santa María $\quad 56.856233 .4828 \quad 48.5906$

Ecatepec
Santa María Guelacé $46.7731 \quad 16.0649 \quad 42.8707$

Santa María $\quad 45.632937 .081 \quad 41.9390$

Guienagat

Santa María Huatulco $53.245 \quad 57.36 \quad 45.9201$

Santa María

$56.734636 .6118 \quad 37.6780$

Huazoloti

Santa María Ipalapa $\quad 50.395942 .5435 \quad 46.2442$

Santa María Ixcatlán $39.0663 \quad 39.1395 \quad 41.3636$

Santa María Jacatepec 58.429551 .758954 .2410

Santa María Jalapa de 16.509442 .885948 .1193

Santa María

$40.342949 .7097 \quad 59.3667$

Jaltiangu

Santa María Lachixío 35.325836 .342737 .7452

Santa María Mixtequil $61.395445 .5943 \quad 40.1644$

Santa María Nativitas $44.057434 .2857 \quad 39.4598$

Santa María Nduayaco $40.196840 .7744 \quad 49.4586$

Santa María

$37.4349 \quad 43.2414 \quad 41.6898$

Ozolotepe

Santa María Pápalo $\quad 52.013 \quad 36.3895 \quad 34.6619$

Santa María Peñoles 31.62047 .600633 .5624

Santa María Petapa $52.111134 .6776 \quad 41.3395$

Santa María $\quad 44.5784 \quad 17.1773 \quad 49.2618$

Quiegolan

Santa María Tataltepe $40.206911 .9643 \quad 36.4318$

Santa María $\quad 55.476916 .3157 \quad 54.6737$

Tecomavac

Santa María $\quad 45.585543 .3281 \quad 51.8340$

Temaxcala

Santa María Temaxcalt $52.75 \quad 37.7871 \quad 46.6832$

Santa María Teopoxco 43.335639 .987553 .3993

Santa María Tepantlal 10.473233 .343835 .0971

Santa María Texcatitl $42.5753 \quad 30.6226 \quad 35.0047$

Santa María Tlahuitol 51.090935 .138851 .2549

Santa María Tlalixtac 42.683333 .009240 .8000

Santa María Tonameca 40.935635 .858739 .4183

Santa María Totolapil 55.973145 .240651 .5282

Santa María Xadani 48.407844 .338645 .4584

Santa María Yalina $\quad 55.422443 .136455 .2614$

Santa María Yavesía $\quad 15.425 \quad 41.0317 \quad 49.3750$

Santa María Yolotepec 39.163835 .669738 .0865

Santa María Yosoyúa 42.938836 .361945 .7326

Santa María Yucuhiti $61.933154 .4204 \quad 52.2003$ 
continúa...

Santa María Zacatepec $56.449342 .8965 \quad 40.5559$

Santa María Zaniza $\quad 40.875 \quad 30.5517 \quad 33.1003$

Santa María Zoquitlán 53.832917 .011150 .4732

Santiago Amoltepec $33.3952 \quad 25.973 \quad 30.3752$

Santiago Apoala $36.567630 .024 \quad 35.0043$

Santiago Apóstol $\quad 46.143 \quad 44.7834 \quad 60.1570$

Santiago Astata $\quad 57.811436 .401238 .3279$

Santiago Atitlán $\quad 39.995740 .946939 .4890$

Santiago Ayuquililla $43.8722 \quad 33.5115 \quad 48.8485$

Santiago Cacaloxtepec $59.7276 \quad 38.897 \quad 37.8437$

Santiago Camotlán 34.403549 .589455 .2663

Santiago Comaltepec $54.052243 .2714 \quad 61.0208$

Santiago Chazumba $\quad 49.8801 \quad 36.1878 \quad 52.0805$

Santiago Choapam 10.714555 .099735 .3575

Santiago del Río $\quad 42.983447 .6795 \quad 53.6215$

Santiago Huajolotitlá 53.838239 .172138 .7030

Santiago Huauclilla $37.4528 \quad 44.1926 \quad 43.5961$

Santiago Ihuitlán Plu 51.923144 .777845 .8701

Santiago Ixcuintepec $48.6383 \quad 44.259 \quad 56.6393$

Santiago Ixtayutla $\quad 42.456431 .1059 \quad 37.7368$

Santiago Jamiltepec $\quad 54.343 \quad 36.9571 \quad 53.1057$

Santiago Jocotepec $\quad 40.652430 .924 \quad 55.6153$

Santiago Juxtlahuaca $54.3519 \quad 50.4646 \quad 62.3390$

Santiago Lachiguiri $46.101839 .8776 \quad 35.3468$

Santiago Lalopa $\quad 45.768241 .8649 \quad 43.8261$

Santiago Laollaga $\quad 47.974 \quad 45.442 \quad 56.5622$

Santiago Laxopa $\quad 41.912457 .691 \quad 56.5769$

Santiago Llano Grande 56.787436 .645754 .8073

Santiago Matatlán $\quad 49.7545 \quad 49.5485 \quad 39.8140$

Santiago Miltepec $\quad 50.039242 .9533 \quad 48.0135$

Santiago Minas $\quad 36.248 \quad 35.1682 \quad 47.1164$

Santiago Nacaltepec $\quad 12.394234 .8463 \quad 33.6828$

Santiago Nejapilla $\quad 44.1702 \quad 14.5526 \quad 64.6370$

Santiago Nundiche $43.872510 .6458 \quad 45.6190$

Santiago Nuyoó $\quad 53.1758 \quad 17.1694 \quad 60.4232$

Santiago Pinotepa $\quad 64.743432 .5105 \quad 38.5207$ $\mathrm{Nac}$

Santiago Suchilquiton $40.7023 \quad 32.2709 \quad 48.7225$

Santiago Tamazola $43.753436 .627 \quad 45.9593$

Santiago Tapextla $\quad 44.693 \quad 33.5678 \quad 38.5591$

\begin{tabular}{|c|c|c|}
\hline $\begin{array}{l}\text { Villa Tejúpam } \\
\text { de la U }\end{array}$ & $46.6047 \quad 41.6721$ & 38.1132 \\
\hline Santiago Tenango & 38.840537 .2976 & 52.5196 \\
\hline Santiago Tepetlapa & 36.588239 .125 & 45.4302 \\
\hline Santiago Tetepec & 49.244243 .5436 & 37.4909 \\
\hline Santiago Texcalcingo & $4.8167 \quad 50.0054$ & 59.5465 \\
\hline Santiago Textitlán & $49.8795 \quad 41.6994$ & 50.8705 \\
\hline Santiago Tilantongo & 52.509431 .5232 & 49.5973 \\
\hline Santiago Tillo & 49.297740 .6897 & 39.3050 \\
\hline Santiago Tlazoyaltepe & 36.061231 .92 & 51.4800 \\
\hline Santiago Xanica & $46.3423 \quad 40.281$ & 28.7297 \\
\hline Santiago Xiacuí & $47.9338 \quad 38.4805$ & 48.9700 \\
\hline Santiago Yaitepec & 47.505140 .113 & 34.7255 \\
\hline Santiago Yaveo & 36.745231 .2375 & 35.6425 \\
\hline Santiago Yolomécatl & 44.657743 .8864 & 57.8454 \\
\hline Santiago Yosondúa & 33.169533 .0375 & 34.6267 \\
\hline Santiago Yucuyachi & 45.961347 .3153 & 52.4259 \\
\hline Santiago Zacatepec & $38.4771 \quad 12.0882$ & 57.0353 \\
\hline Santiago Zoochila & $15.5155 \quad 42.0175$ & 59.8793 \\
\hline Nuevo Zoquiapam & $67.7722 \quad 48.5481$ & 59.3231 \\
\hline $\begin{array}{l}\text { Santo Domingo } \\
\text { Ingenio }\end{array}$ & 18.913443 .1486 & 61.7423 \\
\hline $\begin{array}{l}\text { Santo Domingo } \\
\text { Albarra }\end{array}$ & 45.659154 .2179 & 47.5238 \\
\hline $\begin{array}{l}\text { Santo Domingo } \\
\text { Armenta }\end{array}$ & $\begin{array}{lll}46.7012 & 15.6387\end{array}$ & 47.3429 \\
\hline $\begin{array}{l}\text { Santo Domingo } \\
\text { Chihuit }\end{array}$ & $52.8095 \quad 45.5628$ & 40.6294 \\
\hline $\begin{array}{l}\text { Santo Domingo } \\
\text { de More }\end{array}$ & 36.140946 .1326 & 53.8472 \\
\hline $\begin{array}{l}\text { Santo Domingo } \\
\text { Ixcatlá }\end{array}$ & $38.9737 \quad 42.3743$ & 42.2620 \\
\hline $\begin{array}{l}\text { Santo Domingo } \\
\text { Nuxaá }\end{array}$ & 34.137240 .2786 & 34.0795 \\
\hline $\begin{array}{l}\text { Santo Domingo } \\
\text { Ozolote }\end{array}$ & $44.7341 \quad 38.6702$ & 52.8919 \\
\hline $\begin{array}{l}\text { Santo Domingo } \\
\text { Petapa }\end{array}$ & 47.157941 .2655 & 43.9294 \\
\hline $\begin{array}{l}\text { Santo Domingo } \\
\text { Roayaga }\end{array}$ & 34.502539 .7202 & 41.6569 \\
\hline $\begin{array}{l}\text { Santo Domingo } \\
\text { Tehuant }\end{array}$ & 58.982452 .356 & 44.0188 \\
\hline $\begin{array}{l}\text { Santo Domingo } \\
\text { Teojomu }\end{array}$ & $36.1781 \quad 49.9737$ & 52.8213 \\
\hline $\begin{array}{l}\text { Santo Domingo } \\
\text { Tepuxte }\end{array}$ & 54.922636 .3713 & 57.1062 \\
\hline $\begin{array}{l}\text { Santo Domingo } \\
\text { Tlatayá }\end{array}$ & 39.816339 .8542 & 41.0417 \\
\hline
\end{tabular}


continúa...

\begin{tabular}{|c|c|c|c|c|c|c|c|}
\hline $\begin{array}{l}\text { Santo Domingo } \\
\text { Tomalte }\end{array}$ & 56.2688 & 44.1779 & 41.7265 & Tlacotepec Plumas & 44.6 & 47.2722 & 57.1071 \\
\hline $\begin{array}{l}\text { Santo Domingo } \\
\text { Tonalá }\end{array}$ & 60.3484 & 38.209 & 45.9713 & Tlalixtac de Cabrera & 48.0359 & 43.0381 & 59.1135 \\
\hline $\begin{array}{l}\text { Santo Domingo } \\
\text { Tonalte }\end{array}$ & 29.9573 & 37.2105 & 54.2283 & Trinidad Zaachila & 40.4514 & 34.8279 & 35.8044 \\
\hline $\begin{array}{l}\text { Santo Domingo } \\
\text { Xagacía }\end{array}$ & 40.0394 & 44.3208 & 45.3824 & Trinidad Vista Hermos & 43.3333 & 17.5 & 60.5455 \\
\hline $\begin{array}{l}\text { Santo Domingo } \\
\text { Yanhuit }\end{array}$ & 42.6492 & 49.8586 & 49.5797 & Unión Hidalgo & 69.0831 & 44.7487 & 41.3959 \\
\hline $\begin{array}{l}\text { Santo Domingo } \\
\text { Yodohin }\end{array}$ & 45.7368 & 59.5926 & 56.6212 & San Juan & 45.6681 & 41.2512 & 51.0856 \\
\hline $\begin{array}{l}\text { Santo Domingo } \\
\text { Zanatep }\end{array}$ & 55.8031 & 44.6913 & 38.8181 & Villa Díaz Ordaz & 51.2145 & 45.0913 & 64.9395 \\
\hline Santos Reyes Nopala & 53.3625 & 34.3419 & 54.1577 & Yaxe & 41.6183 & 36.9934 & 40.3904 \\
\hline Santos Reyes Pápalo & 46.2771 & 16.3884 & 37.0020 & Magdalena & 51.1549 & 48.25 & 41.6493 \\
\hline Santos Reyes Tepejill & 58.657 & 47.8218 & 47.0193 & Yodocono de & & & \\
\hline Santos Reyes Yucuná & 41.6821 & 32.3349 & 34.2036 & Yogana & 45.6234 & 34.209 & 42.1505 \\
\hline Santo Tomás Jalieza & 42.5301 & 36.5753 & 35.2870 & $\begin{array}{l}\text { Yutanduchi } \\
\text { de Guerrer }\end{array}$ & 39.2195 & 14.8967 & 34.7013 \\
\hline $\begin{array}{l}\text { Santo Tomás } \\
\text { Mazaltepe }\end{array}$ & 50.3949 & 46.0594 & 59.0866 & Villa de Zaachila & 55.2682 & 35.1731 & 44.6531 \\
\hline Santo Tomás & 37.1877 & 39.6212 & 41.9284 & Zapotitlán del Río & 40.2373 & 36.5876 & 36.2607 \\
\hline Ocotepec & & & & Zapotitlán Lagunas & 48.5853 & 39.3725 & 39.8069 \\
\hline $\begin{array}{l}\text { Santo Tomás } \\
\text { Tamazulap }\end{array}$ & 41.7958 & 41.75 & 53.5215 & Zapotitlán Palmas & 46.4512 & 35.0962 & 37.8829 \\
\hline San Vicente Coatlán & 62.201 & 39.6368 & 55.2543 & $\begin{array}{l}\text { Santa Inés } \\
\text { de Zaragoz }\end{array}$ & 42.2269 & 34.6563 & 46.2679 \\
\hline San Vicente Lachixío & 34.9327 & 36.2325 & 58.9264 & Zimatlán de Alvarez & 14.8101 & 38.4476 & 51.9199 \\
\hline San Vicente Nuñú & 47.2099 & 51.2073 & 51.2667 & PUEBLA & 1990 & 2000 & 2005 \\
\hline Silacayoápam & 41.2684 & 54.2618 & 49.7755 & Acajete & 45.893 & 48.0866 & 57.2657 \\
\hline Sitio de Xitlapehua & 5.3802 & 38.6434 & 29.4854 & Acateno & 51.8999 & 35.3419 & 51.5243 \\
\hline Soledad Etla & 47.2785 & 34.1647 & 49.5211 & Acatlán & 50.8563 & 36.0693 & 56.2889 \\
\hline Villa de Tamazulápam & 58.4156 & 45.6476 & 46.7460 & Acatzingo & 59.8689 & 39.8712 & 56.8629 \\
\hline Tanetze de Zaragoza & 53.4884 & 45.0988 & 52.6250 & Acteopan & 39.3977 & 31.5957 & 46.7086 \\
\hline Taniche & 42.3532 & 19.2217 & 51.4223 & Ahuacatlán & 39.5674 & 36.7494 & 54.8743 \\
\hline Tataltepec de Valdés & 42.1897 & 38.6094 & 37.2378 & Ahuatlán & 43.4393 & 35.8453 & 52.9306 \\
\hline Teococuilco de Marcos & 53.5294 & 51.6243 & 58.3038 & Ahuazotepec & 46.158 & 48.4055 & 60.1425 \\
\hline $\begin{array}{l}\text { Teotitlán de } \\
\text { Flores M }\end{array}$ & 54.2446 & 17.9988 & 43.5393 & Ahuehuetitla & 50.5427 & 31.5974 & 43.0754 \\
\hline Teotitlán del Valle & 49.2437 & 42.6733 & 54.6102 & Ajalpan & 12.5627 & 35.7386 & 53.7904 \\
\hline Teotongo & 42.7024 & 52.3741 & 53.8968 & Albino Zertuche & 49.6535 & 38.9953 & 44.5130 \\
\hline $\begin{array}{l}\text { Tepelmeme } \\
\text { Villa de Mo }\end{array}$ & 48.4691 & 55.7019 & 47.6535 & Aljojuca & 51.4675 & 39.605 & 49.3432 \\
\hline $\begin{array}{l}\text { Tezoatlán de } \\
\text { Segura y }\end{array}$ & 60.2811 & 38.6416 & 45.9559 & Amixtlán & 48.1208 & 37.675 & $\begin{array}{l}51.9022 \\
54.4226\end{array}$ \\
\hline $\begin{array}{l}\text { San Jerónimo } \\
\text { Tlacocha }\end{array}$ & 42.2367 & 50.932 & 50.8703 & Amozoc & 47.5032 & 39.4846 & 54.2493 \\
\hline $\begin{array}{l}\text { Tlacolula de } \\
\text { Matamoro }\end{array}$ & 49.2611 & 45.2761 & 57.4183 & Aquixtla & 40.9141 & 34.8811 & 53.4105 \\
\hline
\end{tabular}


continúa...

\begin{tabular}{|c|c|c|c|c|c|c|c|}
\hline Atexcal & 45.2824 & 36.7728 & 48.3892 & Honey & 39.5551 & 36.9862 & 54.2323 \\
\hline Atlixco & 59.5046 & 52.9138 & 55.5317 & Chilchotla & 45.8051 & 38.3527 & 55.8894 \\
\hline Atoyatempan & 39.4071 & 40.455 & 55.3712 & Chinantla & 42.2806 & 36.5052 & 47.3580 \\
\hline Atzala & 42.8182 & 38.9398 & 47.9968 & Domingo Arenas & 46.0293 & 42.3438 & 50.6082 \\
\hline Atzitzihuacán & 40.3239 & 39.6871 & 58.6588 & Eloxochitlán & 44.807 & 29.5198 & 45.7166 \\
\hline Atzitzintla & 48.9316 & 39.4887 & 56.2271 & Epatlán & 44.7358 & 40.7461 & 50.2021 \\
\hline Axutla & 50.0532 & 38.8924 & 41.6543 & Esperanza & 57.6536 & 42.1289 & 64.1504 \\
\hline Ayotoxco de Guerrero & 56.3002 & 39.5808 & 53.8736 & Francisco Z. Mena & 41.0396 & 33.1908 & 40.3078 \\
\hline Calpan & 50.7768 & 39.9709 & 59.4206 & $\begin{array}{l}\text { General Felipe } \\
\text { Angele }\end{array}$ & 47.7261 & 40.7984 & 57.9031 \\
\hline Caltepec & 41.6858 & 31.4968 & 45.1455 & Guadalupe & 42.2974 & 38.4558 & 56.1021 \\
\hline Camocuautla & 33.3544 & 36.3552 & 54.5395 & Guadalupe Victoria & 51.1189 & 39.5751 & 60.0579 \\
\hline Caxhuacan & 47.8407 & 11.0704 & 46.9158 & Hermenegildo & 44.1522 & 32.2927 & 50.5770 \\
\hline Coatepec & 33.2381 & 39.7826 & 51.4419 & Galeana & & & \\
\hline Coatzingo & 49.2006 & 41.8656 & 48.8564 & Huaquechula & 49.5519 & 38.9119 & 64.6272 \\
\hline Cohetzala & 52.2868 & 30.4762 & 48.8746 & Huatlatlauca & 54.5718 & 37.4709 & 45.6058 \\
\hline Cohuecán & 38.2519 & 33.7886 & 49.5826 & Huauchinango & 57.3065 & 39.3932 & 49.8857 \\
\hline Coronango & 40.203 & 34.1141 & 48.7509 & Huehuetla & 36.6733 & 30.8384 & 49.4800 \\
\hline Coxcatlán & 45.6147 & 36.4787 & 58.2247 & Huehuetlán el Chico & 47.822 & 37.5078 & 48.6462 \\
\hline Coyomeapan & 42.1277 & 35.9292 & 49.9708 & Huejotzingo & 50.7365 & 59.6976 & 59.1877 \\
\hline Coyotepec & 52.1125 & 39.1771 & 51.1368 & Hueyapan & 47.3478 & 37.2043 & 53.3378 \\
\hline Cuapiaxtla de Madero & 45.1871 & 41.0409 & 49.8925 & Hueytamalco & 48.1059 & 37.9611 & 52.9211 \\
\hline Cuautempan & 46.1738 & 37.4587 & 53.6130 & Hueytlalpan & 33.4337 & 28.4917 & 40.7801 \\
\hline Cuautinchán & 47.863 & 52.3183 & 47.4144 & Huitzilan de Serdán & 43.5379 & 35.1047 & 50.5875 \\
\hline Cuautlancingo & 47.981 & 48.9657 & 63.9645 & Huitziltepec & 60.3871 & 40.5101 & 56.6159 \\
\hline Cuayuca de Andrade & 44.218 & 36.1908 & 40.0864 & Atlequizayan & 39.4369 & 37.1175 & 51.5647 \\
\hline Cuetzalan & 45.115 & 35.2116 & 53.9343 & Ixcamilpa de Guerrero & 39.0321 & 35.0674 & 47.0143 \\
\hline del Progres & & & & Ixcaquixtla & 54.6569 & 39.7964 & 50.1106 \\
\hline Cuyoaco & 45.6006 & 39.5672 & 50.9073 & Ixtacamaxtitlán & 41.6704 & 35.3679 & 54.4184 \\
\hline $\begin{array}{l}\text { Chalchicomula de } \\
\text { Sesm }\end{array}$ & 48.0476 & 38.6978 & 54.3894 & Ixtepec & 43.203 & 33.2338 & 53.4377 \\
\hline Chapulco & 45.126 & 36.2747 & 46.4980 & Izúcar de Matamoros & 53.6047 & 41.7688 & 58.2464 \\
\hline Chiautla & 49.8366 & 39.6235 & 57.2684 & Jalpan & 49.5469 & 40.7235 & 51.2615 \\
\hline Chiautzingo & 47.3419 & 40.8868 & 59.5901 & Jolalpan & 42.3429 & 44.4966 & 57.5548 \\
\hline Chiconcuautla & 40.0715 & 39.3767 & 55.0342 & Jonotla & 46.7244 & 42.3418 & 54.2488 \\
\hline Chichiquila & 41.5721 & 33.9337 & 53.7727 & Jopala & 46.3714 & 36.9708 & 57.3190 \\
\hline Chietla & 47.4759 & 39.6421 & 55.3026 & Juan C. Bonilla & 11.7186 & 35.2853 & 47.6451 \\
\hline Chigmecatitlán & 53.8129 & 35.5147 & 49.7108 & Juan Galindo & 60.4346 & 41.4394 & 58.1231 \\
\hline Chignahuapan & 69.6586 & 38.9426 & 61.5871 & Juan N. Méndez & 47.8703 & 38.1458 & 49.2511 \\
\hline Chignautla & 51.0579 & 39.8328 & 55.5388 & Lafragua & 54.0584 & 38.7302 & 56.3375 \\
\hline Chila & 42.6872 & 33.7577 & 49.1982 & Libres & 51.2875 & 45.1215 & 54.8747 \\
\hline la Sal & $42.00 / 2$ & 34.9213 & 46.2523 & $\begin{array}{l}\text { Magdalena } \\
\text { Tlatlauquit }\end{array}$ & 51.5385 & 42.9924 & 49.2609 \\
\hline
\end{tabular}


continúa..

\begin{tabular}{|c|c|c|c|c|c|c|c|}
\hline $\begin{array}{l}\text { Mazapiltepec } \\
\text { de Juáre }\end{array}$ & 53.0123 & 36.2981 & 47.0857 & $\begin{array}{l}\text { San Martín Totoltepec } \\
\text { San Matías Tlalancale }\end{array}$ & 50.3668 & 40.2222 & 41.2526 \\
\hline Mixtla & 44.0204 & 39.8299 & 49.6374 & San Miguel Ixitlán & 43.0058 & 40.8376 & 47.1871 \\
\hline Molcaxac & 50.3378 & 36.2099 & 51.7425 & San Miguel Xoxtla & 61.4563 & 51.3751 & 60.9890 \\
\hline Cańada Morelos & 40.8821 & 36.5714 & 55.3712 & San Nicolás & 43.877 & 39.1748 & 49.9284 \\
\hline Naupan & 47.47 & 41.089 & 52.6955 & Buenos Ai & & & \\
\hline Nauzontla & 42.0699 & 44.394 & 47.3012 & $\begin{array}{l}\text { San Nicolás } \\
\text { de los Ra }\end{array}$ & 49.8234 & 42.1282 & 60.1212 \\
\hline Nealtican & 42.536 & 42.1257 & 58.1332 & San Pablo Anicano & 46.6487 & 36.3389 & 50.6008 \\
\hline Nicolás Bravo & 62.5801 & 37.6409 & 55.2067 & San Pedro Cholula & 56.3689 & 47.5974 & 57.4366 \\
\hline Nopalucan & 51.559 & 42.6602 & 57.3902 & San Pedro & 44.1321 & 42.4872 & 47.8882 \\
\hline Ocotepec & 49.5058 & 37.375 & 53.6497 & & & & \\
\hline Ocoyucan & 12.0136 & 33.4452 & 57.6614 & San Salvador el Seco & 46.9314 & 37.6391 & 49.8330 \\
\hline Olintla & 41.4985 & 32.7941 & 53.1635 & San Salvador el Verde & 52.8242 & 41.9227 & 57.6262 \\
\hline Oriental & 49.0307 & 45.2766 & 54.9786 & San Salvador Huixcolo & 50.9432 & 43.0016 & 56.8571 \\
\hline Pahuatlán & 48.4427 & 42.4622 & 56.9737 & $\begin{array}{l}\text { San Sebastián } \\
\text { Tlacote }\end{array}$ & 35.8413 & 34.689 & 54.3546 \\
\hline Palmar de Bravo & 46.6473 & 38.6674 & 50.8224 & $\begin{array}{l}\text { Santa Catarina } \\
\text { Tlalte }\end{array}$ & 53.4566 & 38.9537 & 47.0478 \\
\hline Pantepec & 41.0599 & 33.4795 & 52.8671 & Santa Inés & 40.5447 & 35.1209 & 45.8683 \\
\hline Petlalcingo & 48.8125 & 37.4733 & 49.1624 & Ahuatempan & & & \\
\hline Piaxtla & 54.6718 & 35.682 & 55.3578 & Santa Isabel Cholula & 41.721 & 42.1823 & 50.1836 \\
\hline Puebla & 61.029 & 53.0942 & 62.1281 & Santiago Miahuatlán & 49.709 & 16.4621 & 54.9251 \\
\hline Quecholac & 44.9019 & 39.2 & 58.8390 & Huehuetlán el Grande & 47.9255 & 40.9953 & 56.8944 \\
\hline Quimixtlán & 37.7432 & 37.618 & 53.1336 & $\begin{array}{l}\text { Santo Tomás } \\
\text { Hueyotlip }\end{array}$ & 46.5202 & 37.9461 & 55.3438 \\
\hline Rafael Lara Grajales & 62.6339 & 58.5623 & 61.9842 & Soltepec & 43.1119 & 39.1804 & 48.7 \\
\hline Reyes de Juárez, Los & 47.1699 & 48.642 & 59.4689 & Tecali de Herrera & 57.1671 & 39.9118 & \\
\hline San Andrés Cholula & 47.5782 & 56.2062 & 65.2992 & Tecamachalco & 47.7604 & 40.7452 & 59.5465 \\
\hline San Antonio Cańada & 50.3623 & 36.1108 & 45.2388 & Tecomatlán & 57.5259 & 45.5789 & 56.6628 \\
\hline $\begin{array}{l}\text { San Diego la } \\
\text { Mesa Toc }\end{array}$ & 34.1382 & 32.7787 & & Tehuacán & 68.3397 & 47.2898 & 63.5414 \\
\hline San Felipe Teotlalcin & 44.249 & 39.2835 & 56.2511 & Tehuitzingo & 42.5151 & 36.0427 & 53.1562 \\
\hline San Felipe Tepatlán & 49.6111 & 34.547 & 51.8275 & Tenampulco & 41.9062 & 33.3331 & 41.2019 \\
\hline San Gabriel Chilac & 51.3111 & 40.5369 & 73.6323 & Teopantlán & 43.6895 & 45.3909 & 50.9014 \\
\hline San Gregorio Atzompa & 59.0611 & 37.9605 & 45.0626 & Teotlalco & 49.4795 & 35.748 & 49.0288 \\
\hline San Jerónimo & 49.4967 & 41.1399 & 48.1103 & Tepanco de López & 44.3376 & 38.5499 & 57.7091 \\
\hline Tecua & & & & Tepango de Rodríguez & 49.6457 & 36.4885 & 48.9247 \\
\hline $\begin{array}{l}\text { San Jerónimo } \\
\text { Xayacatl }\end{array}$ & 51.7229 & 36.5479 & 47.6781 & Tepatlaxco de Hidalgo & 47.2439 & 40.1993 & 57.1971 \\
\hline San José Chiapa & 47.5675 & 38.0022 & 42.7525 & Tepeaca & 56.1875 & 43.1371 & 46.3555 \\
\hline San José Miahuatlán & 47.2254 & 41.3846 & 58.1817 & Tepemaxalco & 34.1872 & 37.2222 & 47.6892 \\
\hline San Juan Atenco & 45.1761 & 41.0142 & 57.0548 & Tepeojuma & 50.5523 & 39.8841 & 59.1886 \\
\hline San Juan Atzompa & 38.1481 & 61.1842 & 50.1481 & Tepetzintla & 37.8331 & 35.7932 & 52.8332 \\
\hline San Martín & 58.8145 & 50.0743 & 57.2051 & Tepexco & 43.4174 & 35.8047 & 44.8676 \\
\hline Texmelucan & & & & Tepexi de Rodríguez & 47.8961 & 34.4127 & 55.2659 \\
\hline
\end{tabular}


continúa..

\begin{tabular}{|c|c|c|c|}
\hline Tepeyahualco & 48.7845 & 38.6106 & 54.4303 \\
\hline $\begin{array}{l}\text { Tepeyahualco de } \\
\text { Cuauh }\end{array}$ & 50.1963 & 43.9402 & 45.1405 \\
\hline Tetela de Ocampo & 44.5917 & 34.0523 & 46.3618 \\
\hline Teteles de Avila Cast & 56.8895 & 41.3148 & 50.5359 \\
\hline Teziutlán & 61.5143 & 50.8565 & 52.7986 \\
\hline Tianguismanalco & 48.823 & 42.1301 & 53.5200 \\
\hline Tilapa & 51.6584 & 40.3912 & 50.5340 \\
\hline Tlacotepec de Benito & 47.8818 & 38.7588 & 57.6070 \\
\hline Tlacuilotepec & 37.8469 & 34.4573 & 52.4748 \\
\hline Tlachichuca & 47.1842 & 40.3755 & 58.0731 \\
\hline Tlahuapan & 49.6283 & 41.9314 & 59.8656 \\
\hline Tlaltenango & 51.6793 & 36.6869 & 49.2092 \\
\hline Tlanepantla & 49.4131 & 38.5522 & 56.1283 \\
\hline Tlaola & 44.2366 & 43.8748 & 55.9239 \\
\hline Tlapacoya & 37.6757 & 40.6635 & 45.3060 \\
\hline Tlapanalá & 45.806 & 41.6918 & 50.5249 \\
\hline Tlatlauquitepec & 51.0613 & 42.9612 & 55.5129 \\
\hline Tlaxco & 37.5088 & 32.965 & 49.4710 \\
\hline Tochimilco & 47.3653 & 40.0083 & 57.2751 \\
\hline Tochtepec & 47.3058 & 39.0045 & 54.1321 \\
\hline $\begin{array}{l}\text { Totoltepec } \\
\text { de Guerrer }\end{array}$ & 51.4419 & 36.6377 & 49.2654 \\
\hline Tulcingo & 46.3061 & 38.5626 & 56.4582 \\
\hline $\begin{array}{l}\text { Tuzamapan } \\
\text { de Galeana }\end{array}$ & 40.5953 & 39.8972 & 56.0856 \\
\hline Tzicatlacoyan & 45.3496 & 34.4275 & 52.0059 \\
\hline Venustiano Carranza & 46.3704 & 38.2728 & 56.1519 \\
\hline Vicente Guerrero & 38.043 & 30.9941 & 52.2415 \\
\hline Xayacatlán de Bravo & 49.9659 & 37 & 46.0748 \\
\hline Xicotepec & 49.5608 & 37.6826 & 57.4631 \\
\hline Xicotlán & 41.7936 & 28.0172 & 40.3557 \\
\hline Xiutetelco & 49.7108 & 40.0898 & 57.7558 \\
\hline Xochiapulco & 45.6125 & 34.5649 & 53.9687 \\
\hline Xochiltepec & 45.5273 & 40.7206 & 52.0699 \\
\hline Xochitlán de Vicente & 45.3941 & 35.0232 & 54.0631 \\
\hline $\begin{array}{l}\text { Xochitlán Todos } \\
\text { Santo }\end{array}$ & 53.6579 & 40.2239 & 50.5628 \\
\hline Yaonáhuac & 57.5722 & 37.2959 & 42.9772 \\
\hline Yehualtepec & 46.0284 & 37.7101 & 57.7462 \\
\hline Zacapala & 48.6606 & 35.3494 & 45.4170 \\
\hline
\end{tabular}

\begin{tabular}{|c|c|c|c|}
\hline Zacapoaxtla & 49.7006 & 49.5466 & 54.2575 \\
\hline Zacatlán & 50.3217 & 39.4181 & 53.6509 \\
\hline Zapotitlán & 44.8264 & 36.4968 & 54.4179 \\
\hline Zapotitlán de Méndez & 53.4974 & 33.9866 & 53.7574 \\
\hline Zaragoza & 54.3064 & 48.0774 & 52.7370 \\
\hline Zautla & 41.957 & 35.5459 & 54.6838 \\
\hline Zihuateutla & 45.4256 & 37.5364 & 52.8098 \\
\hline Zinacatepec & 54.9653 & 55.4648 & 61.4186 \\
\hline Zongozotla & 52.7207 & 41.9352 & 45.0317 \\
\hline Zoquiapan & 43.4747 & 39.9847 & 47.7118 \\
\hline Zoquitlán & 40.1196 & 37.6921 & 57.5864 \\
\hline QUERETARO & 1990 & 2000 & 2005 \\
\hline Amealco de Bonfil & 44.1206 & 54.6442 & 46.9890 \\
\hline Pinal de Amoles & 38.5158 & 34.1752 & 41.8052 \\
\hline Arroyo Seco & 59.9067 & 43.5361 & 46.2721 \\
\hline Cadereyta de Montes & 43.0294 & 55.015 & 48.0673 \\
\hline Colón & 45.0198 & 51.3225 & 48.2436 \\
\hline Corregidora & 56.0415 & 62.8193 & 61.3698 \\
\hline Ezequiel Montes & 51.8402 & 49.1455 & 44.0107 \\
\hline Huimilpan & 41.7993 & 53.4535 & 53.0584 \\
\hline Jalpan de Serra & 50.7749 & 50.8942 & 46.2345 \\
\hline Landa de Matamoros & 39.2048 & 49.8722 & 44.3310 \\
\hline Marqués, El & 55.1091 & 53.1798 & 57.3528 \\
\hline Pedro Escobedo & 48.364 & 55.0549 & 43.2471 \\
\hline Peñamiller & 39.8972 & 51.0666 & 44.4960 \\
\hline Querétaro & 60.2078 & 70.628 & 59.5665 \\
\hline San Joaquín & 41.2553 & 42.8387 & 44.0623 \\
\hline San Juan del Río & 57.9412 & 64.1135 & 73.0321 \\
\hline Tequisquiapan & 61.64 & 64.8218 & 66.5991 \\
\hline Tolimán & 43.2317 & 49.9097 & 46.0574 \\
\hline QUINTANA ROO & 1990 & 2000 & 2005 \\
\hline Cozumel & 65.4596 & 56.5239 & 57.5556 \\
\hline Felipe Carrillo Puert & 62.0645 & 36.5079 & 44.0790 \\
\hline Isla Mujeres & 51.2287 & 56.0581 & 49.8852 \\
\hline Othón P. Blanco & 61.4916 & 48.4496 & 44.6984 \\
\hline Benito Juárez & 56.1611 & 59.5102 & 60.4703 \\
\hline José María Morelos & 65.9856 & 36.1436 & 38.1990 \\
\hline Lázaro Cárdenas & 50.5402 & 36.6851 & 38.2619 \\
\hline Solidaridad & 46.7323 & 59.6127 & 74.5796 \\
\hline
\end{tabular}


continúa...

\begin{tabular}{|c|c|c|c|c|c|c|c|}
\hline SAN LUIS POSTOSI & 1990 & 2000 & 2005 & Tampamolón Corona & 41.3616 & 38.7907 & 48.3665 \\
\hline Ahualulco & 0 & 42.7903 & 46.4905 & Tamuín & 42.1216 & 47.93 & 41.9288 \\
\hline Alaquines & 51.67 & 34.1103 & 40.1530 & Tanlajás & 39.7048 & 44.748 & 41.9314 \\
\hline Aquismón & 41.9623 & 48.7863 & 45.4437 & Tanquián de Escobedo & 47.4808 & 40.1461 & 48.0084 \\
\hline Armadillo de los INFA & 41.656 & 43.4448 & 50.8095 & Tierra Nueva & 40.9911 & 42.1037 & 41.5110 \\
\hline Cárdenas & 37.0836 & 47.4636 & 48.0471 & Vanegas & 50.9232 & 41.2397 & 44.3445 \\
\hline Catorce & 42.567 & 42.2813 & 48.4758 & Venado & 47.245 & 42.0804 & 45.4595 \\
\hline Cedral & 53.5653 & 52.8607 & 43.9589 & Villa de Arriaga & 50.5373 & 38.4577 & 47.2903 \\
\hline Cerritos & 41.9133 & 46.4344 & 51.9830 & Villa de Guadalupe & 42.2768 & 44.1073 & 43.1989 \\
\hline Cerro de San Pedro & 50.343 & 40.5235 & 48.1224 & Villa de la Paz & 41.1052 & 47.677 & 41.5419 \\
\hline Ciudad del Maíz & 48.3207 & 51.9833 & 45.7220 & Villa de Ramos & 45.6005 & 53.5329 & 55.7553 \\
\hline Ciudad Fernández & 46.8985 & 57.3992 & 48.5866 & Villa de Reyes & 50.0102 & 39.8913 & 49.2264 \\
\hline Tancanhuitz de Santos & 41.8488 & 43.6037 & 33.3374 & Villa Hidalgo & 47.6279 & 52.1464 & 46.7201 \\
\hline Ciudad Valles & 49.3708 & 45.9106 & 48.9734 & Villa Juárez & 49.4913 & 43.7639 & 47.3662 \\
\hline Coxcatlán & 40.147 & 43.8792 & 41.7962 & Axtla de Terrazas & 46.5942 & 36.5835 & 44.7973 \\
\hline Charcas & 44.7676 & 48.4548 & 44.9794 & Xilitla & 50.7366 & 49.2553 & 44.3158 \\
\hline Ebano & 45.0575 & 44.5082 & 41.0488 & Zaragoza & 41.7454 & 52.4148 & 40.1830 \\
\hline Guadalcázar & 54.3401 & 46.9158 & 41.3775 & Villa de Arista & 41.4506 & 39.4719 & 44.0293 \\
\hline Huehuetlán & 44.8882 & 39.2537 & 37.1498 & Matlapa & 37.6073 & 49.2816 & 41.2519 \\
\hline Lagunillas & 40.1431 & 38.7979 & 44.4844 & Naranjo, El & 44.4414 & 40.4911 & 43.5100 \\
\hline Matehuala & 41.2546 & 40.9128 & 42.8050 & SINALOA & 1990 & 2000 & 2005 \\
\hline Mexquitic de Carmona & 44.4277 & 52.0179 & 48.6712 & Ahome & 67.8328 & 48.966 & 50.9390 \\
\hline Moctezuma & 49.354 & 41.1948 & 46.5542 & Angostura & 63.032 & 53.0354 & 47.7101 \\
\hline Rayón & 40.8518 & 46.0414 & 46.2191 & Badiraguato & 43.198 & 42.5479 & 39.2282 \\
\hline Ríoverde & 42.6416 & 52.2262 & 48.7031 & Concordia & 51.0355 & 44.1444 & 46.2333 \\
\hline Salinas & 42.589 & 50.0266 & 46.9913 & Cosalá & 52.2481 & 37.3328 & 40.1551 \\
\hline San Antonio & 55.118 & 39.2024 & 44.8340 & Culiacán & 62.3107 & 48.7819 & 53.8768 \\
\hline San Ciro de Acosta & 42.3613 & 42.3858 & 47.2070 & Choix & 48.3645 & 36.0646 & 44.5907 \\
\hline San Luis Potosí & 40.1254 & 44.0784 & 51.5149 & Elota & 56.8417 & 38.1615 & 51.5911 \\
\hline $\begin{array}{l}\text { San Martín } \\
\text { Chalchicua }\end{array}$ & 51.6162 & 34.5072 & 45.0326 & Escuinapa & 55.5241 & 38.9515 & 40.8061 \\
\hline San Nicolás Tolentino & 64.6857 & 45.4711 & 40.2394 & Fuerte, El & 58.3519 & 38.0731 & 39.5853 \\
\hline Santa Catarina & 36.7768 & 41.9853 & 37.4802 & Guasave & 66.2334 & 43.8376 & 47.3024 \\
\hline Santa María del Río & 40.4985 & 48.0849 & 39.7172 & & & & \\
\hline Santo Domingo & 34.8179 & 40.2675 & 49.1069 & & & & \\
\hline San Vicente Tancuayal & 46.5142 & 56.4246 & 40.6610 & & & $8.069 /$ & \\
\hline Soledad de & 41.0294 & 43.0263 & 44.5078 & Salvador Alvarado & 66.3872 & 46.3947 & 46.2532 \\
\hline Graciano S & & & & San Ignacio & 53.5494 & 37.4902 & 39.9561 \\
\hline Tamasopo & 47.3483 & 49.1236 & 44.7490 & Sinaloa & 56.6828 & 46.5871 & 38.2468 \\
\hline Tamazunchale & 63.3369 & 35.8361 & 37.0210 & Navolato & 65.8754 & 43.0717 & 45.3654 \\
\hline
\end{tabular}

Tampacán $\quad 47.139948 .3612 \quad 43.0657$ 
continúa...

\begin{tabular}{|c|c|c|c|c|c|c|}
\hline SONORA & 1990 & 2000 & 2005 & Nácori Chico & 51.485337 .6271 & 41.8323 \\
\hline Aconchi & 53.1627 & 41.0328 & 39.6711 & Nacozari de García & $57.7125 \quad 46.9404$ & 41.4933 \\
\hline Agua Prieta & 57.6032 & 44.668 & 52.1966 & Navojoa & $56.5658 \quad 42.3943$ & 46.4523 \\
\hline Alamos & 48.443 & 35.6149 & 36.3847 & Nogales & 57.340749 .0178 & 44.2222 \\
\hline Altar & 60.5721 & 43.5563 & 43.6706 & Onavas & $47.4874 \quad 43.1032$ & 39.0932 \\
\hline Arivechi & 50.226 & 41.107 & 40.5160 & Opodepe & 53.849739 .2887 & 37.4345 \\
\hline Arizpe & 51.4972 & 40.3491 & 42.8783 & Oquitoa & $53.812 \quad 44.6068$ & 45.9836 \\
\hline Atil & 55.4719 & 45.8043 & 40.5833 & Pitiquito & 56.815640 .1841 & 45.5600 \\
\hline Bacadéhuachi & 52.3574 & 41.5303 & 42.9828 & Puerto Peńasco & 67.112361 .4042 & 63.3894 \\
\hline Bacanora & 52.6429 & 45.3395 & 42.5345 & Quiriego & 51.293234 .9453 & 34.5529 \\
\hline Bacerac & 53.6561 & 37.9731 & 39.7364 & Rayón & 53.095241 .4134 & 40.7207 \\
\hline Bacoachi & 51.6021 & 40.369 & 41.9385 & Rosario & $47.6588 \quad 36.7929$ & 44.4046 \\
\hline Bácum & 51.1606 & 37.9291 & 37.9514 & Sahuaripa & 45.675940 .6558 & 42.7516 \\
\hline Banámichi & 55.7308 & 45.952 & 44.2754 & San Felipe de Jesús & 51.583346 .8843 & 46.9059 \\
\hline Baviácora & 55.6882 & 42.8027 & 42.6410 & San Javier & $53.4688 \quad 42.3483$ & 42.0253 \\
\hline Bavispe & 50.8892 & 39.9773 & 41.7147 & San Luis Río Colorado & 62.787744 .1625 & 50.8756 \\
\hline Benjamín Hill & 55.4944 & 40.7694 & 40.1310 & $\begin{array}{l}\text { San Miguel de } \\
\text { Horcasi }\end{array}$ & 53.358740 .6046 & 44.1575 \\
\hline Caborca & 57.9337 & 51.1862 & 51.1854 & San Pedro de & $54.2755 \quad 41.5996$ & 41.7184 \\
\hline Cajeme & 62.9638 & 49.8356 & 54.3471 & la Cueva & & \\
\hline Cananea & 69.7711 & 49.4871 & 44.5797 & Santa Ana & 62.589253 .1923 & 45.0742 \\
\hline Carbó & 57.6633 & 42.3121 & 42.7097 & Santa Cruz & 55.547944 .8653 & 41.5970 \\
\hline Colorada, La & 59.8255 & 69.7693 & 48.6802 & Sáric & 54.346640 .4161 & 40.4035 \\
\hline Cucurpe & 45.0842 & 41.8639 & 38.5688 & Soyopa & 53.511143 .6004 & 40.3243 \\
\hline Cumpas & 52.8684 & 44.7057 & 41.3091 & Suaqui Grande & 55.169441 .0809 & 41.4266 \\
\hline Divisaderos & 51.4413 & 45.1055 & 39.3947 & Tepache & 58.397543 .0833 & 42.6081 \\
\hline Empalme & 61.5682 & 48.7046 & 43.3501 & Trincheras & 49.674238 .9573 & 41.4432 \\
\hline Etchojoa & 52.0435 & 37.8513 & 37.9925 & Tubutama & 53.550338 .117 & 37.5987 \\
\hline Fronteras & 57.6809 & 40.7285 & 41.6855 & Ures & 55.197941 .5198 & 41.0758 \\
\hline Granados & 52.7943 & 43.4407 & 40.7584 & Villa Hidalgo & $60.4407 \quad 42.594$ & 43.3671 \\
\hline Guaymas & 59.0919 & 52.7995 & 49.3686 & Villa Pesqueira & 50.236339 .8736 & 40.9369 \\
\hline Hermosillo & 60.7163 & 52.5626 & 55.1551 & Yécora & 46.143139 .5567 & 36.7210 \\
\hline Huachinera & 49.1372 & 43.165 & 39.8632 & $\begin{array}{l}\text { General Plutarco } \\
\text { Elía }\end{array}$ & $64.809 \quad 53.0729$ & 52.8378 \\
\hline Huásabas & 56.1992 & 45.8593 & 42.6825 & Benito Juárez & 039.2308 & 38.2158 \\
\hline Huatabampo & 56.9245 & 41.0146 & 37.1691 & San Ignacio & 038.4058 & 37.5334 \\
\hline Huépac & 52.4967 & 41.257 & 51.5915 & Río Muert & & \\
\hline Imuris & 60.801 & 43.9727 & 39.7323 & TABASCO & 2000 & 2005 \\
\hline Magdalena & 62.8611 & 54.8385 & 44.2217 & Balancán & $42.992 \quad 41.9035$ & 44.3083 \\
\hline Mazatán & 50.9512 & 41.3796 & 39.8222 & Cárdenas & 49.013645 .6054 & 46.7383 \\
\hline Moctezuma & 56.6979 & 42.1174 & 41.5663 & Centla & 38.504241 .4396 & 44.2776 \\
\hline Naco & 56.0403 & 55.2012 & 44.3075 & Centro & 46.933151 .3974 & 53.1509 \\
\hline
\end{tabular}


continúa..

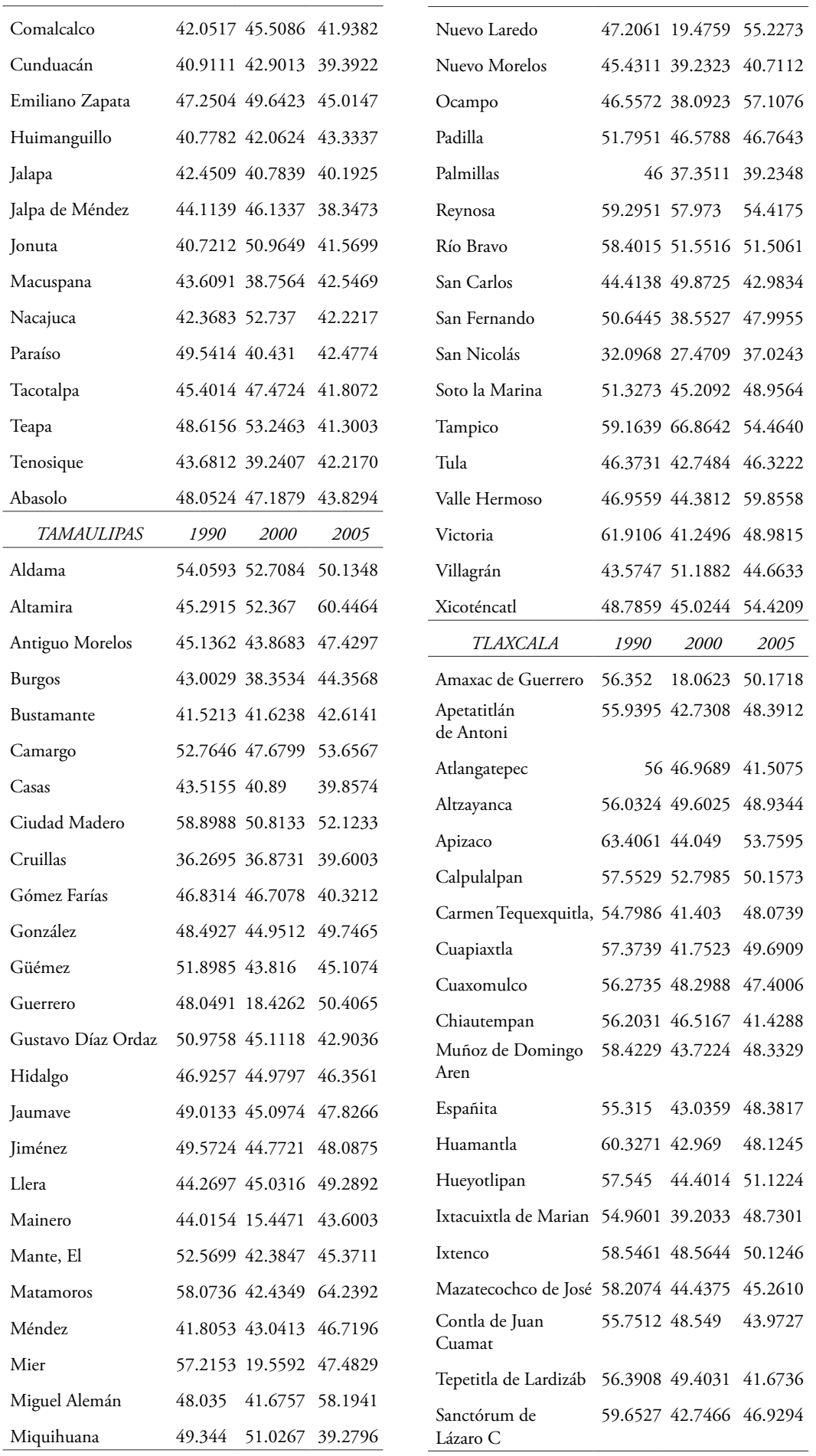


continúa...

\begin{tabular}{|c|c|c|c|c|c|c|}
\hline $\begin{array}{l}\text { Nanacamilpa de } \\
\text { Marian }\end{array}$ & 58.867643 .2517 & 47.4993 & Santa Cruz Quilehtla & 0 & 49.29 & 42.4590 \\
\hline Acuamanala de Miguel & $565675 \quad 427349$ & 502706 & Santa Isabel Xiloxoxt & 0 & 47.3826 & 52.3623 \\
\hline 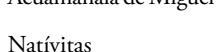 & 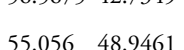 & 50.5221 & VERACRUZ & 1990 & 2000 & 2005 \\
\hline Panotla & 52.861254 .8508 & 48.6902 & Acajete & 55.2713 & 42.6461 & 45.1033 \\
\hline San Pablo del Monte & $52.9708 \quad 52.5459$ & 49.5947 & Acatlán & 46.2986 & 46.5046 & 43.7695 \\
\hline Santa Cruz Tlaxcala & 54.946341 .7035 & 49.9377 & Acayucan & 51.7358 & 42.4 & 56.0590 \\
\hline Tenancingo & 57.969243 .263 & 49.3987 & Actopan & 57.9593 & 45.1958 & 48.9845 \\
\hline Teolocholco & 58.605851 .2321 & 51.1024 & Acula & 55.5766 & 31.8254 & 44.3629 \\
\hline Tepeyanco & $\begin{array}{lll}55.8752 & 47.5978\end{array}$ & 47.0106 & Acultzingo & 45.8691 & 39.5841 & 51.9202 \\
\hline Terrenate & 56.490250 .1841 & 50.0164 & Camarón de Tejeda & 47.1848 & 42.3808 & 49.2373 \\
\hline Tetla de la Solidarid & 56.700552 .763 & 48.6654 & Alpatláhuac & 49.5721 & 15.2875 & 67.1559 \\
\hline Tetlatlahuca & $57.3758 \quad 49.2914$ & 49.8725 & $\begin{array}{l}\text { Alto Lucero } \\
\text { de Gutiér }\end{array}$ & 41.244 & 46.2121 & 50.7052 \\
\hline Tlaxcala & $63.358 \quad 51.9458$ & 51.5261 & Altotonga & 59.2268 & 42.0306 & 56.7115 \\
\hline Tlaxco & 53.403849 .0352 & 48.5430 & Alvarado & 56.0876 & 48.3951 & 48.6369 \\
\hline Tocatlán & $55.2162 \quad 42.9584$ & 42.2614 & Amatitlán & 57.121 & 38.9595 & 44.7692 \\
\hline Totolac & $55.9555 \quad 42.8563$ & 48.2333 & Naranjos Amatlán & 56.7993 & 40.869 & 47.7344 \\
\hline Zitlaltepec de Trinid & $55.7075 \quad 42.9229$ & 48.1397 & Amatlán de los Reyes & 66.3844 & 40.8539 & 43.0925 \\
\hline Tzompantepec & $54.8264 \quad 49.1205$ & 42.0943 & Angel R. Cabada & 46.2515 & 43.2894 & 55.2332 \\
\hline Xaloztoc & 63.715956 .2576 & 49.0550 & Antigua, La & 54.8044 & 46.4845 & 45.1670 \\
\hline Xaltocan & $56.0295 \quad 47.1821$ & 48.9929 & Apazapan & 63.1485 & 43.4793 & 47.3645 \\
\hline Papalotla de Xicohtén & 58.416656 .795 & 51.3179 & Aquila & 49.2875 & 37.9744 & 42.2712 \\
\hline Xicohtzinco & $56.9502 \quad 42.4328$ & 51.2027 & Astacinga & 43.0159 & 30.2552 & 43.3746 \\
\hline Yauhquemecan & 54.602450 .1998 & 48.9977 & Atlahuilco & 39.7086 & 36.4521 & 47.6548 \\
\hline Zacatelco & 57.894950 .42 & 51.2257 & Atoyac & 46.6365 & 42.6621 & 45.3469 \\
\hline Benito Juárez & 044.3491 & 50.5803 & Atzacan & 53.22 & 42.6895 & 49.3259 \\
\hline Emiliano Zapata & 049.508 & 51.0314 & Atzalan & 49.7007 & 45.0395 & 53.6889 \\
\hline Lázaro Cárdenas & 048.3601 & 49.2739 & Tlaltetela & 43.7766 & 44.4875 & 55.2763 \\
\hline Magdalena Tlaltelulco & 051.0121 & 50.7178 & Ayahualulco & 45.4619 & 18.8407 & 55.1654 \\
\hline San Damián Texoloc & 048.5622 & 47.4630 & Banderilla & 48.0992 & 44.5725 & 49.8151 \\
\hline San Francisco Tetlano & 046.1317 & 50.1556 & Benito Juárez & 54.2232 & 13.371 & 48.7352 \\
\hline $\begin{array}{l}\text { San Jerónimo } \\
\text { Zacualpa }\end{array}$ & 041.0015 & 46.9735 & Boca del Río & 43.4729 & 53.5295 & 64.0649 \\
\hline San José Teacalco & 048.3767 & 42.4052 & Calcahualco & 56.9778 & 14.2512 & 66.2243 \\
\hline San Juan Huactzinco & 046.0791 & 41.1434 & Camerino Z. Mendoza & 40.7224 & 45.1879 & 52.2619 \\
\hline San Lorenzo & 048.5307 & 42.5569 & Carrillo Puerto & 63.055 & 37.1891 & 37.7038 \\
\hline & & & Catemaco & 44.2192 & 17.5871 & 54.2865 \\
\hline San Lucas Tecopilco & 043.0985 & 50.0069 & Cazones & 60.9048 & 33.8157 & 42.5689 \\
\hline Santa Ana Nopalucan & 040.8742 & 55.7988 & Cerro Azul & 45.2551 & 43.8677 & 46.0827 \\
\hline Santa Apolonia Teacal & 052.1258 & 50.8010 & Citlaltépetl & 60.9251 & 40.2235 & 49.3615 \\
\hline $\begin{array}{l}\text { Santa Catarina } \\
\text { Ayomet }\end{array}$ & 044.5309 & 51.2428 & Coacoatzintla & 52.9894 & 41.5804 & 48.3099 \\
\hline
\end{tabular}


continúa..

\begin{tabular}{|c|c|c|c|c|c|c|c|}
\hline Coahuitlán & 47.738 & 35.821 & 48.6737 & Ilamatlán & 65.4569 & 34.124 & 49.4627 \\
\hline Coatepec & 43.1888 & 46.7724 & 52.1959 & Isla & 41.4987 & 42.5848 & 48.3829 \\
\hline Coatzacoalcos & 65.3895 & 41.0382 & 56.1183 & Ixcatepec & 53.8527 & 32.9443 & 51.4485 \\
\hline Coatzintla & 57.5612 & 49.0619 & 51.2929 & Ixhuacán de los Reyes & 47.6546 & 42.0345 & 47.1897 \\
\hline Coetzala & 53.8469 & 34.0341 & 35.7875 & Ixhuatlán del Café & 48.2689 & 39.2497 & 47.7030 \\
\hline Colipa & 40.9206 & 42.73 & 42.9879 & Ixhuatlancillo & 43.4292 & 40.7072 & 49.4712 \\
\hline Comapa & 44.3217 & 35.2771 & 53.7294 & Ixhuatlán del Sureste & 52.0257 & 32.8375 & 43.8302 \\
\hline Córdoba & 47.638 & 43.5942 & 51.2230 & Ixhuatlán de Madero & 49.0761 & 35.2526 & 50.2188 \\
\hline $\begin{array}{l}\text { Cosamaloapan } \\
\text { de Carpi }\end{array}$ & 57.9344 & 41.5561 & 55.3577 & Ixmatlahuacan & 44.7162 & 34.0339 & 45.5229 \\
\hline Cosautlán de & 55.3392 & 44.6427 & 50.4896 & Ixtaczoquitlán & 50.8335 & 40.4549 & 42.6489 \\
\hline Carvajal & & & & Jalacingo & 50.9819 & 40.1055 & 58.5124 \\
\hline Coscomatepec & 53.3843 & 41.9993 & 56.8589 & Xalapa & 57.0015 & 41.9144 & 52.3547 \\
\hline Cosoleacaque & 57.4616 & 41.8228 & 44.9325 & Jalcomulco & 59.2144 & 44.4462 & 49.5582 \\
\hline Cotaxtla & 47.5552 & 41.1944 & 44.3214 & Jáltipan & 57.565 & 39.3543 & 60.5475 \\
\hline Coxquihui & 38.4399 & 34.9539 & 49.4206 & Jamapa & 59.7118 & 38.803 & 46.7100 \\
\hline Coyutla & 47.8916 & 36.5196 & 51.5587 & Jesús Carranza & 51.3669 & 39.1585 & 46.3372 \\
\hline Cuichapa & 49.7649 & 45.856 & 46.1970 & Xico & 54.7135 & 45.022 & 49.5715 \\
\hline Cuitláhuac & 52.6726 & 42.7684 & 49.2616 & Jilotepec & 58.7132 & 44.9488 & 47.2877 \\
\hline Chacaltianguis & 55.5825 & 37.5329 & 47.4677 & Juan Rodríguez Clara & 56.707 & 42.532 & 48.4513 \\
\hline Chalma & 51.1555 & 8.726 & 32.9898 & Juchique de Ferrer & 51.9398 & 43.561 & 47.0802 \\
\hline Chiconamel & 38.755 & 31.8588 & 39.4714 & Landero y Coss & 43.0104 & 39.7795 & 41.0748 \\
\hline Chiconquiaco & 38.5839 & 40.4277 & 51.6335 & Lerdo de Tejada & 43.5238 & 45.9171 & 49.9820 \\
\hline Chicontepec & 51.1021 & 37.2587 & 51.0216 & Magdalena & 60.269 & 17.0435 & 45.7620 \\
\hline Chinameca & 46.032 & 39.8405 & 47.5240 & Maltrata & 54.2641 & 41.0487 & 53.9229 \\
\hline $\begin{array}{l}\text { Chinampa de } \\
\text { Gorostiza }\end{array}$ & 62.4707 & 35.0023 & 49.3662 & Manlio Fabio Altamira & 54.3136 & 42.0987 & 50.8372 \\
\hline Choapas, Las & 48.7624 & 39.1278 & 48.7066 & Mariano Escobedo & 50.1912 & 43.011 & 47.7046 \\
\hline Chocamán & 53.7845 & 43.9205 & 56.3133 & Martínez de la Torre & 51.9044 & 39.2071 & 49.1264 \\
\hline Chontla & 59.7127 & 38.1731 & 52.3525 & Mecatlán & 54.2164 & 33.4003 & 50.0984 \\
\hline Chumatlán & 50.1719 & 30.562 & 43.6545 & Mecayapan & 42.0572 & 13.3387 & 51.3724 \\
\hline Emiliano Zapata & 36.1989 & 43.6418 & 49.0097 & Medellín & 69.8322 & 39.1673 & 47.7454 \\
\hline Espinal & 51.6493 & 35.6292 & 49.6025 & Miahuatlán & 44.9776 & 46.2251 & 50.0787 \\
\hline Filomeno Mata & 41.4892 & 34.648 & 45.3863 & Minas, Las & 51.3441 & 34.0174 & 31.4364 \\
\hline Fortín & 46.7431 & 50.864 & 52.5918 & Minatitlán & 38.6236 & 47.6968 & 45.0579 \\
\hline Gutiérrez Zamora & 62.2887 & 38.5927 & 43.6556 & Misantla & 62.0507 & 40.8896 & 52.2492 \\
\hline Hidalgotitlán & 56.9539 & 30.5939 & 47.6044 & Mixtla de Altamirano & 63.8876 & 34.7004 & 47.2354 \\
\hline Huatusco & 53.1782 & 43.3994 & 55.2188 & Moloacán & 30.8988 & 42.3989 & 37.3039 \\
\hline Huayacocotla & 60.5033 & 36.4056 & 40.9042 & Naolinco & 44.578 & 43.9794 & 47.7650 \\
\hline Hueyapan de Ocampo & 52.7364 & 15.0596 & 47.4900 & Naranjal & 52.5941 & 35.0123 & 46.3597 \\
\hline Huiloapan & 43.4915 & 44.2538 & 48.5248 & Nautla & 50.3281 & 37.4869 & 41.6949 \\
\hline Ignacio de la Llave & 52.4329 & 33.7894 & 50.4508 & Nogales & 48.882 & 43.6225 & 49.7366 \\
\hline
\end{tabular}


continúa..

\begin{tabular}{|c|c|c|c|c|c|c|c|}
\hline Oluta & 56.6895 & 40.5565 & 44.7211 & Tantoyuca & 48.4763 & 32.4717 & 48.2837 \\
\hline Omealca & 51.3996 & 43.9389 & 58.1621 & Tatatila & 49.9632 & 34.6165 & 36.2547 \\
\hline Orizaba & 58.224 & 46.3612 & 43.7032 & Castillo de Teayo & 39.3591 & 12.4331 & 43.2428 \\
\hline Otatitlán & 63.5081 & 42.6462 & 41.1124 & Tecolutla & 40.8595 & 35.7911 & 47.7783 \\
\hline Oteapan & 61.9409 & 31.6709 & 42.9516 & Tehuipango & 52.2515 & 7.4706 & 47.7211 \\
\hline \multirow{2}{*}{$\begin{array}{l}\text { Ozuluama de } \\
\text { Mascareńa }\end{array}$} & \multirow{2}{*}{42.981} & \multirow{2}{*}{38.1804} & \multirow{2}{*}{43.7503} & Temapache & 39.0654 & 36.6973 & 47.0252 \\
\hline & & & & Tempoal & 48.7737 & 36.4235 & 49.4575 \\
\hline Pajapan & 51.4562 & 40.7051 & 48.0875 & Tenampa & 49.0628 & 39.2072 & 53.8049 \\
\hline Pánuco & 43.5123 & 39.2794 & 50.9184 & Tenochtitlán & 45.0805 & 39.4818 & 47.9177 \\
\hline Papantla & 54.9695 & 46.9517 & 50.7220 & Teocelo & 49.464 & 40.8005 & 48.2025 \\
\hline Paso del Macho & 44.2942 & 43.8777 & 62.8726 & Tepatlaxco & 57.5257 & 35.5868 & 40.9379 \\
\hline Paso de Ovejas & 58.6383 & 43.6477 & 55.2192 & Tepetlán & 47.6126 & 45.2857 & 64.2606 \\
\hline Perla, La & 56.3495 & 16.7889 & 57.0314 & Tepetzintla & 56.5338 & 42.6138 & 48.5537 \\
\hline Perote & 49.2156 & 47.2905 & 51.5016 & Tequila & 53.164 & 37.4609 & 48.9390 \\
\hline Platón Sánchez & 67.579 & 38.9497 & 51.3741 & José Azueta & 47.501 & 38.7549 & 36.3230 \\
\hline Playa Vicente & 47.1888 & 38.039 & 51.1136 & Texcatepec & 53.5575 & 33.0255 & 47.9985 \\
\hline Poza Rica de Hidalgo & 47.8513 & 48.7741 & 51.7896 & Texhuacán & 44.3738 & 35.5993 & 34.9761 \\
\hline Vigas de Ramírez, Las & 69.4563 & 42.6987 & 47.5241 & Texistepec & 43.0847 & 38.0548 & 43.2671 \\
\hline Pueblo Viejo & 54.3021 & 41.0573 & 53.4590 & Tezonapa & 53.3848 & 36.3456 & 51.1941 \\
\hline Puente Nacional & 53.3895 & 41.734 & 51.6908 & Tierra Blanca & 45.6995 & 42.5602 & 53.3374 \\
\hline Rafael Delgado & 46.7176 & 42.7191 & 54.8949 & Tihuatlán & 57.446 & 36.9971 & 49.3762 \\
\hline Rafael Lucio & 52.339 & 44.5572 & 47.6104 & Tlacojalpan & 51.2997 & 41.2918 & 37.5265 \\
\hline Reyes, Los & 49.9686 & 29.8149 & 29.5764 & Tlacolulan & 51.95 & 36.4286 & 32.7908 \\
\hline Río Blanco & 45.9462 & 20.4174 & 42.6218 & Tlacotalpan & 41.7216 & 39.7837 & 45.6748 \\
\hline Saltabarranca & 57.7895 & 43.1188 & 45.2232 & Tlacotepec de Mejía & 57.3505 & 41.2788 & 43.2982 \\
\hline San Andrés Tenejapan & 58.3706 & 37.7846 & 38.4773 & Tlachichilco & 50.1897 & 8.2476 & 37.1002 \\
\hline San Andrés Tuxtla & 43.8227 & 41.1588 & 57.9261 & Tlalixcoyan & 40.5739 & 38.7012 & 50.4745 \\
\hline San Juan Evangelista & 53.7855 & 44.0785 & 47.1078 & Tlalnelhuayocan & 53.4937 & 42.4124 & 48.5272 \\
\hline Santiago Tuxtla & 58.246 & 40.2329 & 54.7210 & Tlapacoyan & 46.1884 & 43.7684 & 52.2241 \\
\hline Sayula de Alemán & 55.4975 & 35.2097 & 52.6133 & Tlaquilpa & 57.6391 & 35.3564 & 44.4520 \\
\hline Soconusco & 51.8785 & 37.1011 & 48.8594 & Tlilapan & 44.021 & 41.5537 & 45.7694 \\
\hline Sochiapa & 48.8868 & 43.042 & 48.6127 & Tomatlán & 46.2551 & 44.6304 & 49.0202 \\
\hline Soledad Atzompa & 49.5121 & 11.3214 & 52.2809 & Tonayán & 49.5014 & 39.3293 & 48.7543 \\
\hline & & & & Totutla & 43.087 & 43.9076 & 58.6051 \\
\hline Soledad de Doblado & 47.147 & 42.5621 & 53.8432 & Túxpam & 51.783 & 35.1604 & 43.3515 \\
\hline Soteapan & 57.9119 & 15.7617 & 62.4827 & Tuxtilla & 53.8982 & 38.9495 & 35.6290 \\
\hline Tamalín & 42.4754 & 34.378 & 44.5106 & Ursulo Galván & 48.2369 & 45.6381 & 47.2255 \\
\hline Tamiahua & 45.1881 & 35.1813 & 46.7889 & Vega de Alatorre & 58.4833 & 44.1479 & 48.3227 \\
\hline Tampico Alto & 51.6017 & 35.0353 & 42.2222 & Veracruz & 58.6863 & 40.799 & 45.7148 \\
\hline Tancoco & 51.016 & 41.0412 & 46.3901 & Villa Aldama & 49.9226 & 41.1328 & 64.4788 \\
\hline Tantima & 50.0459 & 35.8901 & 48.9191 & Xoxocotla & 50.6301 & 41.4433 & 42.3146 \\
\hline
\end{tabular}


continúa...

\begin{tabular}{|c|c|c|c|c|c|c|}
\hline Yanga & 50.297 & 42.9366 & 50.4418 & Chocholá & 48.382436 .9086 & 37.7755 \\
\hline Yecuatla & 53.2378 & 41.5713 & 46.6422 & Chumayel & 46.793546 .0952 & 39.5854 \\
\hline Zacualpan & 47.9683 & 8.0898 & 46.9672 & Dzán & $47.7033 \quad 49.3091$ & 50.2247 \\
\hline Zaragoza & 35.4005 & 38.1058 & 46.2322 & Dzemul & 43.554940 .1066 & 39.7735 \\
\hline Zentla & 45.0775 & 42.919 & 55.7183 & Dzidzantún & $49.6253 \quad 41.4731$ & 39.2075 \\
\hline Zongolica & 47.1251 & 36.1545 & 50.2311 & Dzilam de Bravo & 48.383739 .198 & 40.7002 \\
\hline Zontecomatlán & 43.585 & 8.7354 & 48.0121 & Dzilam González & 46.872838 .0741 & 42.9085 \\
\hline & & & & Dzitás & 45.846637 .3925 & 38.8050 \\
\hline Zozocolco de Hidalgo & 38.3715 & 34.3401 & 46.7212 & Dzoncauich & $47.4904 \quad 40.7081$ & 42.5197 \\
\hline Agua Dulce & 47.844 & 40.1741 & 42.9675 & Espita & $53.2008 \quad 45.9008$ & 45.4925 \\
\hline Higo, El & 45.087 & 42.6409 & 45.4354 & Halachó & 51.498237 .1677 & 46.7877 \\
\hline $\begin{array}{l}\text { Nanchital de } \\
\text { Lázaro C }\end{array}$ & 47.5437 & 44.5209 & 47.0219 & Hocabá & 47.225139 .1991 & 49.1805 \\
\hline Tres Valles & 61.5127 & 40.3483 & 45.5013 & Hoctún & $48.642 \quad 36.5033$ & 39.1499 \\
\hline Carlos A. Carrillo & 60.2224 & 49.4075 & 53.3545 & Homún & $42.5334 \quad 14.6762$ & 38.3904 \\
\hline Tatahuicapan & 0 & 14.2309 & 53.4450 & Huhí & $45.139 \quad 16.0745$ & 47.2488 \\
\hline de Juáre & & & & Hunucmá & 45.823434 .8748 & 44.5792 \\
\hline Uxpanapa & 0 & 12.8732 & 54.8831 & Ixil & 48.109639 .0973 & 38.6273 \\
\hline YUCATAN & 1990 & 2000 & 2005 & Izamal & 47.355537 .96 & 46.3751 \\
\hline Abalá & 48.2698 & 17.8664 & 48.6228 & Kanasín & $57.295 \quad 43.8594$ & 39.0488 \\
\hline Acanceh & 43.0334 & 16.2235 & 38.2214 & Kantunil & 49.331636 .6205 & 46.6732 \\
\hline Akil & 46.9512 & 64.2432 & 45.5534 & Kaua & 42.634635 .024 & 43.5259 \\
\hline Baca & 46.1144 & 37.1298 & 38.4041 & Kinchil & 38.072634 .6074 & 37.1863 \\
\hline Bokobá & 45.3141 & 37.7033 & 38.0135 & Kopomá & 40.934336 .5935 & 37.0735 \\
\hline Buctzotz & 48.3357 & 15.7664 & 47.9033 & Mama & $42.448 \quad 39.1215$ & 40.0194 \\
\hline Cacalchén & 45.3775 & 36.8353 & 37.4412 & Maní & $45.7788 \quad 45.1648$ & 40.2876 \\
\hline Calotmul & 52.8221 & 20.3502 & 41.4638 & Maxcanú & 45.578944 .2081 & 43.6333 \\
\hline Cansahcab & 45.9902 & 38.7987 & 39.4980 & Mayapán & 45.874341 .6306 & 47.2484 \\
\hline Cantamayec & 42.6418 & 38.0153 & 43.9140 & Mérida & 64.033751 .4378 & 56.0005 \\
\hline Celestún & 52.971 & 39.1557 & 40.3454 & Mocochá & $45.5245 \quad 45.7027$ & 39.3072 \\
\hline Cenotillo & 52.3604 & 40.6974 & 48.2239 & Motul & 48.442938 .1569 & 39.6093 \\
\hline Conkal & 46.2381 & 36.6027 & 38.2494 & Muna & $53.6062 \quad 18.4929$ & 40.6596 \\
\hline Cuncunul & 44.3182 & 43.416 & 40.1672 & Muxupip & 39.596437 .1095 & 38.7607 \\
\hline Cuzamá & 43.7188 & 16.3528 & 37.8761 & Opichén & 47.090418 .375 & 40.6969 \\
\hline Chacsinkín & 45.7288 & 38.1335 & 46.9519 & Oxkutzcab & 52.745746 .9913 & 42.5264 \\
\hline Chankom & 43.268 & 38.014 & 47.2324 & Panabá & $50.1727 \quad 18.039$ & 48.2511 \\
\hline Chapab & 44.7161 & 38.5188 & 40.1085 & Peto & $50.0348 \quad 46.3079$ & 46.0009 \\
\hline Chemax & 45.194 & 15.5898 & 46.9022 & Progreso & 53.710960 .4878 & 48.1734 \\
\hline Chicxulub Pueblo & 40.5067 & 45.2436 & 38.3874 & Quintana Roo & 45.330338 .214 & 39.5217 \\
\hline Chichimilá & 41.746 & 14.3264 & 45.8283 & Río Lagartos & $49.4739 \quad 18.979$ & 41.1021 \\
\hline Chikindzonot & 44.4447 & 16.1495 & 48.9326 & Sacalum & $55.3376 \quad 41.0585$ & 41.9959 \\
\hline
\end{tabular}




\begin{tabular}{|c|c|c|}
\hline Samahil & 39.121136 .567 & 37.5748 \\
\hline Sanahcat & 49.564136 .2468 & 38.7073 \\
\hline San Felipe & $48.9366 \quad 17.1576$ & 40.9506 \\
\hline Santa Elena & 51.747239 .629 & 39.8411 \\
\hline Seyé & 45.687137 .8683 & 39.9643 \\
\hline Sinanché & 47.204639 .5839 & 39.4565 \\
\hline Sotuta & 42.631936 .1092 & 41.3975 \\
\hline Sucilá & $49.8977 \quad 16.5218$ & 45.1851 \\
\hline Sudzal & 45.893138 .731 & 46.1915 \\
\hline Suma & 44.195138 .5632 & 39.7349 \\
\hline Tahdziú & $43.9952 \quad 44.0598$ & 45.1431 \\
\hline Tahmek & 46.040237 .0966 & 39.0439 \\
\hline Teabo & $47.3928 \quad 43.6017$ & 43.3301 \\
\hline Tecoh & $40.0974 \quad 14.3152$ & 43.3809 \\
\hline Tekal de Venegas & $47.8353 \quad 35.021$ & 36.9491 \\
\hline Tekantó & $42.3758 \quad 15.1468$ & 42.4132 \\
\hline Tekax & 50.016240 .2499 & 41.6271 \\
\hline Tekit & 48.349239 .0368 & 39.3401 \\
\hline Tekom & $46.4496 \quad 16.0533$ & 39.5505 \\
\hline Telchac Pueblo & 50.975137 .6491 & 38.5751 \\
\hline Telchac Puerto & $60.3462 \quad 40.4756$ & 43.7305 \\
\hline Temax & $47.7286 \quad 43.1635$ & 46.6583 \\
\hline Temozón & $\begin{array}{lll}46.9237 & 16.7239\end{array}$ & 47.8795 \\
\hline Tepakán & $41.8664 \quad 41.6961$ & 37.7807 \\
\hline Tetiz & 41.363636 .2245 & 37.0721 \\
\hline Teya & $43.2262 \quad 39.2418$ & 39.5252 \\
\hline Ticul & $51.466 \quad 47.2318$ & 42.0745 \\
\hline Timucuy & $\begin{array}{lll}40.7161 & 15.4947\end{array}$ & 43.7549 \\
\hline Tinum & 50.007538 .9427 & 44.3639 \\
\hline Tixcacalcupul & $41.1272 \quad 16.4976$ & 45.5106 \\
\hline Tixkokob & $47.9739 \quad 16.6595$ & 45.0982 \\
\hline Tixmehuac & $\begin{array}{lll}47.6672 & 39.5577\end{array}$ & 45.7973 \\
\hline Tixpéhual & $\begin{array}{lll}45.1084 & 39.4379\end{array}$ & 40.9647 \\
\hline Tizimín & $53.634 \quad 16.1114$ & 50.2104 \\
\hline Tunkás & $44.1003 \quad 40.0809$ & 45.1048 \\
\hline Tzucacab & 50.634537 .9095 & 45.6591 \\
\hline Uayma & $43.0308 \quad 37.1068$ & 44.0524 \\
\hline Ucú & 41.443236 .0304 & 36.8221 \\
\hline Umán & $61.0647 \quad 46.2207$ & 46.0455 \\
\hline Valladolid & 50.187437 .5803 & 45.6769 \\
\hline
\end{tabular}

\begin{tabular}{|c|c|c|c|}
\hline Xocchel & 46.7137 & 35.9837 & 38.3390 \\
\hline Yaxcabá & 42.706 & 36.8886 & 40.1175 \\
\hline Yaxkukul & 47.5276 & 38.2825 & 41.5991 \\
\hline Yobaín & 45.5417 & 46.9905 & 43.1295 \\
\hline ZACATECAS & 1990 & 2000 & 2005 \\
\hline Apozol & 57.9909 & 44.8692 & 49.6995 \\
\hline Apulco & 50.8144 & 38.6093 & 45.3501 \\
\hline Atolinga & 59.3048 & 43.9615 & 50.1325 \\
\hline Benito Juárez & 53.0705 & 45.8146 & 51.2732 \\
\hline Calera & 65.0242 & 49.7755 & 55.3097 \\
\hline $\begin{array}{l}\text { Cañitas de Felipe } \\
\text { Pes }\end{array}$ & 50.7598 & 41.8898 & 41.4645 \\
\hline Concepción del Oro & 46.842 & 40.7229 & 43.8491 \\
\hline Cuauhtémoc & 60.3023 & 48.3711 & 48.0649 \\
\hline Chalchihuites & 57.6496 & 42.2221 & 56.1562 \\
\hline Fresnillo & 59.9188 & 48.1879 & 58.5794 \\
\hline Trinidad García de la & 58.3427 & 43.6365 & 54.2693 \\
\hline Genaro Codina & 54.2004 & 38.9193 & 48.3804 \\
\hline $\begin{array}{l}\text { General Enrique } \\
\text { Estra }\end{array}$ & 51.3484 & 48.079 & 50.2996 \\
\hline General Francisco R. & 54.9587 & 41.5649 & 51.6616 \\
\hline Plateado de Joaquín A & 54.5473 & 42.1837 & 47.5673 \\
\hline General Pánfilo Nater & 50.9493 & 42.3842 & 50.2978 \\
\hline Guadalupe & 60.4527 & 45.5518 & 52.3388 \\
\hline Huanusco & 44.9224 & 38.3113 & 49.0525 \\
\hline Jalpa & 65.6975 & 43.5841 & 48.6231 \\
\hline Jerez & 66.6065 & 46.1123 & 59.3619 \\
\hline Jiménez del Teul & 41.0522 & 39.6517 & 47.6396 \\
\hline Juan Aldama & 60.4187 & 49.5791 & 47.5125 \\
\hline Juchipila & 66.9874 & 55.6039 & 59.1847 \\
\hline Loreto & 59.7158 & 48.7074 & 53.6772 \\
\hline Luis Moya & 60.309 & 43.7046 & 45.2747 \\
\hline Mazapil & 48.2702 & 11.9154 & 44.5863 \\
\hline Melchor Ocampo & 52.0433 & 37.5345 & 38.4313 \\
\hline Mezquital del Oro & 44.0849 & 39.2543 & 47.6677 \\
\hline Miguel Auza & 52.5933 & 43.1348 & 50.8833 \\
\hline Momax & 52.9666 & 43.0735 & 44.1910 \\
\hline Monte Escobedo & 58.4607 & 43.6048 & 53.3593 \\
\hline Morelos & 51.6526 & 43.9339 & 42.3429 \\
\hline Moyahua de Estrada & 63.2344 & 49.6308 & 52.1473 \\
\hline Nochistlán de Mejía & 60.8991 & 45.1649 & 53.8944 \\
\hline
\end{tabular}


continúa...

\begin{tabular}{llll}
\hline Noria de Ángeles & 56.3764 & 47.0036 & 51.9063 \\
Ojocaliente & 48.9892 & 56.3264 & 45.6087 \\
Pánuco & 61.4697 & 54.1362 & 49.6017 \\
Pinos & 51.7779 & 48.7007 & 48.3326 \\
Río Grande & 67.8619 & 45.3289 & 47.6793 \\
Sain Alto & 49.3881 & 46.751 & 52.3535 \\
Salvador, El & 43.349 & 42.7077 & 44.8850 \\
Sombrerete & 62.9436 & 47.4195 & 57.8481 \\
Susticacán & 52.3102 & 48.4608 & 50.8076 \\
Tabasco & 61.6849 & 49.272 & 51.4599 \\
Tepechitlán & 61.1436 & 50.2974 & 44.2736 \\
Tepetongo & 56.9521 & 58.6478 & 55.3003 \\
Teul de González Orte & 48.1569 & 49.3873 & 55.5821 \\
Tlaltenango de Sánche & 57.8181 & 54.8349 & 57.5017 \\
Valparaíso & 47.4905 & 39.9027 & 51.3470 \\
Vetagrande & 49.9007 & 39.111 & 49.7802 \\
Villa de Cos & 63.2864 & 44.3174 & 50.2189 \\
Villa García & 60.6838 & 44.1303 & 49.7596 \\
Villa González Ortega & 60.3098 & 42.0141 & 48.2789 \\
Villa Hidalgo & 50.1012 & 40.1841 & 53.2499 \\
Villanueva & 46.9105 & 44.3935 & 50.3607 \\
\hline Zacatecas & 61.8551 & 45.154 & 52.6080 \\
\hline
\end{tabular}




\section{Bibliografía}

Acedo, Blanca (2007), "La libertad municipal y la democracia", Nexos, 350, México, http://historico.nexos.com.mx/articulos.php?id_ article $=1207 \& i d \_$rubrique $=466$, mayo de 2008 .

Arocena, José (1995), El desarrollo local: un desafio contemporáneo, Centro Latinoamericano de Economía Humana, Montevideo.

Arroyo Alejandre, Jesús y Antonio Sánchez Bernal (1996), "Federalismo fiscal y condiciones de las finanzas públicas municipales", Revista Mexicana de Sociología, 3, Universidad Nacional Autónoma de México, México, pp. 119-131.

Arroyo Alejandre, Jesús y Antonio Sánchez Bernal (2003), "Políticas municipales para la promoción del desarrollo económico regional", en Enrique Cabrero (coord.), Políticas públicas municipales. Una agenda en construcción, Porrúa-CIDE, México, pp. 87-128.

Astogarraga, Eneko (s/f), Elmetodo Delphi, Universidad de Deusto, http:// www.propectiva.eu/zaharra/Metodo_delphi.pdf, mayo de 2009.

Bardhan, Pranab (2002), "Descentralization of governance and development", Journal of Economic Perspectives, 16 (4), American Economic Association, Menasha, Wisconsin, pp. 185-206.

Boisier, Sergio (1996), Modernidad y territorio, Cuadernos del ILPES, Santiago de Chile.

Brugué, Joaquim y Raquel Gallego (2001), “¿Una administración pública democrática?”, en Joan Font (coord.), Ciudadanos y decisiones políticas, Ariel Ciencias Políticas, Barcelona, pp. 43-58.

Brugué, Quim y Ricardo Gomá (1998), "Las políticas públicas locales: agendas complejas, roles estratégicos y estilo relacional”, en Quim Brugué y Ricardo Gomá (coords.), Gobiernos locales y politicas públicas. Bienestar social, promoción económica y territorio, Ariel, Barcelona, pp. 25-35.

Cabrero Mendoza, Enrique (1993), "Las políticas descentralizadoras en el ámbito internacional. Análisis de tendencias y obstáculos en diversos países", documento de trabajo núm. 19, CIDE, México. 
Cabrero Mendoza, Enrique (1995), La nueva gestión municipal en México. Análisis de experiencias innovadoras en gobiernos locales, Miguel Ángel Porrúa-CIDE, México.

Cabrero Mendoza, Enrique (2000), “Gerencia pública municipal. Marco analítico estratégico para la toma de decisiones en gobiernos municipales", en Enrique Cabrero Mendoza y Gabriela Nava Campos (coords.), Gerencia pública municipal. Conceptos básicos y estudios de caso, Miguel Ángel Porrúa-Cide, México, pp.19-190.

Cabrero Mendoza, Enrique (2003), "Políticas de modernización de la administración municipal. Viejas y nuevas estrategias para transformar a los gobiernos locales", en Enrique Cabrero (coord.), Políticas públicas municipales. Una agenda en construcción, Miguel Ángel Porrúa-Cide, México, pp. 87-128.

Cabrero Mendoza, Enrique, Isela Orihuela y Alicia Ziccardi (2007), Competitividad de las ciudades mexicanas 2007. La nueva agenda de los municipios urbanos, CIDE, http://www.CIDE.edu/programas/Documentos_INDICE_COMPETITIVIDAD_CIUDADES_Mex_2007.pdf, 25 de mayo de 2009.

CESOP (Centro de Estudios Sociales y de Opinión Pública) (2004), Fuentes de indicadores de desempeño gubernamental, Cámara de Diputados, http://www3.diputados.gob.mx/camara/content/ downloand/22963/110522/file/DAHC0007\%20Fuentes\%20 de\%20indicadores\%20de\%20desempe\%C3\%20B1\%20gubernamental.pdf, 25 de mayo de 2009.

Finot, Iván (2002), “Descentralización y participación en América Latina: una mirada desde la economía", Revista de la CEPAL, 78, pp. 39149, http://www.eclac.cl/publicaciones/xml/7/19317/lcg2187e_ Finot.pdf, septiembre de 2007.

Flamand, Laura, Sárah Martínez Pellégrini y Ofelia Camacho (2007), Metodología de cálculo. Índice de desarrollo municipal básico (IDMB), El Colegio de México-Inafed, http://www.colef.mx/indices/index. html, 25 de mayo de 2009.

García Bátiz, María Luisa, Sergio M. González Rodríguez, Antonio Sánchez B. y Basilio Verduzco Chávez (1998), Descentralización e 
iniciativas locales de desarrollo, Universidad de Guadalajara-uClA Program on Mexico-Juan Pablos, México.

Guillén López, Tonatiuh (1996), Gobiernos municipales en México: Entre la modernización y la tradición política, Miguel Ángel Porrúa-El Colegio de la Frontera, México.

Ibarra, Jorge, Alfredo Sandoval, Lida Sotres y Rodrigo Pérez (2002), Desempeño del gobierno en los municipios mexicanos, ITESM, México.

INEGI (Instituto Nacional de Estadística, Geografía e Informática) (2004), Sistema municipal de bases de datos (Simbad), www.inegi.gob. mx, junio de 2004.

Inafed (Instituto Nacional para el Federalismo y el Desarrollo Municipal) (2004), Sistema nacional de información municipal (SNIM), www. inafed.gob.mx, junio de 2004.

Merino, Mauricio (1994), “¿Conclusiones? Obstáculos y promesas de la democracia municipal”, en Mauricio Merino (coord.), En busca de la democracia municipal. La participación ciudadana en el gobierno local mexicano, El Colegio de México, México, pp. 283-300.

Montecinos, Egon (2005), "Los estudios de descentralización en América Latina: una revisión sobre el estado actual de la temática”, EURE, 31 (93), Santiago de Chile, pp. 73-88.

Morales Garza, Martagloria (2005), "Los gobiernos locales y los partidos políticos”, Gestión y Política Pública, xIv (2), CIDE, México, pp. 311-340.

Pardo, María del Carmen (1994), "La gestión municipal, ¿̇motor o freno para el ejercicio democrático?”, en Mauricio Merino (coord.), En busca de la democracia municipal. La participación ciudadana en el gobierno local mexicano, El Colegio de México, México, pp. 253-282.

Rodríguez, Victoria E. (1999), La descentralización en México. De la reforma municipal a solidaridad y el nuevo federalismo (Politico y Derecho), Fondo de Cultura Económica, México. 
Rondinelli, Denis A. (2001), "Desarrollo regional y local en una era de integración global: federalismo favorable al mercado en América Latina y el Caribe", en Fernando Carrillo Flores, Democracia en déficit, gobernabilidad y desarrollo en América Latina y el Caribe, BID, Washington, pp. 279-308.

Saltalamacchia, Homero y Alicia Ziccardi (2005), "Las ciudades mexicanas y el buen gobierno local: una metodología para su evaluación", Revista Mexicana de Sociología, 67 (1), México, http://www.ejournal.unam.mx/rms/2005-1/RMS005000102.pdf, 25 de mayo de 2009.

Sánchez Bernal, Antonio (1998), "Relevancia de los estudios en desarrollo municipal. El caso de los municipios mexicanos", Revista Interamericana de Planificación, $\mathrm{xxx}$ (117-118), sIAP, Quito, pp. 238-250.

Sánchez Bernal, Antonio (2003), "El financiamiento del desarrollo municipal en México", Revista Carta Económica Regional, año 15, 84, Universidad de Guadalajara, Jalisco, pp. 3-7.

Sánchez Bernal, Antonio (2008), "Cambio institucional y desempeño de los gobiernos municipales en México. El caso de los municipios de Jalisco y Guanajuato" tesis doctoral, Universidad de Guadalajara, Jalisco.

Sánchez Bernal, Antonio y María Luisa García (2001), "Libertad y desarrollo económico local”, en Antonio Sánchez Bernal (comp.), La ruta del cambio institucional, Universidad de Guadalajara, Jalisco, pp. 53-76.

Sánchez Bernal, Antonio, Édgar Tovar García y Antonia Sánchez Martínez (2003), "Evaluación del desempeño de los gobiernos municipales de Jalisco. Hacia una política regional de fortalecimiento municipal”, Gestión Municipal, año 1, 1, Universidad de Guadalajara, Jalisco, pp. 55-72.

Silva Lira, Iván (2003), Metodología para la elaboración de estrategias de desarrollo local, CEPAL, Chile.

Surawski, Antonieta (2003), Programas y experiencias de innovación en ciudadanía y gestión local, http://www.ciudadania.uchile.cl/ doctostrab.html, 25 de mayo de 2009. 
Vázquez Barquero, Antonio (1998), "Localización industrial y dinámica regional”, Estudios Territoriales, 288, Ministerio de Fomento, Madrid, pp. 39-52.

Ward M., Peter (1998), “Tendencias en los gobiernos municipales de México: del partidismo a la tecnocracia”, en Carlos Garrocho y Jaime Sobrino (coords.), Desarrollo municipal. Retos y posibilidades, El Colegio Mexiquense, Toluca, pp. 135-160.

Ziccardi, Alicia (1995), La tarea de gobernar: gobiernos locales y demandas ciudadanas, Miguel Ángel Porrúa, México.

Recibido: 20 de noviembre de 2008. Reenviado: 4 de junio de 2009. Aceptado: 17 de septiembre de 2009.

Antonio Sánchez-Bernal. Es doctor en ciencias sociales por la Universidad de Guadalajara, maestro en economía por el Centro de Investigación y Docencia Económicas (CIDE) y licenciado en economía por la Universidad de Guadalajara. Actualmente es investigador nivel I en el Sistema Nacional de Investigadores (SNI), es profesor-investigador del Departamento de Estudios Regionales-Ineser de la Universidad de Guadalajara y es presidente de la Academia Jalisciense de Ciencias, A.c. Sus líneas de investigación actual son: cambio institucional, políticas públicas y desarrollo local. Entre sus publicaciones destacan: Cambio institucional y desempeño de los gobiernos municipales en México, Plaza y Valdés-Academia Jalisciense de Ciencias, A.C., México (2008); "Planning hydroelectric power plants with the public: a case of organizacional and social learning in Mexico", Impact Assessment and Project Appraisal, 26 (3), Journal of the International, pp. 163-176 (2008).

María Luisa García-Bátiz. Es doctora en ciencias sociales por la Universidad de Guadalajara, maestra en desarrollo urbano por El Colegio de México y licenciada en economía por la Universidad de Guadalajara. Actualmente es investigadora nivel I en el Sistema Nacional de Investigadores (sNI) y directora del Centro de Estudios de Desarrollo Regional del Departamento de Estudios Regionales-Ineser de la Universidad de Guadalajara. Sus líneas de investigación actual son: cambio institucional, políticas públicas y desarrollo local, planeación participativa y medio ambiente. Entre sus publicaciones destacan: Planeación participativa. La experiencia de la politica ambiental en México, Plaza y Valdés-Universidad 
de Guadalajara (2006); "Las capacidades de las organizaciones de la sociedad civil y su influencia en las políticas de desarrollo en Jalisco", en Iglom, Retos de modernización del municipio mexicano, Memorias del IV Congreso de la Red de Investigadores en Gobiernos Locales Mexicanos, A.C. (2005). 